\title{
Constraining the Evolutionary History of the Moon and the Inner Solar System: A Case for New Returned Lunar Samples
}

\author{
Romain Tartèse $^{1}(D)$ Mahesh Anand ${ }^{2,3}(D) \cdot$ Jérôme Gattacceca $^{4}(D)$ \\ Katherine H. Joy $^{1}$ (D) James I. Mortimer ${ }^{2}$ - John F. Pernet-Fisher ${ }^{1}$ (D) \\ Sara Russell $^{3}(D) \cdot$ Joshua F. Snape $^{5}(D) \cdot$ Benjamin P. Weiss $^{6}(D)$
}

Received: 23 August 2019 / Accepted: 25 November 2019 / Published online: 2 December 2019

(C) The Author(s) 2019

\begin{abstract}
The Moon is the only planetary body other than the Earth for which samples have been collected in situ by humans and robotic missions and returned to Earth. Scientific investigations of the first lunar samples returned by the Apollo 11 astronauts 50 years ago transformed the way we think most planetary bodies form and evolve. Identification of anorthositic clasts in Apollo 11 samples led to the formulation of the magma ocean concept, and by extension the idea that the Moon experienced large-scale melting and differentiation. This concept of magma oceans would soon be applied to other terrestrial planets and large asteroidal bodies. Dating of basaltic fragments returned from the Moon also showed that a relatively small planetary body could sustain volcanic activity for more than a billion years after its formation. Finally, studies of the lunar regolith showed that in addition to containing a treasure trove of the Moon's history, it also provided us with a rich archive of the past 4.5 billion years of evolution of the inner Solar System. Further investigations of samples returned from the Moon over the past five decades led to many additional discoveries, but also raised new and fundamental questions that are difficult to address with currently available samples, such as those related to the age of the Moon, duration of lunar volcanism, the
\end{abstract}

Role of Sample Return in Addressing Major Questions in Planetary Sciences

Edited by Mahesh Anand, Sara Russell, Yangting Lin, Meenakshi Wadhwa, Kuljeet Kaur Marhas and Shogo Tachibana

\footnotetext{
$凶$ R. Tartèse

romain.tartese@manchester.ac.uk

1 Department of Earth and Environmental Sciences, The University of Manchester, Manchester, M13 9PL, UK

2 Planetary and Space Sciences, School of Physical Sciences, The Open University, Walton Hall, Milton Keynes, MK7 6AA, UK

3 Department of Earth Sciences, The Natural History Museum, Cromwell Road, London, SW7 5BD, UK

4 CNRS, Aix-Marseille Univ, IRD, Coll France, INRA, CEREGE, Aix-en-Provence, France

5 Faculty of Sciences, Department of Earth Sciences, Vrije Universiteit, Amsterdam, The Netherlands

6 Department of Earth, Atmospheric and Planetary Sciences, Massachusetts Institute of Technology, Cambridge, MA, USA
} 
lunar paleomagnetic field and its intensity, and the record on the Moon of the bombardment history during the first billion years of evolution of the Solar System. In this contribution, we review the information we currently have on some of the key science questions related to the Moon and discuss how future sample-return missions could help address important knowledge gaps.

Keywords Earth-Moon system · Lunar evolution · Sample-return · Solar System

\section{Overview of Our Lunar Sample Collection}

A total of $\sim 382 \mathrm{~kg}$ of rock and soil samples were brought back to the Earth by the Apollo and Luna programmes between 1969 and 1976. This sample suite has advanced our scientific understanding of the Moon in a profound manner. Over the last five decades, there are many fundamental questions that have only been addressed through our existing lunar sample collection. These are questions that not only have implications for our understanding of the Earth-Moon system, but also for our understanding of the wider Solar System, such as how planets are built and the nature of the impact flux in the inner Solar System over geological time (e.g., National Research Council 2007). In many cases, this has been possible as a result of the high precision and accuracy of geochemical measurements that can be made in laboratories on Earth relative to geochemical analyses that can be achieved by rovers on the Moon's surface or by remote sensing instruments from lunar orbit.

Despite the many advances the lunar sample collection has enabled, the major limitation of this collection stems from the limited areal extent of the Moon represented by the Apollo and Luna landing sites. Remote sensing orbital spacecraft over the last two decades have highlighted that our existing sample collections come from a compositionally anomalous area of the Moon (Fig. 1). This was first hinted by orbital gamma-ray measurements collected by the Apollo 15 and 16 service modules (Metzger et al. 1977, see also Plate 10.1 of the Lunar Sourcebook-Heiken et al. 1991), and observed in more detail by the 1998 Lunar Prospector and 1994 Clementine missions (Jolliff et al. 2000). This area, referred to as the Procellarum-KREEP terrane (PKT), is enriched in incompatible elements such as potassium $(\mathrm{K})$, rare earth elements (REE), phosphorus (P), uranium (U), and thorium (Th). It also coincides with the extent of the Imbrium basin continuous ejecta blanket (Fig. 1). Consequently, without future samples from other areas such as the feldspathic highlands terrane, or the farside South Pole-Aitken (SPA) basin, there are a number of key lunar science questions that cannot be fully addressed (Table 1).

Attempts have been made to answer many of these questions by lunar orbiter remote sensing missions, and lander and rovers missions. For instance, remote sensing instruments (such as the Moon Mineralogy Mapper (Pieters et al. 2009a; Green et al. 2011) $-\mathbf{M}^{3}$ on Chandrayaan-1 and Diviner (Paige et al. 2010a, 2010b) on the Lunar Reconnaissance Orbiter) have geologically mapped the Moon globally in high-spatial and spectral detail. Spectroscopic imaging has identified lithologies that are rare or absent in the Apollo or Luna collections, such as dunites and pink spinel troctolites (e.g., Corley et al. 2018; Pieters et al. 2011). However, $\mathrm{M}^{3}$ has a $70 \mathrm{~m} /$ pixel maximum resolution (Green et al. 2011) and Diviner infrared spectrometer has an average resolution of $250 \mathrm{~m} /$ pixel (Paige et al. 2010a). Therefore, each reported lithology and associated chemical features represent an average over the entire pixel, only painting a broad-scale view of these complex geological features.

Complementary to remote-sensing datasets, rovers on the lunar surface have the potential to make detailed, localised, in situ geological investigations. For instance, China's rover Yutu-2 (part of the Chang'E-4 mission) recently reported orthopyroxene- and olivine- 

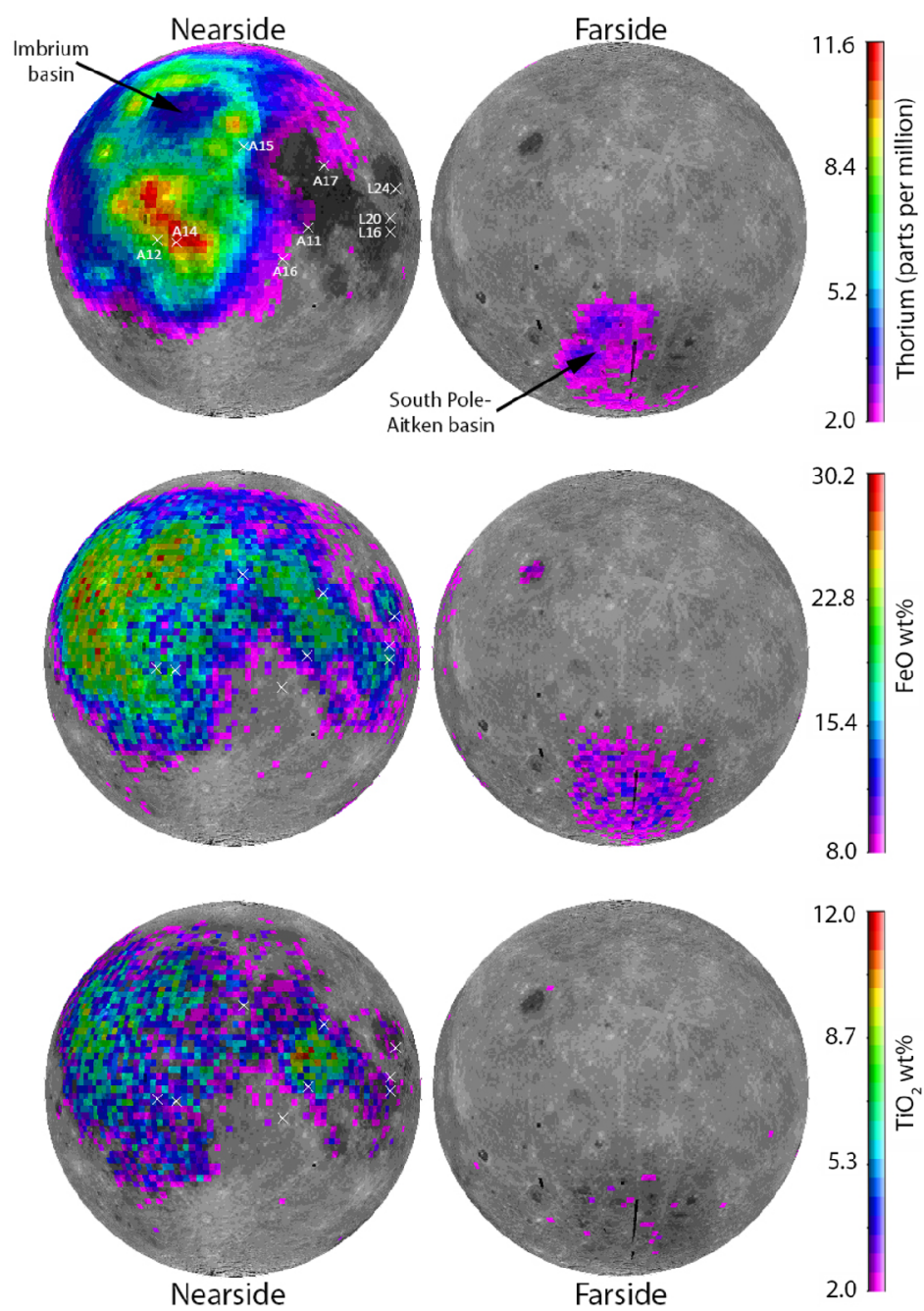

Fig. 1 Nearside and farside of the Moon showing distribution of Th, $\mathrm{FeO}$ and $\mathrm{TiO}_{2}$ abundances obtained by the Lunar Prospector Gamma Ray Spectrometer ( $2^{\circ}$ per pixel data from Prettyman et al. 2006). Data for these elements have been selected to $\mu \mathrm{gg}$ gw abundances of $\mathrm{Th}>2 \mu \mathrm{gg}-1, \mathrm{FeO}>8$ wt. $\%$ and $\mathrm{TiO}_{2}>2$ wt. $\%$. These data are overlain on a Clementine albedo map of the Moon in an orthographic projection. Locations of the Apollo (A) and Luna (L) landing sites are from Wagner et al. (2017). The locations of the Imbrium basin and South Pole-Aitken basin are also indicated

bearing lithologies within the Von Kármán crater (situated within the SPA basin; Li et al. 2019). Such a mineral assemblage, together with the geological context of this crater (i.e. material on the Von Kármán crater floor is thought to have been excavated from $72 \mathrm{~km}$ below the SPA floor; Huang et al. 2018), led Li et al. (2019) to a suggestion that these lithologies could represent excavated mantle material. This is significant because no mantle rocks have conclusively been identified in the Apollo or Luna collections. However, without laboratory-based geochemical measurements of returned samples, the true provenance of these lithologies and what they tell us about the Moon (for instance, testing predicted lunar magma ocean crystallisation sequences) cannot be unambiguously established. 
Table 1 Major outstanding science questions that lunar sample-return missions could address. Adapted from Pernet-Fisher et al. (2019b), based on National Research Council (2007) and Crawford and Joy (2014)

\begin{tabular}{lll}
\hline Science questions & $\begin{array}{l}\text { Opportunities offered by Sampling location } \\
\text { sample-return }\end{array}$
\end{tabular}

Age of the Moon

Primordial crust of the Moon: homogeneous vs. heterogeneous ferroan anorthosite (FAN); Relationship between anorthosites and ancient magmatic (i.e., Mg-suite) rocks

Bombardment history of the inner Solar System

Lunar volcanism: timing, nature, duration, volume, emplacement mechanism

Structure and composition of the lunar interior

Lunar polar volatiles: composition, physical state, form, distribution, context

Flux and composition of ancient solar wind composition recorded in lunar regolith

Galactic record archived in lunar surface samples

Lunar magnetic field and anomalies
Multi-system high precision geochronology; Detailed major and trace element geochemistry; Noble gas geochemistry

Examine petrogenesis of lunar crustal rocks; Multi-system geochronology; Detailed major and trace element geochemistry

Multi-system high precision geochronology; Detailed major and trace element geochemistry; Search for impactor fragments and/or chemical signatures

Examine source regions; Multi-system geochronology; High precision stable isotope measurements (e.g., O); Detailed major and trace element geochemistry

Nearside vs. farside crustal thickness dichotomy; Examine mare basalt source regions; Petrology; Multi-system geochronology; Detailed major and trace element geochemistry; Volatile inventory of the lunar mantle

Volatile release studies; Stable isotope measurements $(\mathrm{H}, \mathrm{C}, \mathrm{N}$, $\mathrm{O}$, etc.); Detailed major and trace element geochemistry

Volatile release studies; Stable isotope measurements $(\mathrm{H}, \mathrm{C}, \mathrm{N}$, $\mathrm{O}$, etc.); Noble gas geochemistry

Analysis of cosmogenic nuclides $\left({ }^{3} \mathrm{He},{ }^{21} \mathrm{Ne},{ }^{38} \mathrm{Ar},{ }^{83} \mathrm{Kr},{ }^{126} \mathrm{Xe}\right.$, ${ }^{10} \mathrm{Be},{ }^{36} \mathrm{Cl}$ ); analysis of supernova-related isotopes (e.g., $\left.{ }^{60} \mathrm{Fe}\right)$

High-precision magnetic measurements; Multi-system geochronology
Primary crust exposures (ideally pure anorthosite-PAN), non PKT

Magnesian anorthosites (MAN) outcrops; Farside PAN

Impact-melt material from major basin-forming impacts (SPA, Nectaris, Crisium, etc.); Key stratigraphic marker craters (Copernicus, Tycho); Young lava surfaces

Young lava flows; Cryptomare lava flows (access ancient volcanism); Mare basalt bedrock (especially within stacked lava flows that would be accessible in lava pit walls); KREEP-rich basalt flows; Pyroclastic glass bead sites

Crustal rocks from the farside; Deep crustal rocks and possible mantle xenoliths from deep basins that breached the crust

Volatile-bearing materials in pristine condition from multiple polar locations

Ancient paleoregolith sites; Present day regolith; Regolith samples from swirl regions; Core samples

Ancient paleoregolith sites; Present day regolith at various sites; Core samples

Ancient magmatic bedrock (samples collected with known orientations and from multiple stratigraphic layers); Samples from swirl regions 
Undoubtedly, remote sensing and rover missions have made invaluable contributions to our understanding of the Moon by conducting a wide range of science investigations such as identifying new lithologies, globally mapping the chemical heterogeneity of the lunar crust, estimating gravity anomalies, and measuring surface temperature. However, there are some important questions that can only be addressed by detailed geochemical and physical experiments on rock samples in labs on Earth. In this regard, our current best tools for understanding the geology of the Moon outside of the nearside PKT comes from lunar meteorites. Even though lunar meteorites are limited by the fact that they lack exact geographical provenance, precise geological context, and have unknown original orientation, they have uniquely advanced our understanding of the Moon (e.g., Korotev 2005; Joy and Arai 2013). For instance, the lunar meteorite collection contains fragments of the youngest and oldest mare basalts reported to date (e.g., Borg et al. 2009; Snape et al. 2018a; Curran et al. 2019). However, for this example, without known geographic and geological context of where these samples originated on the Moon, it is hard to fully interpret how these mare basalts fit into the wider picture of lunar volcanism.

In this chapter, we detail some of the major outstanding lunar science questions that can only be resolved by the collection of new lunar samples from a geographically diverse set of locations for investigation in labs on Earth (see summary in Table 1).

\section{When Did the Moon Form?}

\subsection{Overview}

The formation of the Moon is commonly linked with a catastrophic impact between the proto-Earth and a large (potentially Mars-sized or larger) impactor (e.g., Hartmann and Davis 1975). Given this unique relationship between the Earth and the Moon, the timing of this event represents not just a fundamental starting point for lunar evolution, but a key stage in the early evolution of the Earth. Since the return of the first Apollo samples, there have been numerous efforts to determine the age of the Moon (e.g., Tatsumoto 1970; Tera and Wasserburg 1974; Tilton and Chen 1979; Carlson and Lugmair 1988), and significant differences exist among recently published age estimates (e.g., Borg et al. 2011; Gaffney and Borg 2014; McLeod et al. 2014; Avice and Marty 2014; Connelly and Bizzarro 2016; Barboni et al. 2017; Kruijer and Kleine 2017; Thiemens et al. 2019). These age estimates will often be divided into those proposing either an "old Moon" forming at around 4.5 Ga or earlier, and those advocating a "young Moon" age of $<4.5 \mathrm{Ga}$.

\subsection{Estimates for the Time of Lunar Formation}

Because the Moon is not a primitive planetary body, and has had a complex geological history of differentiation, impact modification and extensive volcanic activity, there is no single rock whose age can be measured in order to obtain a direct determination for the time of lunar formation. Nonetheless, perhaps the most straightforward approach employed for constraining the time of the Moon's formation has been to determine the ages of the oldest available lunar samples. For example, Borg et al. (2011) determined an age of $4.360 \pm$ $0.003 \mathrm{Ga}$ for the FAN sample 60025, using three independent chronometers $\left(\mathrm{Pb}-\mathrm{Pb},{ }^{147} \mathrm{Sm}\right.$ ${ }^{143} \mathrm{Nd}$ and ${ }^{146} \mathrm{Sm}-{ }^{142} \mathrm{Nd}$ ). The FAN rocks are believed to represent the remnants of the ancient lunar crust, formed as flotation cumulates in the lunar magma ocean (LMO). As such, the age reported by Borg et al. (2011) can be interpreted as the time at which the LMO crystallised, and by inference suggests a relatively young age for the Moon. 
An alternative approach has been to calculate model ages for the mantle sources of a variety of lunar rock types, using different long-lived isotope systems (e.g. U-Pb, Rb-Sr, $\mathrm{Sm}-\mathrm{Nd}$ and Lu-Hf). While the rocks used in such studies (e.g., basalts formed between $\sim 3.1-4.0 \mathrm{Ga}$ ) will often have relatively young crystallisation ages compared to the FAN sample studied by Borg et al. (2011), they will retain an initial isotopic composition from the time at which they crystallised. If these isotopic fingerprints can be determined, it is then possible to calculate the amount of time necessary for radiogenic ingrowth in the mantle sources to generate the initial isotopic composition. Notably, many of these model ages for different lunar lithologies appear to cluster around an age range similar to that of the 60025 FAN sample, as well as that of a number of other ancient lunar crustal rocks $(\sim 4350$ 4400 Ga; e.g., Lugmair and Carlson 1978; Nyquist et al. 1995; Rankenburg et al. 2006; Brandon et al. 2009; Gaffney and Borg 2014; McLeod et al. 2014; Carlson et al. 2014; Snape et al. 2016a). Once again, these model ages have been interpreted as marking the final stages of LMO crystallisation, and potentially suggestive of a relatively young Moon. By contrast, evidence for an older Moon $(\sim 4.5 \mathrm{Ga})$ has been provided by a date of $4.417 \pm$ $0.006 \mathrm{Ga}$ obtained on a zircon grain in Apollo 17 breccia 72215 (Nemchin et al. 2009) and by model ages calculated for zircon grains in lunar breccias based on their initial Hf isotopic compositions and ${ }^{207} \mathrm{~Pb} /{ }^{206} \mathrm{~Pb}$ crystallisation ages (Taylor et al. 2009; Barboni et al. 2017).

Frustratingly, even studies looking at the same isotope system have produced different estimates for the age of the Moon. A good example, is the ${ }^{182} \mathrm{Hf}-{ }^{182} \mathrm{~W}$ system, which can potentially provide unique insights due to the short half-life of ${ }^{182} \mathrm{Hf}$ ( $\mathrm{ca} .9 \mathrm{Ma}$ ) and the fact that Hf (lithophile) and W (siderophile) are fractioned during planetary core formation. Therefore, if the formation of a planet's core has occurred during the lifetime of ${ }^{182} \mathrm{Hf}$, the remaining silicate fraction of the planet will develop an excess of ${ }^{182} \mathrm{~W}$. Analyses of lunar samples have identified a relative excess of ${ }^{182} \mathrm{~W}$ (Touboul et al. 2015; Kruijer et al. 2015) and higher Hf/W ratios (Thiemens et al. 2019) compared to terrestrial values. These observations can be explained by radiogenic ingrowth of ${ }^{182} \mathrm{~W}$ in the bulk silicate Moon (BSM), provided lunar differentiation occurred no later than $\sim 4.51$ Ga (Lee et al. 1997; Halliday and Lee 1999; Righter and Shearer 2003; Kleine et al. 2005; Thiemens et al. 2019). Conversely, it has also been suggested that the Moon could have formed later than $4.5 \mathrm{Ga}$, with the ${ }^{182} \mathrm{~W}$ excess in lunar samples being explained via a disproportionate accretion of meteoritic material to the Earth-Moon system during the so-called "late veneer" (Touboul et al. 2015; Kruijer et al. 2015; Kruijer and Kleine 2017).

A number of studies looking at terrestrial rocks have also provided constraints for the timing of the Moon's formation. For example, Avice and Marty (2014) used I-Pu-Xe isotope systematics to determine an age for the Earth's atmosphere of $40_{-10}^{+20}$ Ma after Solar System formation, which they suggest might provide a lower limit for the timing of the last giant impact event that could have formed the Moon (i.e. the giant impact occurred prior to ca. 40 Ma after Solar System formation). Meanwhile, a much younger estimate for the Moon's age was derived by Connelly and Bizzarro (2016). Based on the assumption that the bulk silicate Earth (BSE) originally had a much lower ${ }^{238} \mathrm{U} /{ }^{204} \mathrm{~Pb}$ ratio ( $\mu$-value) than it does today and that the subsequent increase was the result of $\mathrm{Pb}$ loss during the giant impact, the authors calculated that this event must have occurred between $4.426-4.417 \mathrm{Ga}$, in order to explain modern day $\mathrm{BSE} \mathrm{Pb}$ isotopic compositions.

\subsection{How Can New Lunar Samples Help Address This Issue?}

The lack of agreement with regard to the time of lunar formation is primarily due to different assumptions that have been made in calculating various ages (e.g., the duration of different 
stages of planetary differentiation, the occurrence and effect of a late veneer), and how these ages are interpreted (e.g., are they representative of global processes and can they be tied to the LMO model?). It is quite possible that new samples will not completely resolve these uncertainties. Furthermore, they will almost certainly raise new questions. However, a wider range of lunar samples has the potential to address a number of key questions that have arisen from previous studies.

Determining ages for the oldest fragments of the lunar crust is particularly challenging, partly due to the age of these samples and the fact that they have been subjected to more than 4 billion years of impact modification. Furthermore, the Apollo samples were all collected from locations on the nearside of the Moon and near to, and in some cases within, the geochemically anomalous PKT region (Fig. 1). Even the Apollo 16 landing site, which provided many of the known FAN samples (such as 60025), is likely not representative of "typical" lunar highlands as it has a fairly elevated KREEP component (e.g., Korotev et al. 2003). Therefore, returning samples from more representative regions of the lunar highlands, particularly on the lunar farside well away from the PKT, will provide a better chance to determine ages for the most ancient crustal lithologies on the Moon.

One of the most striking features about the model ages derived from the Apollo samples is the preponderance of $\sim 4.35-4.4 \mathrm{Ga}$ ages. If similar model ages are derived from samples collected from a wider range of locations (particularly on the lunar farside), it would provide much stronger support for the age representing final crystallisation stages of a global LMO. This would suggest either that the Moon is significantly younger than $4.5 \mathrm{Ga}$, or that the LMO cooled more slowly than most models predict (Elkins-Tanton et al. 2011). If, on the other hand, samples returned from the lunar farside indicate that the $\sim 4.35-4.4$ Ga model ages are an artefact of the lunar nearside or the PKT, it would support the suggestion that previous model ages represent a later large-scale (but not global) resetting of isotope systems. A potential cause of this event could be a particularly large impact event, such as the one previously suggested to have generated the hypothetical "Procellarum basin" (Cadogan 1974). Remote sensing data have failed to detect the typical gravity anomaly associated with impact basins around the Oceanus Procellarum (Andrews-Hanna et al. 2014). Nevertheless, such a large impact event would not only provide a way to explain observed asymmetries between the lunar nearside and farside (Zhu et al. 2019), but could also provide explanation for the $\sim 4.35-4.4$ Ga model ages.

A key goal for future sample-return missions is to investigate predicted exposures of material derived from the lunar mantle, particularly in the SPA basin (Yamamoto et al. 2010; Melosh et al. 2017). Our current understanding of the lunar mantle and its composition is based on inferences from samples such as the lunar mare basalts. While it is generally agreed that these rocks have their origins in partial melts of mantle cumulates, they are not a direct representation of the lunar mantle. Having more direct determinations of lunar mantle compositions, particularly regarding the isotopic systematics of mantle material, could address a number of uncertainties associated with models discussed above, which rely on assumptions regarding the nature of the lunar mantle and the BSM.

In case of the Sm-Nd and Lu-Hf model ages described above, an important constraint is whether or not the mantle sources of the Apollo samples evolved from a BSM with a chondritic composition. The ${ }^{182} \mathrm{Hf}-{ }^{182} \mathrm{~W}$ studies used to constrain the Moon's age rely on estimates for the ratio of Hf/W in the early BSM (Kruijer and Kleine 2017; Thiemens et al. 2019). Similarly, although recent studies of lunar basalts have made it possible to construct a multistage model of $\mathrm{Pb}$ isotopic evolution in the Moon (Snape et al. 2016a), using this model to determine the age of the Moon would require a better understanding of the BSM ${ }^{238} \mathrm{U} /{ }^{204} \mathrm{~Pb}$ ratio (known as the $\mu$-value) during the Moon's early differentiation. If lunar 
mantle material indicated that the BSM had very high $\mu$-values $(>1000)$, it would argue strongly in favour of a young Moon $(<4.5 \mathrm{Ga})$, while evidence for lower BSM $\mu$-values more typical of those determined for many mare basalt sources $(<500)$, would imply that the Moon is old ( $\sim .5 \mathrm{Ga}$ ) (Snape et al. 2016a).

\section{Petrology and Formation History of the Lunar Anorthositic Crust}

As a geologically ancient surface, the Moon can inform us about both its own early history and more generally about the expected evolution of the terrestrial planets. The first reports of anorthite-rich lithologies in samples returned from the Apollo missions led to a very simple view of the evolution of the Moon crystallising from a LMO (Wood et al. 1970). In this model, the first minerals to solidify, olivine followed by pyroxene, sank downwards to make a mafic Mg-rich mantle. After solidification of $\sim 75-80 \%$ of the LMO, plagioclase began to crystallise (e.g., Snyder et al. 1992). Being less dense than the melt, it rose to form a crust on the lunar surface, bringing with it co-crystallising Fe-bearing mafic minerals. The relative homogeneity of the anorthite composition $\left(\mathrm{An}_{94-98}\right)$ in Apollo FAN samples supports the LMO model (see discussion in Gross and Joy 2016, and references therein).

Evidence for formation of the different silicate layers in planetary bodies from a magma ocean is most obvious for the Moon, but a fully molten state may be a ubiquitous stage in the evolution of planetary sized bodies and learning about the LMO has implications for planetary evolution more generally. The howardite, eucrite and diogenite (HED) meteorites, thought to originate from asteroid 4-Vesta (e.g., McCord et al. 1970; McSween et al. 2013), have genetic similarities to each other that may be explained by formation from a magma ocean (Righter and Drake 1997). This is likely to be replicated in many large rocky asteroids (McCoy et al. 2006). Mars may also have had a magma ocean, although the wide variety of mineral compositions observed in martian meteorites requires a post-magma ocean period of considerable overturn, mixing and reprocessing (Elkins-Tanton et al. 2003).

The Earth's structure and composition is also consistent with it having a magma ocean stage (Righter et al. 1997). A recent model suggests that the Earth may have been partially molten when it was impacted by a large impactor to produce the Moon. Its molten state may have enabled most of the lunar material to have originated from the Earth rather than from the impactor (Hosono et al. 2019). Thus, magma oceans can have critical implications for how bodies evolve and indeed, how the Moon itself formed.

The study of lunar meteorites, which originate from random locations on the lunar surface, and the comparison of these meteorites to returned Apollo samples, have increased our understanding of crustal heterogeneities and, therefore, of the evolution of the LMO. Most lunar anorthositic meteorites have compositions clearly different from those of the majority of returned Apollo samples in both major and trace element compositions, leading to recent questions about the lunar magma ocean evolution. In terms of major element composition, around $80 \%$ of lunar meteorites are significantly more magnesian (and named MAN for magnesian anorthosites) than Apollo FAN samples (Gross et al. 2014). Gross et al. (2014) interpreted this as an indication that much of the lunar crust cannot be the product of a primary magma ocean, in which more ferroan compositions are expected, but likely formed from complex multiple melting events. Trace element analyses of lunar meteorite minerals show a similar picture of complexity. Anorthite in lunar meteorites differs from that in Apollo samples in REE abundances that cannot be explained by crystallisation from a single magma composition (Russell et al. 2014). More recently, FAN clasts in Apollo 15 and 16 samples have been demonstrated to exhibit wide variations in REE abundances that overlap 
Fig. 2 CI chondrite-normalised (CI chondrite REE abundances from Barrat et al. 2012) $\mathrm{Eu} / \mathrm{Sm}$ vs. Na abundance in lunar plagioclase from Apollo 15 and 16 hand samples and clasts in breccias (after Joy 2013; Pernet-Fisher et al. 2019a), feldspathic lunar meteorites (from Cahill et al. 2004;

Treiman et al. 2010; Joy et al. 2011a;

Russell et al. 2014), and Apollo Mg-suite and high alkali-suite samples (from Papike et al. 1996; Shervais and McGee 1998, 1999)

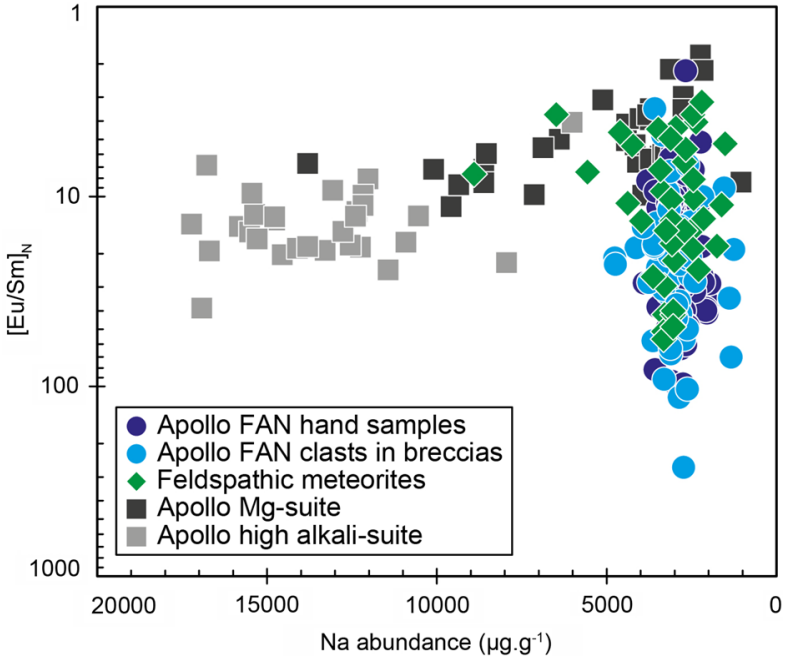

those observed in lunar meteorites, and which cannot be explained by fractional crystallisation from a single source (Pernet-Fisher et al. 2019a) (Fig. 2). The Nd isotope compositions of lunar meteorites and FAN samples likewise suggest that their parent magmas vary in REE abundances, sometimes being enriched in HREE and sometimes in LREE, whereas according to the LMO model the residual melt should always trend towards LREE enrichment, as observed in KREEP samples (Nyquist et al. 2010).

All these recent results acquired on lunar meteorites and clasts within Apollo suite samples require a more complex geological history than that provided by simple LMO solidification models. While the Moon is indeed likely to have experienced a magma ocean stage, it seems unlikely that the majority of the lunar surface is comprised mostly of unmodified primordial crust formed about 4.5 billion years ago. Sample-return missions at selected locations could help answer some outstanding questions about the degree of remelting of the lunar crust post-LMO. In order to understand this very early history of the Moon, we require more samples from a variety of lunar locations. The far side of the Moon may be more magnesium-rich than the nearside FAN lithologies (Arai et al. 2008; Ohtake et al. 2012) and, therefore, some anorthosite outcrops from these terrains (Ohtake et al. 2009; Donaldson Hanna et al. 2014; Yamamoto et al. 2015; Lemelin et al. 2015) may be a good focus for a sample-return landing site. Returning samples from anorthosite areas from regions remote from Apollo and Luna landing sites will enable investigating these outstanding issues related to the LMO formation, crystallisation, and the subsequent lunar igneous evolution.

\section{The Bombardment History of the Inner Solar System}

Impact bombardment is one of the main geological processes affecting all bodies throughout the Solar System. Because it is not affected by geological reprocessing and hydrospheric/atmospheric weathering, the Moon has preserved a near complete record of the inner Solar System impact history since its formation (e.g., Joy et al. 2016 and references therein) around 4.5 billion years ago (see Sect. 2: When did the Moon form?). The traces left on the Moon by impact bombardment range in size from several thousands of kilometres 
across (e.g., $\sim 2000 \times 2400 \mathrm{~km}$ for the SPA basin; Garrick-Bethell and Zuber 2009) down to micron-sized crater pits observed on pyroclastic glass beads (e.g., McKay et al. 1991). Deciphering the lunar bombardment record can provide crucial information on (i) the secular evolution of bombardment in the inner Solar System, and (ii) the source of material involved and possible changes of impactor types through time.

\subsection{Timing of Lunar Bombardment}

Constraining the temporal evolution of impactor delivery to the Moon is one of the top priorities of research in Solar System science (e.g., National Research Council 2007). This is because the lunar cratering chronology anchors the cratering chronology of all other inner Solar System bodies, and is used to derive crater count model ages for geological units at their surface. Surface observations and gravity data enable deciphering the relative ages of the different lunar basins and craters compared to one another (e.g., Shoemaker and Hackman 1962; Hartmann and Wood 1971; Wilhelms 1987; Stöffler et al. 2006; Fassett et al. 2012; Neumann et al. 2015). However, only samples can provide absolute age constraints derived from precise analysis of parent-daughter radiometric chronometers (e.g., Turner 1970a, 1970b; Tera et al. 1974; Cohen et al. 2000; Norman et al. 2006; Fernandes et al. 2013; Snape et al. 2016a).

The temporal evolution of the flux of impactors to the Moon for its first billion years of evolution is still highly controversial (see Bottke and Norman 2017; Morbidelli et al. 2018 for recent reviews). It is generally believed that immediately after the formation of the Moon the impact flux was high and dominated by leftovers from the planetary accretion epoch, a time period commonly referred to as 'late accretion' during which impactors may have imprinted their chemical signatures into the crystallising LMO (e.g., Walker 2009; Day and Walker 2015; Barnes et al. 2016). Once the crust was formed and the LMO fully solidified, it is unlikely that any extraneous sources could have been added and efficiently mixed into the lunar mantle. The Moon then suffered an intense period of bombardment, as recorded by ca. 30-40 impact basins larger than $300 \mathrm{~km}$ in diameter scattered at its surface (Fig. 3 and Table 2) (e.g., Fassett et al. 2012; Neumann et al. 2015). However, the formation ages of most of these basins are not precisely known. The SPA basin is probably the oldestcrater counting studies and ${ }^{40} \mathrm{Ar} /{ }^{39} \mathrm{Ar}$ data obtained on samples that are postulated to have originated from SPA, based on their formation depth for example, have tentatively dated formation of SPA at ca. 4.25-4.3 Ga (e.g., Hiesinger et al. 2012; Fernandes et al. 2013; Garrick-Bethell and Miljković 2018). Orientale is probably the youngest basin but its age is indirectly constrained at $c a$. 3.9-3.7 Ga (e.g., Stöffler et al. 2006; Whitten et al. 2011). The Imbrium basin is one of the youngest basins, and its age has recently been proposed to be $3.926 \pm 0.002 \mathrm{Ga}$ based on U-Pb dating of zircon in an Apollo 12 impact melt breccia and in lunar meteorite Sayh al Uhaymir 169, and of phosphates in four Apollo 14 impact melt breccias (e.g., Snape et al. 2016b). About 30 impact basins larger than $300 \mathrm{~km}$ in diameter are proposed to have formed over a time window of $\sim 350-400$ million years between the formation of SPA and Imbrium (see Table 2).

Whether impact events during this basin-forming period largely occurred as a cataclysmic spike at ca. 3.9 Ga ago (e.g., Tera et al. 1974; Ryder 1990; Cohen et al. 2000; Marchi et al. 2012) or decayed monotonically after the end of planetary accretion from 4.3-4.2 Ga until 3.9-3.8 Ga ago (e.g., Hartmann 1970; Neukum et al. 2001; Morbidelli et al. 2012; Werner 2014; Morbidelli et al. 2018), or even after (e.g., Fernandes et al. 2013; Zellner 2017), remains highly debated. One of the explanations for the apparent concentration of chronometric dates at $c a .3 .9 \mathrm{Ga}$ links it to a bias in largely sampling Imbrium 


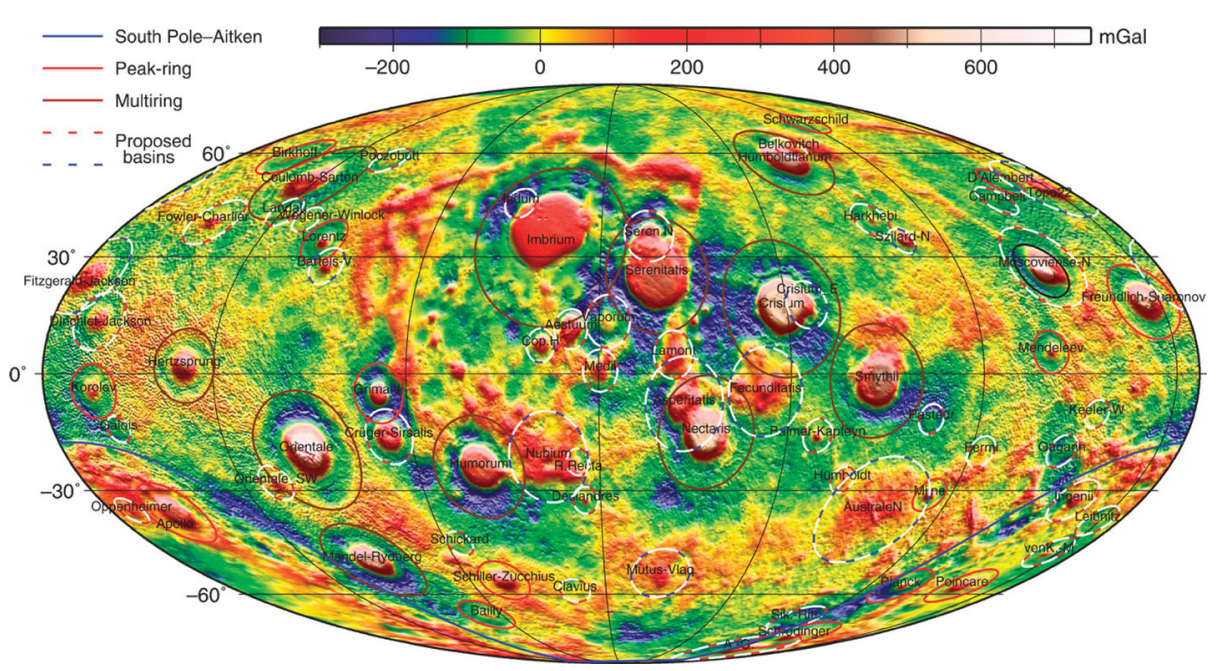

Fig. 3 Bouguer anomaly map of the Moon showing the location of large mass concentrations under impact basins (from Neumann et al. 2015). Bouguer-corrected GRAIL gravity anomaly in Mollweide equal-area projection centred on the nearside at $7^{\circ} \mathrm{E}$ longitude

ejecta in the Apollo sample collection (Fig. 1) (e.g., Haskin 1998; Spudis et al. 2011; Fernandes et al. 2013; Zellner 2017).

\subsection{Sources of Impactors}

The lunar record contains direct and indirect evidence that projectiles have hit the Moon throughout its history (see Joy et al. 2016 for a recent review). During the 'late accretion' window, a time period of up to around 200 million years between the segregation of the lunar core and the end of the LMO crystallisation (e.g., Elkins-Tanton et al. 2011), impactors may have been efficiently mixed into the lunar mantle and modified its chemical composition. We only have indirect, chemical and isotopic, evidence to estimate the flux and sources of impactors during this early period. The highly siderophile element (HSE) abundances and Os isotope signatures of mare basalts suggest that $c a .0 .02 \mathrm{wt} \%$ of the mass of the Moon has been added by chondritic impactors during late accretion (e.g., Day et al. 2007; Day and Walker 2015). These chondritic projectiles may have also delivered the bulk of the indigenous lunar $\mathrm{H}$ and $\mathrm{N}$ budgets (Barnes et al. 2016).

Projectiles continued hitting the Moon after crystallisation of the LMO and formation of a thick anorthosite crust. Volatile elements (H, C, N, S) and HSE abundances and isotopic compositions of lunar regolith and impact-melt samples provide indirect evidence for the types of impactors involved. Analysis of Apollo 14, 15, 16 and 17 samples show a broadly linear correlation between HSE/Ir and ${ }^{187} \mathrm{Os} /{ }^{188}$ Os signatures (Puchtel et al. 2008; Fischer-Gödde and Becker 2012; Sharp et al. 2014; Liu et al. 2015; Gleißner and Becker 2017), reflecting the addition of chondritic and non-chondritic components to the lunar crust, the non-chondritic component HSE composition resembling that of iron meteorites, and contributing up to $30 \mathrm{wt}$.\% HSE in the most fractionated Apollo 16 impact-melt samples (e.g., Gleißner and Becker 2017). Siderophile element abundances in mature regolith samples that have been exposed at the lunar surface for hundreds of millions of years suggest the addition of $c a$. 1-3 wt.\% of a CI chondrite-like micrometeorite component (e.g., Keays et al. 1970; 
Table 2 Sequence of lunar basins with diameters greater than $300 \mathrm{~km}$ (after Fassett et al. 2012). Basins in brackets are those whose diameters and/or stratigraphic relationships are uncertain because of observational challenges. Main ring and Bouguer anomaly diameters are from Neumann et al. (2015); ring diameters italicised are probable/possible

\begin{tabular}{|c|c|c|c|c|}
\hline Name & Period & $\begin{array}{l}\text { Main ring } \\
\text { diameter } \\
(\mathrm{km})\end{array}$ & $\begin{array}{l}\text { Bouguer } \\
\text { anomaly } \\
\text { diameter }(\mathrm{km})\end{array}$ & $\begin{array}{l}\text { Superposition } \\
\text { relationships }\end{array}$ \\
\hline South Pole-Aitken & Pre-Nectarian & 2400 & & no basin older \\
\hline Coulomb-Sarton & Pre-Nectarian & 672 & $330 \pm 18$ & $>$ Birkhoff \\
\hline Dirichlet-Jackson & Pre-Nectarian & 452 & 220 & $>$ Korolev \\
\hline Cruger-Sirsalis & Pre-Nectarian & 430 & 268 & \\
\hline Smythii & Pre-Nectarian & 878 & $438 \pm 62$ & $>$ Crisium \\
\hline [Schiller-Zucchius] & Pre-Nectarian & 361 & 210 & \\
\hline [Amundsen-Ganswindt] & Pre-Nectarian & 378 & 170 & $>$ Schrödinger \\
\hline Nubium & Pre-Nectarian & 690 & 416 & $>$ Humorum \\
\hline [Poincaré] & Pre-Nectarian & 312 & 188 & \\
\hline Lorentz & Pre-Nectarian & 351 & 156 & \\
\hline [Fitzgerald-Jackson] & Pre-Nectarian & 600 & 334 & $>$ Freundlich-Sharonov \\
\hline [Birkhoff] & Pre-Nectarian & 334 & 130 & \\
\hline [Ingenii] & Pre-Nectarian & 342 & 154 & \\
\hline [Serenitatis] & Pre-Nectarian? & 923 & $556 \pm 64$ & > Nectaris (?) \\
\hline Apollo & Pre-Nectarian/Nectarian & 492 & 264 & $>$ Korolev, Hertzsprung \\
\hline Freundlich-Sharonov & Pre-Nectarian/Nectarian & 582 & 318 & $>$ Moscoviense \\
\hline Nectaris & Start of Nectarian & 885 & $440 \pm 61$ & \\
\hline Korolev & Nectarian/Pre-Nectarian & 417 & 202 & > Hertzsprung (?) \\
\hline [Mendeleev] & Nectarian/Pre-Nectarian & 331 & 156 & \\
\hline Hertzsprung & Nectarian/Pre-Nectarian & 571 & $254 \pm 38$ & \\
\hline [Grimaldi] & Nectarian/Pre-Nectarian & 460 & 220 & > Mendel-Rydberg \\
\hline Mendel-Rydberg & Nectarian/Pre-Nectarian & 650 & $328 \pm 26$ & \\
\hline [Planck] & Nectarian/Pre-Nectarian & 321 & 128 & $>$ Schrödinger \\
\hline Moscoviense & Nectarian & 421 & & \\
\hline Crisium & Nectarian & 1076 & $498 \pm 31$ & $>$ Humboldtianum \\
\hline Humorum & Nectarian & 816 & $360 \pm 21$ & \\
\hline Humboldtianum & Nectarian & 618 & $312 \pm 27$ & \\
\hline Imbrium & Start of Imbrian & 1321 & $684 \pm 45$ & \\
\hline Schrödinger & Imbrian & 326 & 154 & \\
\hline Orientale (no buff.) & Imbrian & 937 & $436 \pm 20$ & \\
\hline
\end{tabular}

Morgan et al. 1972; Korotev et al. 2003; Wolf et al. 2009) often present in the form of micrometre-sized metallic particles, with, on average, about $70 \%$ of the total metallic iron content of lunar soils being derived from micrometeorite impactors (Morris 1980).

The lunar regolith also contains relict fragments of various types of projectiles. These are dominated by asteroidal materials, ranging from enstatite chondrite-like to carbonaceous chondrites and iron meteorites (see Joy et al. 2016 for a full list of recovered meteoritic debris). To date no cometary fragments have been positively identified in lunar regolith samples, although there are suggestions that some lunar regolith samples have volatile element 
signatures consistent with an added cometary component (Gibson and Moore 1973). Finally, a recent investigation of a ca. 4.0 billion year old clast from Apollo 14 breccia 14321 suggests that it formed at oxygen fugacity and pressure conditions incompatible with a lunar crustal environment, potentially representing the first positive identification of a terrestrial meteorite in the lunar regolith (Bellucci et al. 2019).

\subsection{Outstanding Questions and the Potential of Future Sample-Return}

\subsubsection{Determining the Magnitude and Duration of the Basin-Forming Period}

To test the magnitude and duration of the postulated late heavy bombardment, we need samples to be collected and returned to Earth for analysis in our laboratories collected from one, or ideally several, of the older, pre-Nectarian lunar basins. Accessing samples will require careful assessment of site geology and sampling of specific targets to provide wellunderstood geological context (Norman 2009; Pernet-Fisher et al. 2019b). Site selection ideally needs to consider (i) accessing basins of different ages to test different key stratigraphic markers throughout the early bombardment interval, and (ii) where possible collecting material directly from impact melt deposits, or reworked impact melt deposits to be able to access material formed within the basin event rather than re-processed by later superimposed impact events. Key periods, with targets providing opportunities for sampling multi-ring basin targets, include:

- Pre-Nectarian age: The SPA basin, on the lunar farside, which is the largest $(>2000 \mathrm{~km}$ diameter) and oldest preserved basin on the Moon (Wilhelms 1987). The formation age of SPA is unknown from direct geological sampling. However, it is inferred from crater size-frequency distribution (CSFD) age models to be $>4 \mathrm{Ga}$, with estimates ranging from $\sim 4.25 \mathrm{Ga}$ to $\leq 4.33 \mathrm{Ga}$ (Hiesinger et al. 2012; Morbidelli et al. 2012; Fernandes et al. 2013; Marchi et al. 2013; Garrick-Bethell and Miljković 2018). Anchoring the age of SPA will constrain the onset of bombardment (Jolliff et al. 2017) after the lunar crust formed and had the material strength to be able to retain a large basin structure (Conrad et al. 2018).

- Pre-Nectarian or Nectarian age: The Serenitatis basin ( $~ 900 \mathrm{~km}$ diameter), for which there is significant debate whether it is an older Pre-Nectarian basin, or a Nectarian basin younger than Nectaris and only just older than Imbrium at ca. 3.93 Ga (Spudis et al. 2011; Fassett et al. 2012). This debate is important as the lunar sample community is currently challenged about how to interpret the ages of samples collected from the North and South Massif at the Apollo 17 landing site, and notably if these samples represent Imbrium, Nectaris or Serenitatis ejecta (e.g., Hurwitz and Kring 2016; Thiessen et al. 2017).

- Nectarian age: The Nectaris basin ( $~ 900 \mathrm{~km}$ diameter) is a key stratigraphic marker that gives its name to the Nectarian period (Stuart-Alexander and Wilhelms 1975). It has been postulated that Nectarian ejecta was sampled at the Apollo 16 landing site at North Ray Crater, with basin age estimates ranging from 3.9 Ga to 4.2 Ga (e.g., Fischer-Gödde and Becker 2011, 2012). Collecting various impact melt samples from this nearside highlands site (e.g., Norman 2009; Cohen et al. 2016) is of key interest for potentially determining the timing of formation of about ten basins formed between Nectaris and Imbrium (Table 2). This would provide crucial constraints on whether the putative late heavy bombardment was a true cataclysm (Ryder 1990), followed a longer duration, less intense, 'sawtooth' model (e.g., Turner 1979; Morbidelli et al. 2012), or consisted in a monotonic decline over time (e.g., Hartmann 1970; Neukum et al. 2001; Morbidelli et al. 2018). 


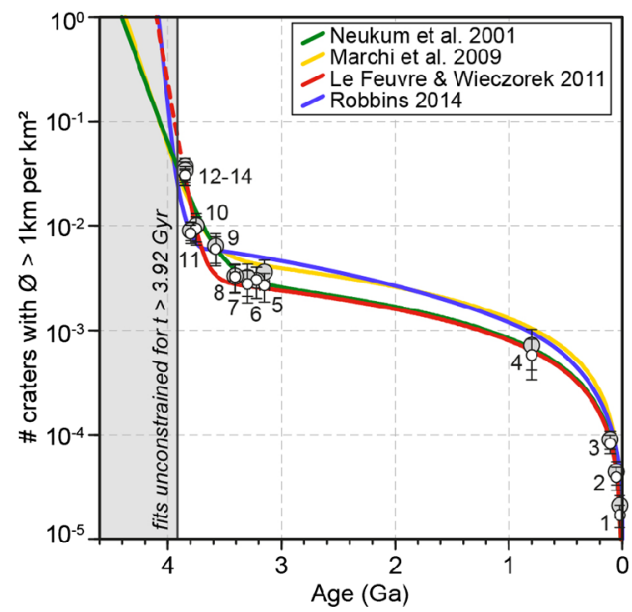

1. Cone crater

2. North Ray crater

3. Tycho crater

4. Copernicus

5. Ocean Procellarum (A12)

6. Mare Crisium (L24)

7. Mare Imbrium (A15)

8. Mare Fecunditatis (L16)

9. Mare Tranquillitatis young (A11)

10. Mare Serenitatis (A17)

11. Mare Tranquillitatis old (A11)

12. Imbrium/Apennines

13. Fra Mauro (A14)

14. Descartes (A16)

Fig. 4 Examples of different lunar crater chronology calibration curves and the Apollo sample age calibration points used (redrawn after Le Feuvre and Wieczorek 2011). Note that (4) Copernicus and (3) Tycho are from indirect sampling at the Apollo 12 and Apollo 17 landing sites, respectively

\subsubsection{Anchoring the Lunar Cratering Chronology}

Samples collected from known locations on the Moon, and in particular the mare basalts, have made it possible with CSFDs to quantify the relationship between the age of a geologic unit on a planetary surface and the density of impact craters on that surface (Fig. 4) (Neukum et al. 2001; Stöffler and Ryder 2001; Robbins 2014; Fassett 2016). Returning and dating any new samples that can be confidently linked with particular locations and geologic units on the Moon would provide valuable new data-points for future cratering chronology studies. The importance of this development extends beyond just understanding the impact history of the Moon, since the lunar cratering chronology model is commonly extrapolated to studies of other terrestrial planets (Neukum et al. 2001; Marchi et al. 2009).

The current plans for the China National Space Administration (CNSA) Chang'E-5 mission, planned for late 2019-early 2020, involve returning samples from the Mons Rümker region in northern Oceanus Procellarum (Qian et al. 2018; Zhao et al. 2017), with potential target landing sites close to the young $(\sim 1.2-1.5 \mathrm{Ga})$ basalt flows identified in previous remote sensing studies (Hiesinger et al. 2003; Stadermann et al. 2018). Likewise there are NASA mission proposals to sample $c a$. 1 Ga-old lava flows adjacent to the Aristarchus region of the nearside of the Moon (Draper et al. 2019). Given that current lunar crater chronology studies still rely predominantly on samples with ages between 3.0-4.0 Ga (Fig. 4), samples from these young basalt flows would be immensely valuable, helping to calibrate parts of the lunar cratering curve more relevant to Mars and Venus surface geological processes. Similarly, as meteorite bombardment is thought to have been so much more intense during the first billion years of solar system history, returning samples from any exposed basaltic flows older than $4.0 \mathrm{Ga}$ would place better constraints at the other end of the timescale.

\subsubsection{Secular Evolution of Types of Projectiles Hitting the Moon}

A thorough investigation of potential changes in the origin(s) of projectiles hitting the Moon requires precise age constraints on (i) impact-melt lithologies in which chemical and isotopic signatures of impactors are measured, and of (ii) regolith and soil samples from which 
projectile fragments are recovered. Projectiles in regolith samples $>3.5$ Ga-old could, for example, contain ancient terrestrial and martian crustal fragments that would be key for tackling questions linked with habitability of terrestrial planets and the origin of life on Earth (Armstrong et al. 2002; Crawford et al. 2008; Armstrong 2010; Bellucci et al. 2019).

There are different proxies for determining the duration of exposure of regolith samples to the space environment (see Joy et al. 2016), including (i) the ferromagnetic resonance maturity index $\left(\mathrm{I}_{\mathrm{s}} / \mathrm{FeO}\right.$ - this corresponds to the intensity of the ferromagnetic resonance caused by non-interacting fine-grained metal particles ratioed to the $\mathrm{FeO}$ abundance, since the amount of fine-grained metal is proportional to both the duration of surface exposure and the amount of $\mathrm{FeO}$ available for reduction; Morris 1976, 1978) used to classify surface exposure of regolith samples into immature $\left(I_{s} / F e O \leq 29\right)$, submature $\left(I_{s} / F e O=30-59\right)$ and mature $\left(\mathrm{I}_{\mathrm{s}} / \mathrm{FeO} \geq 60\right.$ ) (Morris 1976, 1978), (ii) the amount of 'trapped' solar windderived ${ }^{36} \mathrm{Ar}$ (e.g., Wieler and Heber 2003), or (iii) the agglutinate content (McKay et al. 1972). Quantitative exposure ages can be derived from measurement of the abundance of cosmogenic noble gases $\left({ }^{3} \mathrm{He},{ }^{21} \mathrm{Ne},{ }^{38} \mathrm{Ar},{ }^{81} \mathrm{Kr},{ }^{126} \mathrm{Xe}\right)$ produced during regolith interaction with cosmic rays in the top few meters of regolith (e.g., Eugster et al. 2001). However, none of these proxies allow estimating when the samples were exposed at the lunar surface, and exposure ages could even be influence by several discrete episodes of exposure due to the constant gardening of the lunar regolith. A semi-quantitative method of estimating regolith closure ages can be found using the ${ }^{40} \mathrm{Ar} /{ }^{36} \mathrm{Ar}$ antiquity indicator, which relates the amount of solar wind-derived ${ }^{36} \mathrm{Ar}$ to the amount of 'parentless' ${ }^{40} \mathrm{Ar}$ derived from the lunar exosphere (e.g., McKay et al. 1986; Eugster et al. 2001; Joy et al. 2011b; Fagan et al. 2014; Wieler 2016). The model closure ages for 74 Apollo, Luna and lunar meteorite regolith breccias range from ca. 0.1 Ga for some Apollo 15 samples up to ca.3.8-3.9 Ga for some Apollo 14 samples, displaying a rough bimodal distribution with broad peaks between $\sim 3.4-3.8 \mathrm{Ga}$ and 1-2 Ga (Fig. 5), indicating that most regolith breccia samples in our collections formed around 1-2 Ga ago and 3.5-3.8 Ga ago, and that none is older than ca. $4 \mathrm{Ga}$.

Sample-return missions targeting regolith breccias with lithification ages older than $c a$. 3.8-3.9 Ga would greatly complement the record present in our collections, potentially providing crucial information on the types of projectiles hitting the Earth-Moon system during the basin-forming epoch before $3.9 \mathrm{Ga}$ ago. The most scientifically important sample sites would be 'palaeoregolith' horizons, which are ancient regolith layers or lenses trapped between datable geological units, such as lava flows or impact melt flows (Crawford et al. 2007, 2010; Fagents et al. 2010; Crawford and Joy 2014). Whilst deep drilling might be necessary to access deeply seated palaeoregolith horizons, some natural access might be provided through layers exposed in the walls of lava tube skylights or in layered boulders in which palaeoregolith horizons may be preserved between volcanic layers (Fig. 6). For instance, Lunar Reconnaissance Orbiter Camera (LROC) Narrow Angle Camera (NAC) images of a Mare Tranquillitatis pit show that several tens of meters of layered units are present below the surface (Robinson et al. 2012a). The basaltic units at the surface where the pit is located are $\sim 3.6 \mathrm{Ga}$ old (Hiesinger et al. 2000), so the deepest palaeoregolith layers in the Mare Tranquillitatis pit may well be over $4 \mathrm{Ga}$ old, considering typical regolith formation rates on the order of 1-2 mm/Ma (Hörz et al. 1991).

\section{Nature, Timing, and Duration of Lunar Mare Volcanism}

\subsection{Overview}

The most obvious expressions of volcanic activity on the Moon are the mare basalt infillings of impact basins, particularly on the lunar nearside. The majority of these maria 
Fig. 5 Histogram of regolith breccias model closure ages (data and sources can be found in Fagan et al. 2014)
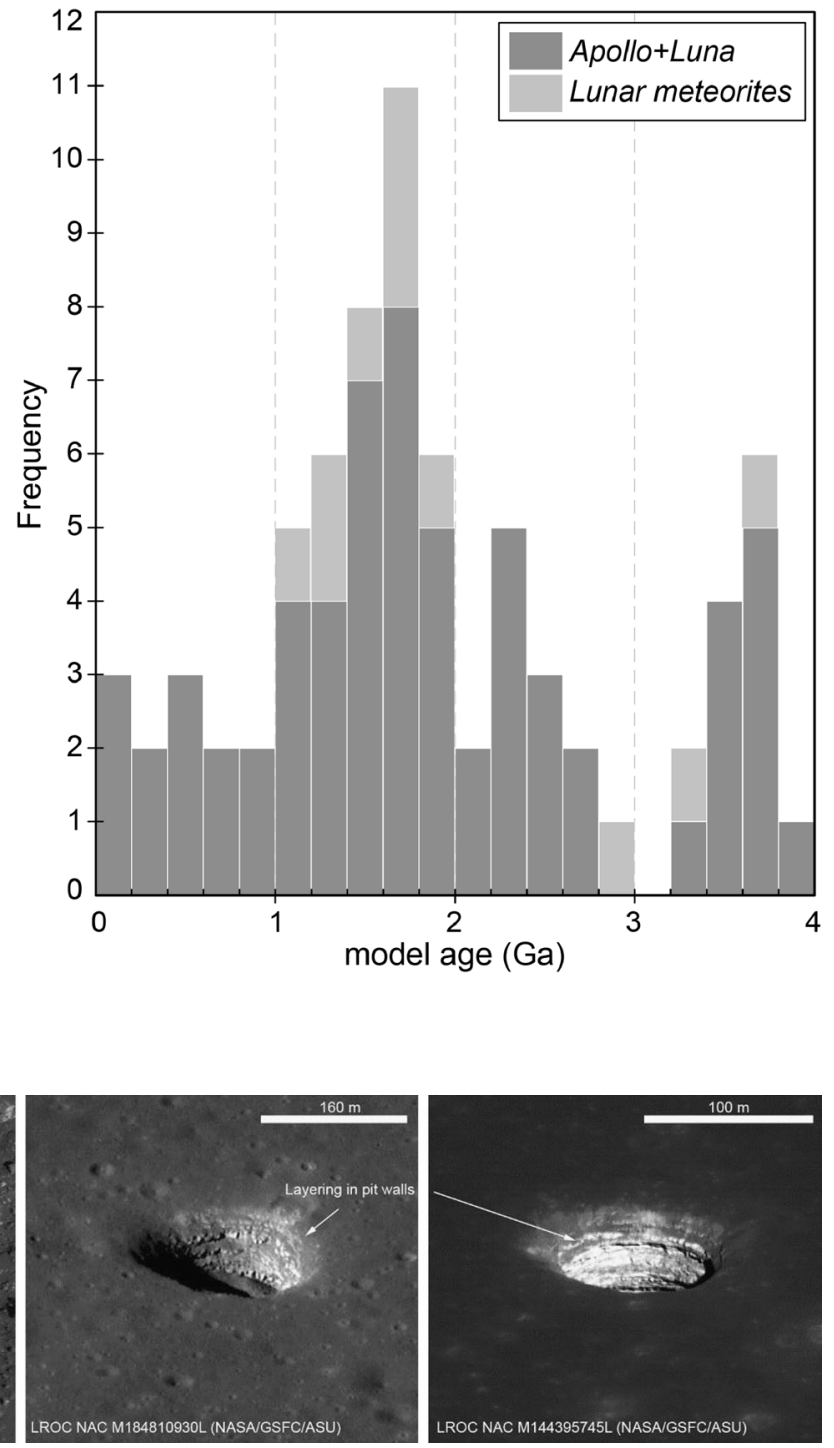

Fig. 6 Oblique LROC NAC view of layered boulders found on the lunar surface within Aristarchus crater (left), and of layered pits in Mare Ingenii (centre) and Mare Tranquillitatis (right). Scale bars in all cases have been estimated from the pixel resolution of NAC images (images: NASA/GSFC/Arizona State University, modified by K.H. Joy)

appear to have been emplaced between approximately 3.8-3.1 Ga (Nyquist and Shih 1992; Hiesinger et al. 2003, 2010). Older rocks identified in both the Apollo collection and in lunar meteorites, indicate that some form of basaltic volcanism was occurring on the Moon as early as approximately 4.35 Ga (Terada et al. 2007a; Snape et al. 2018a; Curran et al. 2019). It is not clear to what extent this early volcanism resembled the large scale eruptions of the younger mare basalts, or if these samples resulted from more localised volcanic activity. Meanwhile, the presence of less heavily cratered mare basalt flows 
indicates that mare volcanism continued until approximately $1.0 \mathrm{Ga}$ in restricted geographical locations (Hiesinger et al. 2003, 2011; Stadermann et al. 2018), but examples of such young lunar basalts have yet to be identified in the sample collection. In this section, we review the current understanding of the Moon's volcanic history based on the Apollo, Luna and meteoritic samples, and highlight outstanding issues that could be addressed by future sample-return missions.

\subsection{The Nature and Origin of Lunar Volcanism}

Discussions of volcanism on the Moon have typically divided samples into those formed as a result of mare and non-mare (or pre-mare) volcanism (Nyquist and Shih 1992). The focus of this paper is primarily on the geochemical nature of samples generated by volcanic processes. The readers interested in recent studies on magma ascent from the lunar mantle and on the possible eruption mechanisms that produced these samples and associated volcanic structures are referred to Head and Wilson (2017) and Wilson and Head (2017, 2018). In addition to basaltic rocks, the mare volcanic samples also include glass beads, produced during pyroclastic "fire fountain" eruptions (Rutherford et al. 2017). Moving beyond these top-level classifications, petrologic and geochemical analyses of samples returned by the Apollo and Luna missions have revealed a compositional diversity in the Moon's basaltic rocks that necessitates more specific classification schemes (Papike et al. 1976; Neal and Taylor 1992). Using the classification proposed by (Neal and Taylor 1992), the lunar basalts are defined first by their bulk $\mathrm{TiO}_{2}$ content (where: $>6 \mathrm{wt} \%=$ high-Ti; $1-$ $6 \mathrm{wt} \%=$ low-Ti; $<1 \mathrm{wt} \%=$ very low-Ti [VLT]), then by $\mathrm{Al}_{2} \mathrm{O}_{3}$ content $(>11 \mathrm{wt} \%=$ high-Al; $<11 \mathrm{wt} \%=$ low-Al) and finally by K content $(>2000 \mathrm{ppm}=$ high-K; $<2000 \mathrm{ppm}$ $=$ low-K). At a more detailed level, even within the mare basalt samples collected from individual landing sites, it is possible to define multiple different basaltic suites based on petrologic texture, relative abundance of minerals, chemical composition and isotope systematics (Rhodes et al. 1976, 1977; Beaty and Albee 1978; Warner et al. 1979; Paces et al. 1991; Jerde et al. 1994; Neal et al. 1994; Snyder et al. 1994). One notable group of samples that are not described by the above classification scheme are the KREEP-rich basalts, which are best represented by samples collected during the Apollo 15 mission (Nyquist et al. 1975; Carlson and Lugmair 1979; Nyquist and Shih 1992), and are characterised by elevated trace element compositions similar to the KREEP signature identified in other Apollo samples (Warren and Wasson 1979).

All of these volcanic samples are generally accepted to have been derived from 5-10\% partial melting in the Moon's interior (e.g. Shearer et al. 2006 and references therein), with a common starting point for most petrogenetic models being mafic cumulates formed during the LMO crystallisation. Simply varying the proportions of these different cumulates cannot adequately explain the variability observed in lunar basalts, and so a variety of mechanisms have been proposed to address this issue. This includes the presence of more evolved residual LMO melt enriched in incompatible trace elements (ITE) in the lunar mantle (Snyder et al. 1997; Borg et al. 2004; Hallis et al. 2014), the introduction of ilmenite-bearing material during density-driven overturn of the lunar mantle (Snyder et al. 1997), and the assimilation of KREEP and more evolved plutonic rocks (e.g. granite) by the magmas (Neal and Kramer 2006). Additionally, it is not clear what the heat source for the melting of this material would have been. Trapped ITE-rich material in the lunar mantle provides one potential heat source, but external heat sources, such as meteoritic bombardment and tidal heating, have also been proposed (Borg et al. 2004; Elkins-Tanton et al. 2004; Garrick-Bethell et al. 2006; Shearer et al. 2006). 


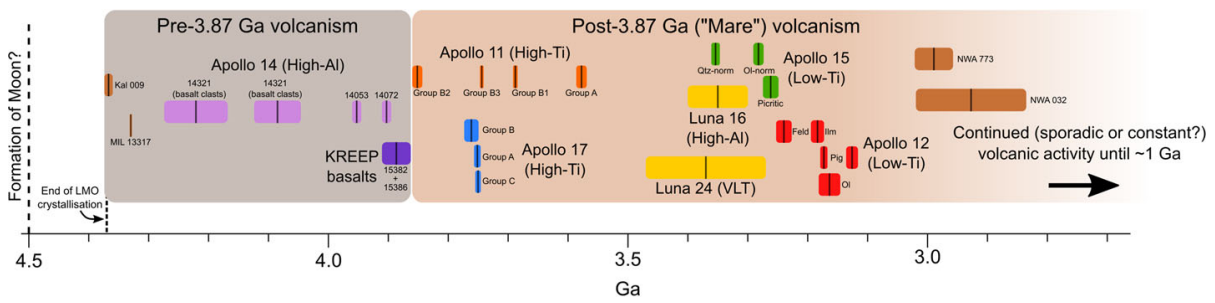

Fig. 7 Compilation of crystallisation ages determined for lunar basaltic samples. The boxes are coloured to correspond to different groups of basaltic samples. The widths of the boxes represent 2 standard deviation uncertainties of either individual sample ages (in the case of the four lunar meteorites; Borg et al. 2004, 2009; Terada et al. 2007a; Sokol et al. 2008; Snape et al. 2018a), or weighted averages of multiple age determinations (including data from: Turner 1970a, 1970b; Papanastassiou and Wasserburg 1971a, 1971b; Compston et al. 1972; Stettler et al. 1973; Turner et al. 1973; Nyquist et al. 1975, 1976; Murthy and Coscio 1976; Guggisberg et al. 1979; Carlson and Lugmair 1979; Paces et al. 1991; Snyder et al. 1994, 1997; Cohen et al. 2001; Fernandes and Burgess 2005; Snape et al. 2016a, 2018b, 2019)

\subsection{Timing of Lunar Volcanism}

Currently, evidence for the oldest basaltic volcanism on the Moon comes from two lunar meteorites: the basaltic breccia Kalahari (Kal) 009 (4.369 \pm 0.007 Ga; Terada et al. 2007a; Sokol et al. 2008; Snape et al. 2018a) and the basalt-bearing regolith breccia, Miller Range (MIL) 13317 (4.332 $\pm 0.002 \mathrm{Ga}$; Snape et al. 2018a) (Fig. 7). Prior to the discovery of these meteorites, the oldest samples of lunar basalt were the high-Al basalts collected during the Apollo 14 mission. Early studies of the volcanic rocks returned from the Apollo 14 landing site yielded ages of approximately 3.9-4.1 Ga, based on internal $\mathrm{Rb}$-Sr isochrons (Compston et al. 1971; Papanastassiou and Wasserburg 1971a; Compston et al. 1972), but further investigations of basaltic clasts in several Apollo 14 breccias determined ages of up to 4.3 Ga (Taylor et al. 1983; Dasch et al. 1987) (Fig. 7). The KREEP basalts collected during the Apollo 15 and 17 missions appear to have formed soon after (and potentially overlapping with) the eruption of the last high-Al basalts, with the largest of these samples (15382 and 15386) having crystallised at ca. 3.9 Ga (Stettler et al. 1973; Turner et al. 1973; Nyquist et al. 1975; Carlson and Lugmair 1979; Snape et al. 2016a) (Fig. 7).

The formation of the high-Al and KREEP basalts was followed by the emplacement of the mare basalts. Based on the samples currently available, this period of lunar volcanism appears to have begun with the eruption of high-Ti basalts. Samples collected at the Apollo 11 landing site have ages varying from $\sim 3.6-3.85 \mathrm{Ga}$ (Turner 1970a, 1970b; Papanastassiou and Wasserburg 1971b; Guggisberg et al. 1979; Snyder et al. 1994; Snape et al. 2016a, 2019), while those sampled by the Apollo 17 mission have a more narrow range of ages, between 3.75-3.8 Ga (Murthy and Coscio 1976; Nyquist et al. 1976; Paces et al. 1991; Snape et al. 2019) (Fig. 7). The oldest low-Ti mare basalts $(\sim 3.28$ $3.35 \mathrm{Ga}$; Snape et al. 2019) collected during the Apollo missions were returned from the Hadley-Appennine province by Apollo 15 (Papanastassiou and Wasserburg 1973; Husain 1974; Snape et al. 2019) (Fig. 7). By comparison, the low-Ti basalts collected during the Apollo 12 mission have ages between $~ 3.24-3.13$ Ga (Snyder et al. 1997; Snape et al. 2018b), making them the youngest lunar basalts to have been returned by human sampling (Fig. 7).

Sample-based evidence for more recent magmatic activity on the Moon has been identified in the meteorites Northwest Africa (NWA) 773 (Borg et al. 2004) and NWA 032 (Borg et al. 2009). Both of these samples have ages of $\sim 2.9 \mathrm{Ga}$ (determined by internal $\mathrm{Sm}-\mathrm{Nd}$ and 
Rb-Sr isochrons) (Fig. 7). In the case of NWA 773, it is notable that the sample appears to be strongly enriched in ITEs, and exhibits a KREEP-rich geochemical signature, despite it being significantly younger than any of the KREEP-rich samples returned by Apollo, while NWA 032, by contrast, has relatively low ITE concentrations. While these are currently the youngest identified volcanic samples from the Moon, crater size-frequency distribution studies have identified basaltic flows that appear to have been emplaced at $\sim 1.0 \mathrm{Ga}$ (Hiesinger et al. 2003; Stadermann et al. 2018), and potentially some even younger "irregular mare patches" for which ages of $<0.1 \mathrm{Ga}$ have been proposed (Braden et al. 2014).

\subsection{Outstanding Questions and the Potential of Future Sample-Return}

\subsubsection{Duration and Flux of Lunar Volcanism}

Identifying and sampling the youngest lunar basalts would provide new insight into how long small terrestrial planetary bodies can sustain volcanic activity. This issue is connected to a more general issue of the changing flux of lunar volcanism with time (e.g., Hiesinger et al. 2011; Robinson et al. 2012b). Based on the ages of the Apollo, Luna and meteorite basaltic samples, together with crater size-density frequency studies of exposed mare basalt units, the majority of the lunar maria appear to have been emplaced between 3.8-3.1 Ga (Nyquist and Shih 1992; Hiesinger et al. 2003, 2010). Upcoming missions such as the CNSA Chang'E-5 or the Inner SOlar System CHRONology (ISOCHRON) missions could constitute a first step in this direction, since it may involve returning samples from very young basalt flows $(\sim 1.2-1.5 \mathrm{Ga})$ identified in previous remote sensing studies (Hiesinger et al. 2003; Qian et al. 2018; Stadermann et al. 2018; Draper et al. 2019).

Assessing the amount of recent volcanic activity should be a relatively simple issue of identifying and mapping exposed volcanic units. By contrast, determining how common ancient $(>4.0 \mathrm{Ga}$ ) lunar volcanism was, is likely to be more challenging due to the potential for older units to have been obscured by subsequent eruptions and impact processes. In addition to the ancient volcanic lunar samples discussed previously, remote sensing studies have identified evidence for ancient ( $>4.0 \mathrm{Ga}$ ) mare volcanism in the form of "dark-haloed" craters. These were interpreted as instances where basaltic flows had been buried by the ejecta deposits from large impact craters and basins, and then subsequently re-exposed by smaller impacts (Schultz and Spudis 1979, 1983). Buried basaltic flows of this kind have since been designated by the name "cryptomare" (Head and Wilson 1992; Whitten and Head 2015a, 2015b). Terada et al. (2007a) proposed that the Kal 009 meteorite represented a fragment from such a deposit, and it is true that the bulk-rock composition and mineral chemistry data from the sample are consistent with mare basalts collected during the Apollo and Luna missions (Sokol et al. 2008). Nonetheless, it remains unclear just how much basaltic material could have been buried by impact ejecta.

Sample-return missions to identified dark-haloed craters would provide a valuable first step in testing the cryptomare theory. By performing detailed petrologic, geochemical and isotopic studies of potential cryptomare basalts it would be possible to determine how similar they are to previously studied lunar basalts, as well as when they crystallised. However, individual sample-return missions will almost certainly struggle to provide a definitive answer to the larger question of how common such deposits are. This will likely require a more prolonged human presence on the Moon, enabling protracted and focused geologic sorties with the potential to obtain core samples and map the extent of cryptomare deposits. 


\subsubsection{Petrogenesis of Lunar Basalts}

Returning samples of young and old lunar basalts, together with an increased knowledge of the locations and extent of cryptomare deposits, will be vital to gaining a more complete understanding of mantle sources for lunar volcanism, and addressing questions related to the petrogenesis of lunar basalts. One of the most striking aspects about the lunar mare basalts is their assymetric distribution between the lunar nearside and farside, as well as the spatial correlation between the exposed mare units, the nearside lunar basins and the PKT (Jolliff et al. 2000) (see Fig. 1). Determining the significance of these correlations appears to be fundamental to understanding the sources of lunar basalts and the mechanism(s) that led to partial melting in the lunar mantle.

One suggested explanation for the asymmetric distribution of mare basalts is a propencity for more extrusive volcanism on the thinner nearside crust compared with the thicker crust of the lunar farside (Head and Wilson 2017). Given the location of so many mare basalt flows within large impact basins, there is also a temptation to try and link the period of apparently more intense volcanic activity on the Moon (from $\sim 3.8-3.1 \mathrm{Ga}$ ) with the end of the basin-forming period of lunar history and the proposed cataclysm (at $\sim 3.9 \mathrm{Ga}$ ). One suggestion is that the formation of the large impact basins on the nearside of the Moon could have led to adiabatic melting in the lunar mantle (e.g., Solomon and Head 1980; Elkins-Tanton et al. 2004). For example, in the model proposed by Elkins-Tanton et al. (2004), partial melting occurs in two stages: (i) in situ melting first occurs in response to the decompression associated with basin excavation; (ii) a second stage of adiabatic melting then occurs in response to convection at the lithosphere-astenosphere boundary, triggered by the isostatic rebound of the lithosphere after basin formation. In the case of the Orientale basin, a significant (60-100 Ma) time gap has been estimated between the formation of the basin $(\sim 3.68 \mathrm{Ga})$ and the subsequent eruption of the Mare Orientale units $(\sim 3.58 \mathrm{Ga})$, which has been cited as evidence against such impact-induced melting (Whitten et al. 2011). However, melts produced during the second stage of adiabatic melting of the Elkins-Tanton et al. (2004) model could form as late as ca. 350 million years after the impact event (ElkinsTanton et al. 2004). Identifying the distribution of ancient (>4.0 Ga) volcanic units, and determining the times at which they were emplaced by dating returned samples, would be a significant step towards testing the link between lunar volcanism and impact events.

The connection between impact basins and basalts does not, in itself, explain the correlation between the mare basalts and the PKT or the extent to which lunar volcanism is connected with KREEP. Returning basaltic samples further away from the PKT than the Apollo basalts, would help address this issue, and a hint of what might be expected from such samples may be seen in several basaltic lunar meteorites (Yamato-793169, Asuka-881757, Meteorite Hills 01210 and MIL 05035). These samples have lower concentrations of ITEs than most Apollo mare basalts and appear to have been derived from mantle sources with low ratios of $\mathrm{U} / \mathrm{Pb}$ and $\mathrm{Rb} / \mathrm{Sr}$, and high $\mathrm{Sm} / \mathrm{Nd}$ ratios (Misawa et al. 1993; Terada et al. 2007b; Joy et al. 2008; Liu et al. 2009; Arai et al. 2010). These features have been interpreted as evidence that these rocks may be derived from partial melts of more primitive lunar mantle cumulates than those from which the majority of Apollo basalts originated (Joy et al. 2008; Liu et al. 2009; Arai et al. 2010). The low-ITE concentrations and lack of a KREEP signature in these samples also indicate that their parental magmas did not assimilate significant amounts of KREEP-rich material. Furthermore, while the presence of ITE-rich material in the lunar mantle may have triggered the partial melting that eventually produced many of the Apollo basalts, these samples indicate that the same mechanism may not be sufficient to explain the petrogenesis of all lunar basalts. If these characteristics were found to be common in basalt samples collected away from the PKT, it could provide important insights into 
the petrogenesis of lunar basalts, the distribution of the proposed urKREEP layer, and the early magmatic evolution and differentiation of the Moon.

\section{Structure and Composition of the Lunar Interior}

\subsection{Geophysical Insights}

The Apollo Lunar Surface Experiments Packages (ALSEP) deployed across the Moon's surface by astronauts on the Apollo 12, 14, 15, 16 and 17 missions are one of the key legacies of the Apollo programme. These included active and passive seismic experiments, gravimeters, magnetometers, and heat flow probes at the Apollo 15, 16 and 17 landing sites, for example (e.g., Eichelman and Lauderdale 1974; Wieczorek et al. 2006; Jaumann et al. 2012; Weber 2014). This lunar network of seismometers recorded $c a .13000$ catalogued events between 1969 and 1977 (e.g., Nakamura et al. 2008), including nonnatural events related to impacts of booster rockets and lunar modules from Apollo spacecraft. Natural seismic sources on the Moon have been divided into three categories: meteoroid impacts, shallow moonquakes and deep moonquakes. Deep moonquakes are more frequent than shallow moonquakes. About 7,000 deep moonquakes have been recorded, originating from distinct source regions $c a$. 700-1200 km deep (e.g., Jaumann et al. 2012; Weber 2014). The precise location and periodicity of deep moonquakes are not well understood, but it seems that most deep moonquakes occur at monthly intervals, suggesting that they could be triggered with tidal stress (e.g., Latham et al. 1971). Shallow moonquakes are less frequent than deep moonquakes-28 events have been recorded between 1969 and 1977 (Nakamura 1980) — and more powerful, with magnitudes of $c a .1 .5$ to 5 on a Richterequivalent scale (e.g., Lammlein 1977; Nakamura 1980). Estimates for the depth of their epicentres range from $\sim 10 \mathrm{~km}$ down to $\sim 100 \mathrm{~km}$ deep (e.g., Gillet et al. 2017), the shallowest ones being potentially linked with recent thrusting activity on fault scarps suggesting that the Moon is still tectonically active (Watters et al. 2019). Seismic data also point to possible compositional stratification within the lunar mantle-modelling results suggest that there may be a seismic discontinuity $c a$. 500-600 km deep, below which P- and S-wave velocity seems to increase with depth (Nakamura et al. 1982; Khan et al. 2000). The presence of a zone of mineralogical phase transition and change in mantle composition toward more magnesian and aluminous compositions below $\sim 500 \mathrm{~km}$ may be interpreted as indicating (i) the base of the LMO, if the whole Moon was not fully melted, (ii) the limit between olivinedominated early cumulates and orthopyroxene-rich later cumulates in a whole Moon melted scenario, or (iii) the maximum depth of partial melting of the basaltic melt source regions (see Wieczorek et al. 2006 for further discussion).

One of the key findings that arose from interpretation of lunar seismic data is that the Moon is a differentiated body, consisting of a crust, a mantle and a ca. 400-500 km radius metallic core comprising a solid inner core and a fluid outer core (e.g., Weber et al. 2011). Gravity data also provide valuable constraints on the Moon's internal structure. The gravity field of the Moon has been mapped with increasing levels of details by successive orbiting spacecraft (NASA Lunar Prospector in the 1990s, JAXA SELENE in the 2000s and NASA GRAIL in the 2010s), the latest maps produced by the GRAIL mission being actually the highest resolution gravity maps for any Solar System body including the Earth (e.g., Zuber et al. 2013). Combined with constraints from Apollo seismic experiments, GRAIL data suggest that the lunar crust has an average thickness of $34-43 \mathrm{~km}$, with the farside crust being ca. 10-15 km thicker compared to that of the nearside (Wieczorek et al. 2013). The other 
main feature revealed by gravity data is the presence of anomalous mass concentrations, known as 'mascons' (Fig. 3). These are associated with large impact basins and thought to originate from the excavation and collapse of impact basins, followed by isostatic adjustment and cooling and contraction of voluminous melt pools (e.g., Melosh et al. 2013).

\subsection{Sample-Based Insights}

Samples of the lunar mantle have yet to be found in our Apollo, Luna and lunar meteorite collections. Our knowledge of the composition of the lunar mantle thus mostly relies on petrological and geochemical studies of mare basalts and pyroclastic glasses produced via mantle partial melting. Importantly, their compositions only reflect that of their mantle source regions at the time of their extraction from the mantle $c a .4 .3$ to 3 billion years ago (see Sect. 5: Nature, timing, and duration of lunar mare volcanism). Numerous primitive lunar basaltic melts, sampled by pyroclastic glasses, are rich in $\mathrm{FeO}$ and $\mathrm{TiO}_{2}$ (e.g., Delano 1986). Experimental work suggests that most of these primitive melts formed at pressures of $c a$. 1.5 to $3 \mathrm{GPa}$, roughly corresponding to depths of 300-600 km (e.g., Delano and Livi 1981; Longhi 1992; Grove and Krawczynski 2009; Brown and Grove 2015), while crystalline mare basalts seem to originate from partial melting at depth shallower than $\sim 350 \mathrm{~km}$ (e.g., Wieczorek et al. 2006). This thus provides evidence for the presence of Fe- and Ti-rich sources deep in the lunar mantle, which is not predicted by LMO crystallisation models (e.g., Snyder et al. 1992; Charlier et al. 2018; Rapp and Draper 2018). To account for this observation, it has been proposed that RayleighTaylor instability causes dense ilmenite-rich cumulates and underlying Fe-rich upper mantle layers formed at the end of the LMO crystallisation to sink and mix in with earlierformed Mg-rich lower mantle (e.g., Hess and Parmentier 1995). This mantle overturn mechanism also provides a way to bring radioactive incompatible elements such as $\mathrm{K}, \mathrm{U}$ and Th, enriched in late stage LMO liquids, deep into the mantle. However, it remains unclear whether heating via radioactive decay of these ITEs is a viable mechanism for sustaining mantle partial melting during the main period of mare basalt volcanism $\sim 3.8$ to 3.0 Ga ago or if the influx of hotter deep mantle material was required to trigger partial melting in cold mare basalt and pyroclastic glasses source regions (e.g., Spohn et al. 2001; Grove and Krawczynski 2009).

Compositionally, the mare basalt source regions are characterised by (i) low alkali and siderophile element abundances, (ii) $\mathrm{Sm}-\mathrm{Nd}$ and $\mathrm{Lu}-\mathrm{Hf}$ isotope compositions fractionated compared to chondritic compositions, and (iii) very low oxygen fugacities, as indicated by the presence of $\mathrm{Fe}$ metal and reduced valence state of $\mathrm{Fe}$, $\mathrm{Ti}$ and $\mathrm{Cr}$ in mare basalts (see Wieczorek et al. 2006 et references therein). For decades after the return of Apollo samples, it has been assumed that the lunar mantle was extremely dry, with estimates of lunar mantle water content lower than 1 part per billion (Taylor et al. 2006). However, with technological advances in lab instrumentation detection limits for species such as water, carbon or halogens such as fluorine and chlorine greatly improved, which permitted the successful detection in 2008 of indigenous water in lunar pyroclastic glasses (Saal et al. 2008). This was followed by a wealth of studies reporting the abundance of water and other volatile species (e.g., C, N, F, S, and Cl) in trapped melt inclusions and mineral phases such as apatite in basaltic lava products (see recent reviews by Anand et al. 2014; McCubbin et al. 2015; Hauri et al. 2017). Reconstructing mantle volatile abundances from those measured in volcanic products is not trivial, notably because volatile elements can be modified by numerous processes such as magmatic degassing, assimilation of solar wind-enriched soils, spallogenic reactions at the surface, or contamination during sample preparation on Earth. Therefore, current estimates for the water abundance in the mantle source regions of mare basalts 
and pyroclastic glasses range between $c a$. 1 and 100 parts per million (e.g., McCubbin et al. 2015; Hauri et al. 2017). It remains unclear whether this fairly large range of estimates reflects uncertainties in back-calculating water contents for mare basalt source regions, heterogeneous distribution of water in the lunar mantle, or a combination of both.

\subsection{Outstanding Questions and the Potential of Future Sample-Return}

The location of Apollo landing sites within or just around the anomalous PKT area (Fig. 1) suggests that Apollo samples provide us with a biased view of the Moon (see Sect. 5: Nature, timing, and duration of lunar mare volcanism). This is also where ALSEP packages were deployed by Apollo astronauts, suggesting that inferences about the stratification of the lunar interior based on seismic data might also be biased. A global geophysical network (e.g., Neal 2011; Smith et al. 2012; Neal et al. 2019) with stations distributed all over the lunar surface would provide invaluable information for better constraining the structure of the Moon's interior, including the possible discontinuity at $\sim 500 \mathrm{~km}$ depth, the presence of partially molten layers deep in the lower mantle, and the size and structure of the core. Global geophysical data such as the gravity data obtained by GRAIL support the crustal thickness dichotomy, the farside crust being $c a$. 10-15 km thicker compared to the nearside crust (Wieczorek et al. 2013). Several scenarios have been proposed to explain such dichotomy, including (i) asymmetric convection during LMO crystallisation and crustal growth (Loper and Werner 2002; Ohtake et al. 2012), (ii) asymmetric impact cratering (Wood 1973), (iii) ejecta deposition from SPA (Zuber et al. 1994), (iv) inhomogeneous early tidal heating (Garrick-Bethell et al. 2010), (v) accretion of a companion moon (Jutzi and Asphaug 2011), or (vi) giant impact of a 500-800 km diameter impactor onto the lunar nearside soon after the Moon's formation (e.g., Zhu et al. 2019). Returning samples from the farside crust would certainly help in disentangling between these different scenarios, in addition to providing opportunities to evaluate the possible chemical differences between farside magnesian anorthosites and nearside ferroan anorthosites (see Sect. 3: Petrology and formation history of the lunar anorthitic crust).

Sampling pieces of the lunar mantle would prove crucial to our understanding of its mineralogical and chemical nature. In particular, this would allow direct measurement of its volatile and water inventory, which has key implications for investigations of how the Moon formed (e.g., Hauri et al. 2017), and of LMO crystallisation and thermal evolution of the Moon's interior (e.g., Evans et al. 2014; Khan et al. 2014). Impact cratering processes may have breached the crust periodically and could have brought up the pieces of lunar mantle at the surface; SELENE/Kaguya spectral data indeed suggest that numerous olivinerich (mantle) exposures are found around large impact basins characterised by thin crustal thickness, including Mare Moscoviense, Crisium, Imbrium, Humorum, Nectaris, Serenitatis and basins within SPA such as Schrödinger (Yamamoto et al. 2010; see location of basins on Fig. 3). The Yutu-2 rover, which landed successfully in Von Kármán crater within the SPA basin on the lunar farside (bottom right corner on Fig. 3) on-board the CNSA Chang'e 4 lander, may indeed have identified, remotely through near infrared spectroscopy, samples excavated from the lunar mantle ( $\mathrm{Li}$ et al. 2019). Such impact basins with very thin crust thus represent key targets for sample-return missions of pieces of the Moon's mantle.

\section{Icy Deposits at the Lunar Poles}

\subsection{Evidence for the Presence of Volatiles at the Moon's Poles}

The occurrence of water ice at the lunar poles has been postulated for decades (e.g., Watson et al. 1961; Arnold 1979) because of the presence of deep topographic lows at the 


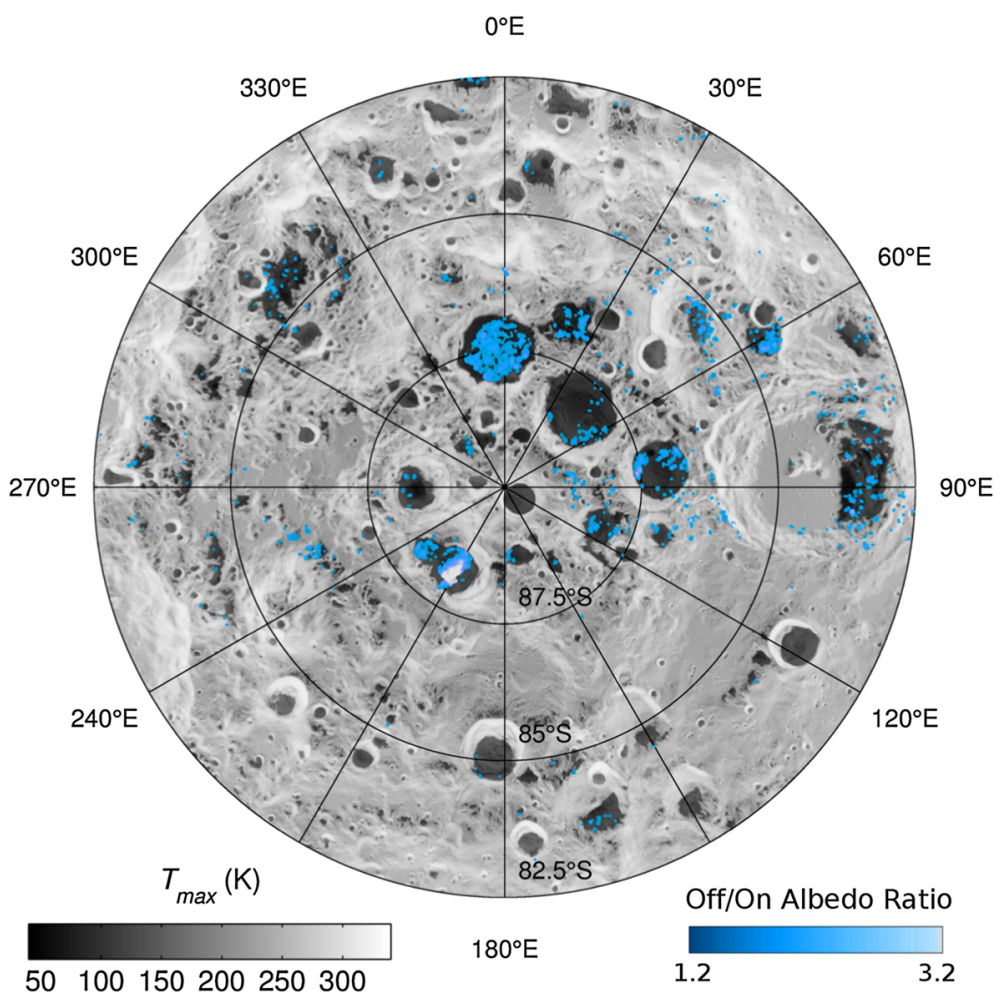

Fig. 8 Locations of anomalous UV albedo consistent with water ice (figure from Hayne et al. 2015). Colours indicate points with off/on-band albedo ratio values $>1.2$ and Lyman- $\alpha$ albedo $<0.03$, increasing from deep blue (1.2) to white (>3.2). The average Moon outside of cold traps has a ratio of 0.9 . Ratio values in the range 1.2-4.0 are consistent with water ice concentrations of $0.1-2.0 \mathrm{wt}$. $\%$. If patchy exposures of pure water ice are mixed with dry regolith, the abundance could be up to $10 \mathrm{wt} . \%$

poles and the low obliquity of the Moon. In the 1990s, possible detection of water ice in polar regions of Mercury using Earth-based radar observations (Harmon and Slade 1992) refuelled the speculation that the lunar poles might also act as a trap for water ice and other volatiles. At the same time, data returned by instruments on board the two NASA lunar orbiters Clementine and Lunar Prospector supported the presence of water ice in permanently shadowed regions (PSR) at the lunar poles (Nozette et al. 1996, 1997; Feldman et al. 1998, 2000), although subsequent Earth-based radar investigations challenged the existence of lunar polar water ice, which became a topic of strong scientific controversy (see Campbell et al. 2006, and references therein). Further remote observations carried out by a broad range of instruments on-board India's Chandrayaan-1 and NASA's Deep Impact, Cassini, and Lunar Reconnaissance Orbiter (LRO) missions, coupled with the direct detection of $c a .5 \mathrm{wt} . \%$ water and other volatile species in the plume formed by the LCROSS impact-experiment in the Cabeus crater, strongly suggested that there is indeed $\mathrm{OH} / \mathrm{H}_{2} \mathrm{O}$ molecules and water ice at the surface or sub-surface of lunar polar regions (Clark 2009; Pieters et al. 2009b; Sunshine et al. 2009; Colaprete et al. 2010; Gladstone et al. 2010; Hayne et al. 2010, 2015; Mitrofanov et al. 2010; Paige et al. 2010b; Schultz et al. 2010; Spudis et al. 2013; Fisher et al. 2017; Li and Milliken 2017; Li et al. 2018) (Fig. 8). However, we have little insights on how ice occurs (i.e. solid lumps of ice vs. 
ice mixed in with lunar soils), on its vertical and lateral distributions, and on its origin(s). For example, the production of $\mathrm{OH} / \mathrm{H}_{2} \mathrm{O}$ species at the surface could result from interaction of solar-wind protons with the regolith (e.g., Farrell et al. 2015). Cometary and volatile-rich asteroidal objects that have impacted the Moon for billions of years are obvious sources for accumulation of ice at the lunar poles. The migration of water molecules from lower latitudes to polar cold traps in permanently shadowed craters is also possible (e.g., Schorghofer and Taylor 2007), implying that magmatic water degassed onto the lunar surface during volcanic eruptions could have made its way to polar traps.

\subsection{Prospecting Missions to the Poles}

At this stage only future prospecting missions to the lunar surface can provide firmer constraints on the abundance, form, distribution, and origin(s) of water ice and other lunar polar volatiles. Landers with drilling capabilities should be able to provide crucial information on the composition, abundance and vertical distribution of polar volatiles at a given location. In addition to providing important scientific constraints on the source and processing of these polar volatiles, each single point measurement will represent ground truth for orbital measurements. PROSPECT (Package for Resource Observation and in-Situ Prospecting for Exploration Commercial Exploitation and Transportation) is a payload currently developed by the European Space Agency (ESA) to carry out these types of activities (Carpenter et al. 2016). Broadly, PROSPECT can be deployed on a mobile platform or a fixed lander, and its technical capabilities can be tailored to different objectives. Currently, the first deployment of PROSPECT on the lunar surface is planned on the Russian Luna-27 mission that should land in a lunar south polar region. PROSPECT is comprised of a drill (ProSEED) that will extract regolith samples from up to $c a .1 .2 \mathrm{~m}$ depth. The samples will be delivered to a miniature chemical laboratory (ProSPA) where volatile species (e.g., $\mathrm{H}_{2}, \mathrm{H}_{2} \mathrm{O}, \mathrm{CO}, \mathrm{CO}_{2}$, $\mathrm{N}_{2}$, noble gases) will be degassed in order to measure their abundances and stable isotope compositions (Barber et al. 2017). Thanks to their mobility, rovers could provide complementary information on the composition, abundance and lateral distribution of subsurface polar volatiles across traverses up to a few kilometres long, which would also reveal key scientific information and ground truth for orbital measurements. One such example is the NASA Volatiles Investigating Polar Exploration Rover (VIPER) mission concept (Colaprete et al. 2019). To characterise the budget of polar volatiles, VIPER would rove across the lunar surface and locate areas of high hydrogen concentration using its neutron spectrometer. Once the presence of subsurface volatiles is confirmed, regolith samples would be drilled and delivered to a miniature chemical laboratory in which volatile species (e.g., $\mathrm{H}_{2}, \mathrm{H}_{2} \mathrm{O}$, $\mathrm{CO}, \mathrm{CO}_{2}, \mathrm{~N}_{2}$, noble gases) would be degassed and their abundances quantified (Colaprete et al. 2019).

If the presence of polar volatiles at the lunar subsurface is confirmed by prospecting missions, the next logical step would then be to collect and return samples to the Earth for further characterisation of polar volatiles. Only sample-return missions allow fully comprehensive scientific investigations using present day state-of-the-art analytical equipment. In the future, technological improvements should allow addressing new questions provided the returned samples are curated properly. The paradigm shift seen over the last decade on the issue of indigenous lunar water, through re-investigation of Apollo samples using 21st century lab equipment, perfectly illustrates the scientific importance of collection and curation of samples (e.g., Anand et al. 2014; McCubbin et al. 2015). In addition to providing ground truth for orbital measurements, a sample-return mission from a polar site where cold trapped volatiles occur would establish a comprehensive inventory of what species are present. Analysis of the isotopic composition of species such as $\mathrm{H}, \mathrm{C}, \mathrm{N}, \mathrm{O}, \mathrm{S}$, and noble gases would 


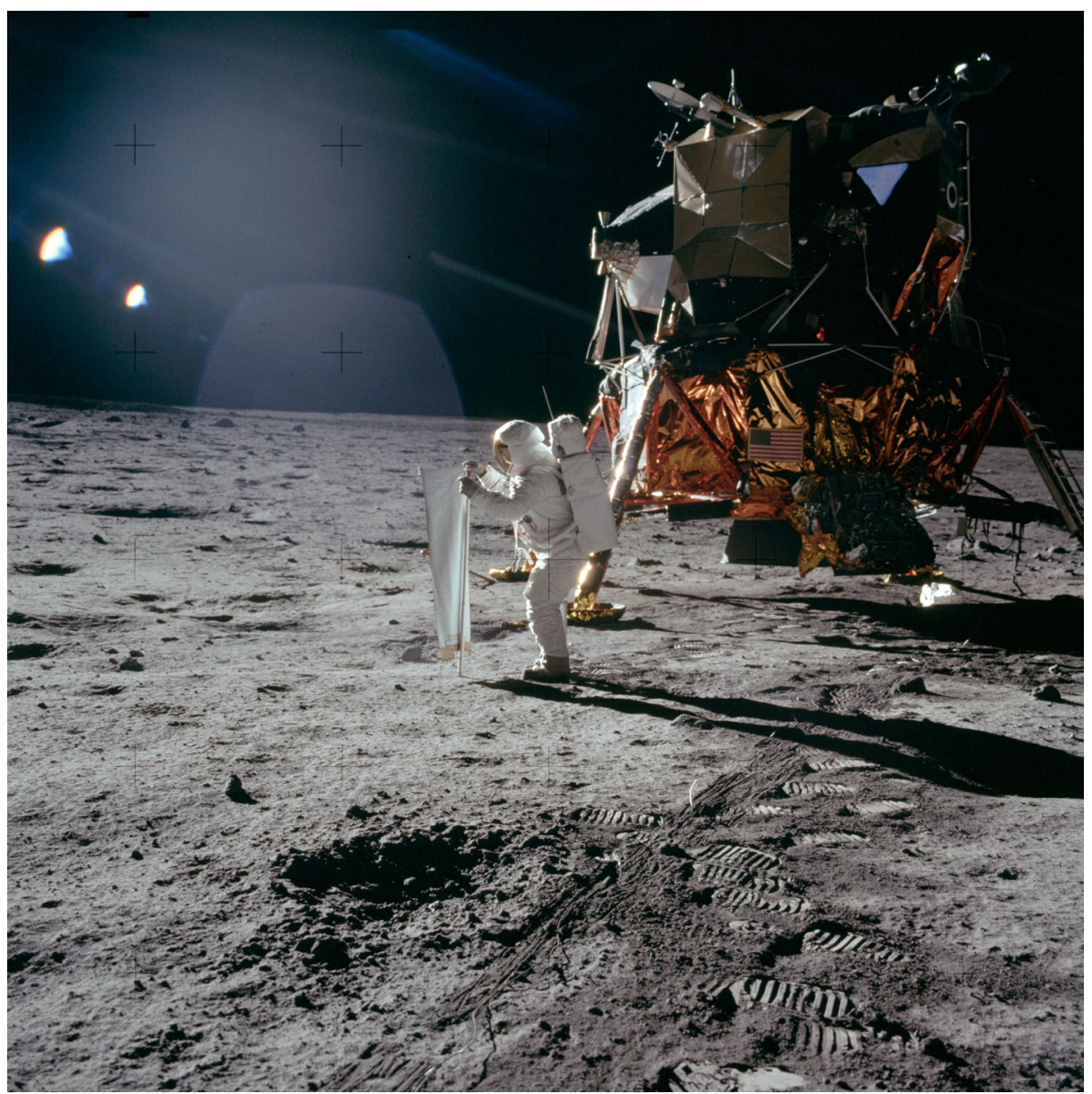

Fig. 9 Astronaut Buzz Aldrin deploying the Solar-Wind Experiment about 5 meters north-northwest of the Apollo 11 lunar module. Credit NASA photograph AS11-40-5872

provide key constraints on the source(s) of these volatiles and the processes that may have helped to concentrate them. To this end great care would be needed during sample collection and handling on the lunar surface, in the returned capsule to Earth, and on Earth. Temperature increase during sample collection through drilling for example could lead to ice and gas loss through sublimation. Therefore, the thermal and mechanical history of the samples collected will need to be precisely recorded.

\section{The Lunar Regolith as a Recorder of the Sun's Composition, Activity and Galactic Environment}

For half a century, the lunar regolith record has been used to decipher the elemental and isotopic composition of the solar wind (SW). In fact the first experiment deployed on the Moon by Apollo astronauts was designed to directly collect SW (Fig. 9). A $30 \mathrm{~cm} \times 140 \mathrm{~cm}$, 15 -micron thick, aluminium foil sheet was exposed to solar rays at the lunar surface for 77 
minutes in order to determine the SW He, Ne and Ar abundances and isotopic compositions (Geiss et al. 1969).

The SW is dominated by $\mathrm{H}(\sim 95 \%)$ and $\mathrm{He}(\sim 4 \%)$, with heavier elements such as $\mathrm{C}, \mathrm{N}, \mathrm{O}, \mathrm{Ne}, \mathrm{Mg}, \mathrm{Si}$ and $\mathrm{Fe}$ comprising <1\% (e.g., Anders and Grevesse 1989; Ogilvie and Coplan 1995). If the outermost layers of recently irradiated (i.e. in the last $100 \mathrm{Ma}$ or so) lunar soil grains preserve an accurate record of the present-day composition of the SW, it has been proposed that systematic variations of isotopic ratios of some elements such as $\mathrm{He}, \mathrm{Ne}, \mathrm{Ar}, \mathrm{N}$ or $\mathrm{C}$, in soils irradiated billions of years ago could reflect changes of the SW composition through time (e.g., Becker and Clayton 1975; Kerridge 1975; Becker 1980; Clayton and Thiemens 1980; Becker and Pepin 1989; Geiss and Bochsler 1982, 1991; Kerridge et al. 1991; Benkert et al. 1993). Several hypotheses have been proposed to account for such changes, including (i) variations in acceleration conditions in the solar corona for light species such as He, (ii) contamination of the composition of the solar convective zone by interstellar material with exotic compositions, or (iii) change of spallation reaction rates and/or depth of occurrence in the photosphere with time (e.g., Kerridge 1980). However, coordinated analyses of multiple species in ilmenite from Apollo 12, 14 and 17 soil and regolith breccia samples via progressive etching (e.g., Heber et al. 2003), combined with high precision measurement of the noble gas and nitrogen isotope compositions of the SW directly collected in ultrapure targets at the L1 Lagrangian point for more than 2 years by the NASA Genesis spacecraft, seem to indicate that no such secular variations of the SW isotopic composition are recorded in lunar regolith samples (see Wieler 2016 for an extensive discussion on this topic).

\subsection{Solar Wind Isotope Compositions Estimated from Lunar Sample Analysis}

Estimates of the solar wind isotope compositions for the noble gases $\mathrm{He}, \mathrm{Ne}$ and $\mathrm{Ar}$, and for $\mathrm{H}, \mathrm{C}, \mathrm{N}$, and $\mathrm{O}$, obtained through analysis of lunar samples are summarised in Table 3.

\subsubsection{Hydrogen, Carbon, Nitrogen and Oxygen}

Both bulk and secondary ion mass spectrometry (SIMS) analysis of $\mathrm{H}$ isotope ratios in lunar soils, regolith breccia samples, soil minerals, and glassy agglutinates show that $\mathrm{SW}$ is an important source of $\mathrm{H}$ in the lunar regolith, as indicated by very low $\delta D_{V S M O W}$ signatures $^{1}$ down to $c a$. $-850 \%$ o to $-970 \%$ (e.g., Epstein and Taylor 1970; Friedman et al. 1970; Hashizume et al. 2000; Liu et al. 2012). The lowest $\delta D_{V S M O W}$ values measured in lunar samples are slightly higher than the SW $\delta D_{V S M O W}$ value of $c a$. $-999 \%$ ostimated for a Genesis Si collector (Huss et al. 2012a), indicating that lunar surface soils may contain some non-solar deuterium that may have formed via spallation reactions for example. The SW $\mathrm{D} / \mathrm{H}$ ratio does not seem to have evolved much, if any, over time since sample 79035 , which has a ${ }^{40} \mathrm{Ar} /{ }^{36} \mathrm{Ar}$-derived antiquity age of around $2 \mathrm{Ga}$ (e.g., Wieler et al. 1996; Heber et al. 2003), yielded $\left(\delta D_{V S M O W}\right)_{S W}<-950 \%$ o (Hashizume et al. 2000).

Depth profile analyses in grains from soil 79035, which contains surface $\mathrm{H}$ dominated by SW sources (Hashizume et al. 2000), have yielded very low $\delta^{13} C_{V P D B}$ values $^{2}$ of $c a .-105 \pm$

\footnotetext{
${ }^{1}$ This $\delta D$ notation corresponds to the per mil deviation of a measured $D / H$ ratio from that of the Vienna Standard Mean Ocean Water $\left(V S M O W-D / H=1.5576 \times 10^{-4}\right)$, given by $\left[(D / H)_{\text {sample }} /(D / H)_{V S M O W}-\right.$ 1] $\times 1000$.

${ }^{2} \mathrm{This} \delta^{13} \mathrm{C}$ notation corresponds to the per mil deviation of a measured ${ }^{13} \mathrm{C} /{ }^{12} \mathrm{C}$ ratio from that of the Vienna Pee Dee Belemnite $\left(V P D B-{ }^{13} \mathrm{C} /{ }^{12} \mathrm{C}=0.0112\right)$, given by $\left[\left({ }^{13} \mathrm{C} /{ }^{12} \mathrm{C}\right)_{\text {sample }} /\left({ }^{13} \mathrm{C} /{ }^{12} \mathrm{C}\right)_{V P D B}-1\right] \times 1000$.
} 
Table 3 Summary of some lunar sample-based estimates for solar wind isotope compositions and compositions measured on Genesis samples or estimated from absorption lines in the solar photosphere

\begin{tabular}{|c|c|c|c|c|}
\hline Ratio & Value & \pm & Analysed target & References \\
\hline \multirow{4}{*}{$\begin{array}{l}{ }^{3} \mathrm{He} /{ }^{4} \mathrm{He} \\
\left(\times 10^{4}\right)\end{array}$} & 4.64 & 0.18 & Genesis DoS & 1 \\
\hline & 4.26 & 0.22 & Apollo SWE & 2 \\
\hline & 4.57 & 0.16 & Ilmenite in “young” soil 71501 & 3 \\
\hline & 4.47 & 0.26 & Average of ilmenite from soils and breccias & 4 \\
\hline \multirow[t]{5}{*}{${ }^{20} \mathrm{Ne} /{ }^{22} \mathrm{Ne}$} & 13.78 & 0.06 & Genesis DoS & 1 \\
\hline & 13.97 & 0.05 & Genesis AloS & 5 \\
\hline & 14.00 & 0.04 & Genesis Au foil, AuoS and Al collectors & 6 \\
\hline & 13.70 & 0.30 & Apollo SWE & 2 \\
\hline & 13.80 & 0.20 & Ilmenite in "young" soil 71501 & 3 \\
\hline \multirow[t]{7}{*}{${ }^{36} \mathrm{Ar} /{ }^{38} \mathrm{Ar}$} & 5.47 & 0.02 & Genesis DoS & 1 \\
\hline & 5.50 & 0.02 & Genesis Si collectors & 7 \\
\hline & 5.50 & 0.01 & Genesis AloS & 5 \\
\hline & 5.50 & 0.01 & Genesis Au foil, AuoS and Al collectors & 6 \\
\hline & 5.40 & 0.30 & Apollo SWE & 2 \\
\hline & 5.48 & 0.10 & Ilmenite in "young" soil 71501 & 3 \\
\hline & 5.53 & 0.06 & $\begin{array}{l}\text { From surface-correlated Ar from Apollo } 15 \text { soil } \\
\text { feldspar }\end{array}$ & 8 \\
\hline \multirow{4}{*}{$\begin{array}{l}\delta D_{V S M O W} \\
(\% o)\end{array}$} & $<-999$ & & Genesis Si collector & 9 \\
\hline & $<-970$ & & Bulk Apollo 11 breccia samples & 10 \\
\hline & $<-950$ & & Depth profile in soil grains in sample 79035 & 11 \\
\hline & $<-840$ & & Lowest $\delta D$ in Apollo 11 and 17 agglutinates & 12 \\
\hline \multirow{3}{*}{$\begin{array}{l}\delta^{13} \mathrm{C}_{V P D B} \\
(\% o)\end{array}$} & $?$ & & Genesis collectors & - \\
\hline & -105 & 40 & Depth profile in soil grains in sample 79035 & 13 \\
\hline & -85 & 25 & $\begin{array}{l}\text { SW estimates from solar photosphere } \delta^{13} \mathrm{C} \text { value } \\
\text { obtained by analysing } \mathrm{CO} \text { absorption lines }\end{array}$ & 14 \\
\hline \multirow{4}{*}{$\begin{array}{l}\delta^{15} \mathrm{~N}_{A I R} \\
(\% \circ)\end{array}$} & -390 & 180 & Genesis Au cross arms & 15 \\
\hline & -407 & 7 & Genesis concentrator & 16 \\
\hline & -417 & 100 & Genesis DoS & 17 \\
\hline & $<-240$ & & Depth profile in soil grains in sample 79035 & 11 \\
\hline \multirow{2}{*}{$\begin{array}{l}\delta^{18} \mathrm{O}_{V S M O W} \\
(\% \circ)\end{array}$} & $<-40$ & 15 & Depth profile in metal grains in sample 79035 & 18,19 \\
\hline & -102.3 & 6.6 & Genesis $\mathrm{SiC}$ collector & 20 \\
\hline
\end{tabular}

Abbreviations: DoS — diamond-like carbon on silicate substrate; AloS—aluminium deposited on sapphire; AuoS-gold deposited on sapphire. References: 1-Heber et al. (2009); 2-Geiss et al. (2004); 3-Benkert et al. (1993); 4-Heber et al. (2003); 5-Meshik et al. (2007); 6-Pepin et al. (2012); 7—Vogel et al. (2011); 8-Frick et al. (1975); 9-Huss et al. (2012a); 10—Friedman et al. (1970); 11—-Hashizume et al. (2000); 12 — Liu et al. (2012); 13 — Hashizume et al. (2004); 14 - Lyons et al. (2018); 15—Marty et al. (2010); 16Marty et al. (2011); 17-Huss et al. (2012b); 18-Hashizume and Chaussidon (2005); 19-Hashizume and Chaussidon (2009); 20-McKeegan et al. (2011)

$40 \%$ at a depth of 15-30 $\mathrm{nm}$ (Hashizume et al. 2004). Such values cannot be compared to Genesis data since the $\left({ }^{13} \mathrm{C} /{ }^{12} \mathrm{C}\right)_{S W}$ has not yet been determined. However, it matches fairly well with recent estimates for $\left(\delta^{13} \mathrm{C}_{V P D B}\right)_{S W}$ of $c a .-75 \pm 15$ to $-90 \pm 15 \%$ o derived from a 
new estimate for the $\delta^{13} \mathrm{C}_{V P D B}$ of the Sun's photosphere of $-48 \pm 15 \%$ and modelling of $\mathrm{C}$ isotope fractionation during transport from the photosphere to the corona via Coulomb drag (Lyons et al. 2018). Overall this suggests that the SW is depleted in ${ }^{13} \mathrm{C}$ compared to most planetary and asteroidal materials that are characterised by $\delta^{13} \mathrm{C}_{V P D B}$ ratios around $0 \pm 30 \%$ 。 (e.g., Lyons et al. 2018 and references therein).

Analyses of nitrogen isotopes in Apollo and Luna regolith samples have yielded $\delta^{15} \mathrm{~N}_{A I R}{ }^{3}$ values ranging from $c a$. $-200 \%$ up to around +100\%o (e.g., Becker and Clayton 1975; Kerridge 1975, 1993; Thiemens and Clayton 1980; Frick et al. 1988; Füri et al. 2012; Mortimer et al. 2016). Based on the apparent correlation of increasing $\delta^{15} \mathrm{~N}_{A I R}$ with decreasing ${ }^{40} \mathrm{Ar} /{ }^{36} \mathrm{Ar}$ antiquity ratios, it has been suggested that the SW nitrogen isotope composition evolved through time to present-day values around +100\%o (e.g., Becker and Clayton 1975; Kerridge 1975; Thiemens and Clayton 1980). However, based on depth profile analyses of individual mineral grains from soil and regolith samples by SIMS, Hashizume et al. (2000) proposed that the present-day $\mathrm{SW}$ is depleted in ${ }^{15} \mathrm{~N}$, with $\delta^{15} \mathrm{~N}_{A I R}$ values $\leq-240 \%$ o. A ${ }^{15} \mathrm{~N}$ depleted solar nitrogen was eventually confirmed by analysis of Genesis targets that yielded a best $\delta^{15} \mathrm{~N}_{\text {AIR }}$ estimate of $-407 \pm 7 \%$ o for SW nitrogen (Marty et al. 2011). Recent highresolution step-heating analyses of Apollo 12, 14, 15, 16 and 17 surface soil samples and Luna 24 drill core samples are consistent with such a ${ }^{15} \mathrm{~N}$-depleted SW nitrogen (Füri et al. 2012; Mortimer et al. 2016).

Based on depth profile $\mathrm{O}$ isotope analyses in metal grains isolated from lunar soils, Hashizume and Chaussidon $(2005,2009)$ have argued that solar gas is characterised by $\delta^{18} \mathrm{O}_{\text {VSMOW }}{ }^{4}<c a .-40 \pm 15 \%$ o. This is consistent with analysis of Genesis SiC collectors that yielded a $\left(\delta^{18} \mathrm{O}_{V S M O W}\right)$ value of $-102 \pm 7 \%$ (McKeegan et al. 2011). However, the fact that such ${ }^{16} \mathrm{O}$-rich values have not yet been found in lunar samples suggests that either some processes have fractionated the SW oxygen isotope composition during or after its implantation in lunar materials, or that samples with unfractionated SW have not been analysed so far.

\subsubsection{The Noble Gases He, Ne and Ar}

Heber et al. (2003) carried out high resolution acid etching experiments on ilmenite separates from soil and regolith breccia samples with a wide range of antiquity ages from $c a$. 0.1 to $3.7 \mathrm{Ga}$ (see Sect. 4.3.3 for a discussion of how antiquity ages are estimated). The $\left({ }^{3} \mathrm{He} /{ }^{4} \mathrm{He}\right)_{S W}$ ratios they measured are well correlated with antiquity ages of the samples, suggesting an apparent increase of $\left({ }^{3} \mathrm{He} /{ }^{4} \mathrm{He}\right)_{S W}$ by $\sim 6 \%$ per billion years. Similarly, the $\left({ }^{20} \mathrm{Ne} /{ }^{22} \mathrm{Ne}\right)_{S W}$ ratios measured by Heber et al. (2003) on the samples were also correlated with antiquity ages, with $\left({ }^{20} \mathrm{Ne} / 22 \mathrm{Ne}\right)_{S W}$ apparently increasing with time by $\sim 2 \%$ per billion years. However, Heber et al. (2003) observed that the apparent temporal changes of $\left({ }^{3} \mathrm{He} /{ }^{4} \mathrm{He}\right)_{S W}$ and $\left({ }^{20} \mathrm{Ne} /{ }^{22} \mathrm{Ne}\right)_{S W}$ ratios were correlated with each other, mimicking the correlation displayed by single etch steps and indicating progressive etching of deeper sited isotopically heavier solar energetic particles. This led Heber et al. (2003) to conclude that the apparent temporal variations of the $\left({ }^{3} \mathrm{He} /{ }^{4} \mathrm{He}\right)_{S W}$ and $\left({ }^{20} \mathrm{Ne} /{ }^{22} \mathrm{Ne}\right)_{S W}$ ratios resulted from secondary processes on the lunar surface causing partial removal of surface-correlated SW.

\footnotetext{
${ }^{3}$ This $\delta^{15} \mathrm{~N}$ notation corresponds to the per mil deviation of a measured ${ }^{15} \mathrm{~N} /{ }^{14} \mathrm{~N}$ ratio from that of the terrestrial air $\left(A I R-{ }^{15} \mathrm{~N} /{ }^{14} \mathrm{~N}=0.003676\right)$, given by $\left[\left({ }^{15} \mathrm{~N} /{ }^{14} \mathrm{~N}\right)\right.$ sample $\left./\left({ }^{15} \mathrm{~N} /{ }^{14} \mathrm{~N}\right)_{A I R}-1\right] \times 1000$.

${ }^{4}$ This $\delta^{18} O$ notation corresponds to the per mil deviation of a measured ${ }^{18} \mathrm{O} /{ }^{16} \mathrm{O}$ ratio from that of the Vienna Standard Mean Ocean Water $\left(V S M O W-{ }^{18} \mathrm{O} /{ }^{16} \mathrm{O}=2.005 \times 10^{-3}\right)$, given by $\left[\left({ }^{18} \mathrm{O} /{ }^{16} \mathrm{O}\right)\right.$ sample $/$ $\left.\left({ }^{18} \mathrm{O} /{ }^{16} \mathrm{O}\right)_{\text {VSMOW }}-1\right] \times 1000$.
} 
The average corrected $\left({ }^{3} \mathrm{He} /{ }^{4} \mathrm{He}\right)_{S W}$ ratio of $4.47( \pm 0.26) \times 10^{-4}$ obtained on ilmenite from six samples with antiquity ages from ca. 0.1 up to $~ 3.7$ Ga by Heber et al. (2003) is indeed identical to the $\left({ }^{3} \mathrm{He} /{ }^{4} \mathrm{He}\right)_{S W}$ ratio of $4.57( \pm 0.16) \times 10^{-4}$ estimated for recent SW implanted in the last $100 \mathrm{Ma}$ on ilmenite grains in lunar soil 71501 (Benkert et al. 1993). The He isotope composition estimated for SW from lunar regolith samples matches very well with the average $\left({ }^{3} \mathrm{He} /{ }^{4} \mathrm{He}\right)_{S W}$ ratio of $4.64( \pm 0.18) \times 10^{-4}$ obtained for $\mathrm{SW}$ collected for $\sim 2.5$ years by the Genesis spacecraft (Heber et al. 2009). The $\left({ }^{3} \mathrm{He} /{ }^{4} \mathrm{He}\right)_{S W}$ ratio derived from lunar soil and Genesis analyses appear to be slightly higher than the average $\left({ }^{3} \mathrm{He} /{ }^{4} \mathrm{He}\right)_{S W}$ ratio of 4.26 $( \pm 0.22) \times 10^{-4}$ for SW collected by the Apollo $11,12,14,15$ and 16 collectors (Geiss et al. 2004). However, this average value may be slightly uncertain considering that Apollo 11 and 12 experiments yielded $5.38( \pm 0.40) \times 10^{-4}$ and $4.08( \pm 0.17) \times 10^{-4}$, respectively, with $\left({ }^{3} \mathrm{He} /{ }^{4} \mathrm{He}\right)_{S W}$ ratios for Apollo $14\left(4.48 \pm 0.28 \times 10^{-4}\right), 15\left(4.33 \pm 0.22 \times 10^{-4}\right)$ and $16\left(4.42 \pm 0.20 \times 10^{-4}\right)$ being consistent with the $\left({ }^{3} \mathrm{He} /{ }^{4} \mathrm{He}\right)_{S W}$ ratio derived from lunar soil and Genesis analyses (Benkert et al. 1993; Heber et al. 2003, 2009; Geiss et al. 2004).

As discussed above the apparent increase of $\left({ }^{20} \mathrm{Ne} /{ }^{22} \mathrm{Ne}\right)_{S W}$ with antiquity measured in Apollo samples by Heber et al. (2009) has been interpreted as an artefact related to secondary processes while samples resided on the lunar surface. The $\left({ }^{20} \mathrm{Ne} /{ }^{22} \mathrm{Ne}\right)_{S W}$ of $13.80 \pm 0.20$ measured in ilmenite in sample 71051 (Benkert et al. 1993) is consistent with the ${ }^{20} \mathrm{Ne} /{ }^{22} \mathrm{Ne}$ isotope ratio of $13.70 \pm 0.30$ measured on Apollo collectors (Geiss et al. 2004), both measurements being consistent within error with the $\left({ }^{20} \mathrm{Ne} / 22 \mathrm{Ne}\right)_{S W}$ ratios of $13.78 \pm 0.06$ (Heber et al. 2009), $13.97 \pm 0.05$ (Meshik et al. 2007) and $14.00 \pm 0.04$ (Pepin et al. 2012) measured in different types of Genesis collectors. Note that the $\left({ }^{20} \mathrm{Ne} /{ }^{22} \mathrm{Ne}\right)_{S W}$ ratio calculated by Heber et al. (2009) is not consistent with those obtained by Meshik et al. (2007) and Pepin et al. (2012) thought, a discrepancy that is still not yet understood (see Pepin et al. 2012 for further discussion on this). At present, our best estimate for the $\left({ }^{20} \mathrm{Ne} /{ }^{22} \mathrm{Ne}\right)_{S W}$ ratio is thus $c a .13 .9 \pm 0.1$.

Lunar sample studies yielded estimates for the $\left({ }^{36} \mathrm{Ar} /{ }^{38} \mathrm{Ar}\right)_{S W}$ ratio of ca. 5.50 (e.g., Frick et al. 1975; Benkert et al. 1993), which are consistent with both the relatively imprecise $\left({ }^{36} \mathrm{Ar} /{ }^{38} \mathrm{Ar}\right)_{S W}$ ratio of $5.40 \pm 0.30$ determined on Apollo collectors (Geiss et al. 2004) and with the much more precise $\left({ }^{36} \mathrm{Ar} /{ }^{38} \mathrm{Ar}\right)_{S W}$ ratios of $5.50 \pm 0.05$ obtained on Genesis collectors (Meshik et al. 2007; Heber et al. 2009; Vogel et al. 2011; Pepin et al. 2012). Isotopic analyses of young lunar regolith materials also provided very good estimates for the SW Kr and Xe isotope compositions (Pepin et al. 1995), with Kr and $\mathrm{Xe}$ isotope ratios within $1 \%$ of current best estimates for SW compositions measured on Genesis samples (e.g., Crowther and Gilmour 2013; Meshik et al. 2014).

\subsection{Investigating Past Solar Activity and Changes of Galactic Environments}

Characterising the evolution of the Sun's activity over the past 4.6 billion years is key to investigating the evolution of inner Solar System planetary surfaces and atmospheres, and by extension the habitability of terrestrial planetary bodies (e.g., Airapetian et al. 2016). Investigation of the meteorite record suggests enhanced solar activity during the early Solar System history (e.g., McKeegan et al. 2000; Aléon et al. 2005; Sossi et al. 2017; Kööp et al. 2018), which is consistent with greater flare activity associated with a shorter rotational period for the young Sun (e.g., Güdel 2007). The lunar regolith can also help characterise the rotational rate of the Sun during its first billion years of evolution since solar flares and associated coronal mass ejection (CME) directly affect the surface of airless bodies and could have driven loss of volatile species such as $\mathrm{Na}$ and $\mathrm{K}$ from the Moon's surface (e.g., Killen et al. 2012; Saxena et al. 2019). Based on the abundance of $\mathrm{Na}$ and $\mathrm{K}$ in the 
lunar crust, and on modelling of the effect of CME on Na and K loss, Saxena et al. (2019) argued that the Sun likely rotated relatively slowly during its first billion years of evolution compared to other young stars.

The lunar regolith also preserves a record of changes of the Solar System galactic environment as a whole (Spudis 1996). Over the past 4.5 billion years the Solar System has orbited the centre of the Milky Way approximately 20 times (e.g., Gies and Helsel 2005) and passed through spiral arms 2 to 6 times (Gillman et al. 2019). While moving around the Galaxy, the lunar regolith could have recorded changes in the flux and types of impactors delivered to the inner Solar System (see Sect. 4: The bombardment history of the inner Solar System). Over this period of time, the Solar System would have also been exposed to changing galactic environment conditions-passing through the Milky Way spiral arms would have enhanced the probability of passing close to supernovae, which could be recorded in the lunar regolith via supernova ejecta implanted in regolith materials and/or as an enhanced galactic cosmic ray (GCR) flux (e.g., Crawford 2017 and references therein). When GCRs interact with geological materials, a wide array of cosmogenic nuclides are produced in response to neutron capture and spallation reactions, including noble gases such as ${ }^{3} \mathrm{He},{ }^{21} \mathrm{Ne},{ }^{38} \mathrm{Ar},{ }^{83} \mathrm{Kr}$ and ${ }^{126} \mathrm{Xe}$ and other isotopes such as ${ }^{10} \mathrm{Be}$ and ${ }^{36} \mathrm{Cl}$. However, our current Apollo and Luna collections are not ideally suited for investigating possible variations of the GCR flux through time. All these samples were collected at the surface or within the top few meters of the lunar regolith and have undergone constant regolith gardening over the past 3-4 billion years. As a result their exposure history records an integrated GCR flux since they were first exposed, which is generally complicated and poorly constrained (e.g., Levine et al. 2007; Füri et al. 2018). In addition to an increased GCR flux, passing by a supernova could also be recorded by deposition of ejecta enriched in radioactive isotopes such as ${ }^{60} \mathrm{Fe}$, for which spikes have been identified in $\sim 2-3$ and $6-$ 9 Ma-old terrestrial ocean sediments and linked to a supernova origin (see Wallner et al. 2016 and references therein). Spikes of ${ }^{60} \mathrm{Fe}$ have also been measured in Apollo samples and have been linked with deposition of supernova ejecta $\sim 2$ Ma ago (Cook et al. 2009; Fimiani et al. 2016). This bears promise for investigating galactic changes through time; however, similarly to examining variations of the GCR flux, detecting older supernova events in the Apollo and Luna collections is complicated by regolith gardening, which would average supernova-related spikes over the period of exposure of studied samples (e.g., Crawford 2017).

\subsection{Opportunities Offered by Future Sample-Return Missions}

Study of soil and regolith samples have provided us with solid estimates for the noble gas isotopic compositions of the SW that were later confirmed by samples returned by the Genesis mission. The composition of the SW for other important elements such as $\mathrm{Si}, \mathrm{Mg}, \mathrm{Fe}$, S, Cl has not yet been measured in Genesis samples (Burnett et al. 2019), and could be estimated based on targeted analyses on constituents of lunar soil and regolith samples already present in our collections. However, thoroughly tackling questions related to possible changes in solar activity, solar wind composition, and galactic environment through time will require accessing regolith samples that have been exposed to the space environment at a known point in time and for a well constrained duration. Such samples could be returned from palaeoregolith horizons (see Sect. 4.3.3: Secular evolution of types of projectiles hitting the Moon) trapped between datable lava flows or impact melt flows, some of them being potentially accessible to robotic or human explorers through layers exposed in the walls of lava skylights or in layered boulders (Fig. 6) (Crawford et al. 2007, 2010; Fagents et al. 2010; Crawford and Joy 2014). 


\section{The Lunar Magnetic Field}

\subsection{State of the Art}

The search for evidence of past or present lunar magnetism was one of the objectives of the very first missions to the Moon. The second robotic mission to the Moon, Luna 2 in 1959, carried a magnetometer that found no sign of a detectable global magnetic field (Dolginov et al. 1962). After this was confirmed by Explorer 35 (Sonett et al. 1967), the Moon was generally thought to be magnetically uninteresting, in agreement with the preconception that the Moon was too small to have sustained a dynamo field. However, one of the bigger surprises of the early Apollo missions was the discovery of past lunar magnetism. Examination of Apollo 11 samples revealed strong natural remanent magnetizations (Doell and Grommé 1970) indicative of ancient surface fields with intensities comparable to that of the present-day Earth. Subsequent measurements with the Apollo 12 and subsequent surface magnetometers revealed significant present-day remanent magnetic fields (tens to hundreds of nanotesla-nT) on the surface of the Moon indicating near-surface sources of crustal remanent magnetization (Dyal et al. 1970). Paleomagnetic measurements of lunar samples started right after the return of Apollo 11 and were very active over the whole Apollo sample-return period with about 70 samples studied (see Fuller and Cisowski 1987 for a review). After a period of relative disinterest for more than 20 years, this field of research was reactivated with a series of detailed studies on key samples that benefited from improved analytical techniques and methods for paleomagnetism, as well as better geoand thermochronology, and an overall more comprehensive understanding of the geological evolution of the Moon (see Weiss and Tikoo 2014 for a review; Tikoo et al. 2017; Lepaulard et al. 2019).

It is now established that the Moon generated a magnetic field through advection in its liquid core for a large portion of its history (Fig. 10). This magnetic field was highest between about $4.25 \mathrm{Ga}$ and $3.5 \mathrm{Ga}$ (during the so called "high-field epoch"), with an average paleointensity of $55 \mu \mathrm{T}$, much higher than the maximum value of a few tenths of a $\mu \mathrm{T}$ estimated from dynamo scaling laws (e.g., Laneuville et al. 2014, Evans et al. 2014, 2018). The field then decayed but a dynamo was still operating with surface fields in the several $\mu \mathrm{T}$ range around 1.5-2.0 Ga (Tikoo et al. 2017). Today, lunar surface magnetic fields are mostly below $10 \mathrm{nT}$, with localised higher values (and a maximum measured surface field of $327 \mathrm{nT}$ at the Apollo 12 landing site; Dyal and Daily 1978). This spatial variability of the lunar surface field reflects lithological heterogeneities and/or different magnetisation histories of the underlying crustal rocks.

\subsection{Outstanding Questions Requiring Sample-Return Missions (See Summary in Table 4)}

\subsubsection{Intensity of the Dynamo Field with Time}

The paleomagnetic data (Fig. 10) have notable temporal gaps. In particular, the absence of paleomagnetic data between about $3.0 \mathrm{Ga}$ and $1.5 \mathrm{Ga}$ prevents the understanding of the transition between the high and low field epochs. The apparent sharp transition at the precipitous collapse of the dynamo around $3.5 \mathrm{Ga}$ (Tikoo et al. 2014) has been recently reevaluated with suggestions for paleointensities in the 10-50 $\mu \mathrm{T}$ range between $3.5 \mathrm{Ga}$ and 3.0 Ga (Lepaulard et al. 2019). The extent of the weak field period and the behaviour of the magnetic field during this period are also largely unconstrained with only one published 


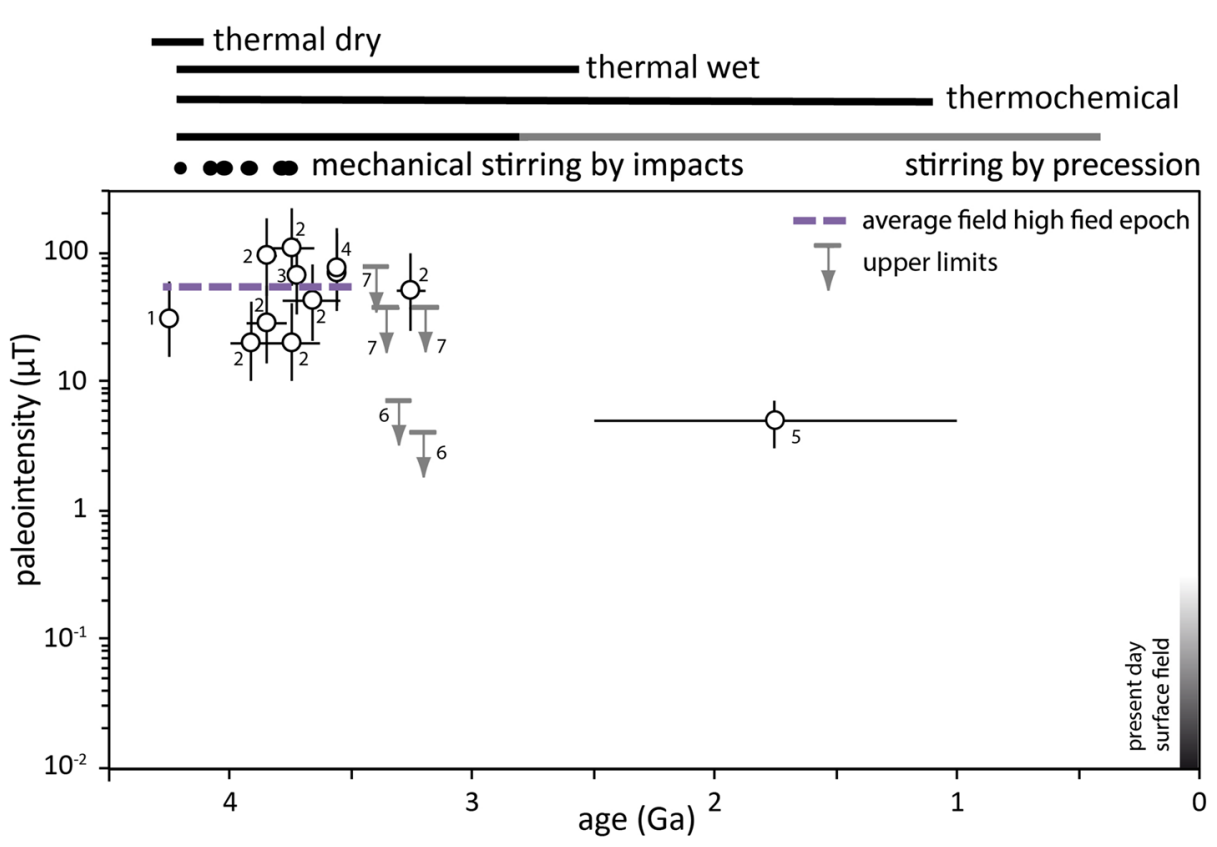

Fig. 10 Intensity of lunar surface field versus time. Note the lack of data between 3.0 and $2.0 \mathrm{Ga}$ and the scarcity of data between 2.0 and $1.0 \mathrm{Ga}$. Bars and dots above the diagram represent the time intervals over which the various dynamo generation mechanisms listed may have operated. References: 1 -Garrick-Bethell et al. (2017), 2-Cournède et al. (2012), 3-Shea et al. (2012), 4-Suavet et al. (2013), 5-Tikoo et al. (2017), 6-Tikoo et al. (2012), 7-Tikoo et al. (2014)

Table 4 Science questions and sample requirements for lunar paleomagnetic studies

\begin{tabular}{ll}
\hline Sample requirements & Science questions \\
\hline $\begin{array}{l}\text { Regolith breccias younger than } 3 \mathrm{Ga} \\
\text { Regolith breccias with age between }\end{array}$ & $\begin{array}{l}\text { Constrain weak field epoch intensity and duration } \\
\text { Transition between high and low field epochs }\end{array}$ \\
Regolith breccias older than $3 \mathrm{Ga}$ & $\begin{array}{l}\text { Confirm the high paleointensity during the high-field epoch using } \\
\text { thermal paleointensity experiments }\end{array}$ \\
$\begin{array}{l}\text { One oriented sample from one } \\
\text { location }\end{array}$ & $\begin{array}{l}\text { Testing the dipole geometry (if location of the paleopole is } \\
\text { assumed), locating the paleopole if a dipolar geometry is assumed }\end{array}$ \\
$\begin{array}{l}\text { Several oriented samples from one } \\
\text { location }\end{array}$ & $\begin{array}{l}\text { Testing the occurrence of reversals, constraining the field geometry, } \\
\text { determining the paleopole with implications for true polar wander }\end{array}$ \\
$\begin{array}{l}\text { Oriented samples from several } \\
\text { locations }\end{array}$ & $\begin{array}{l}\text { Testing the dipole geometry and defining the paleopole with } \\
\text { implications for true polar wander }\end{array}$ \\
\hline
\end{tabular}

paleointensity estimate over the last 2 Ga of the Moon history (Tikoo et al. 2017). Clearly more paleomagnetic studies of samples with magnetisation ages younger than $3.0 \mathrm{Ga}$ are required. Regolith breccias are excellent material for lunar paleomagnetism because their glassy matrices contain very fine metal grains that are favourable for recording and maintaining a record of the paleomagnetic field. However, the age at which a regolith breccia was assembled and, therefore, the age of its magnetisation is not easy to determine notably be- 
cause materials it contains may have been affected by multiple impact events (e.g., Mercer et al. 2015). Basalt samples younger than $3.0 \mathrm{Ga}$ would be a prime target for lunar paleomagnetism. Providing that their formation ages can be accurately determined through high resolution in situ geochronological analyses, regolith breccias with formation ages in the interval 3.0-2.0 Ga, and older than $3 \mathrm{Ga}$, if they exist, are other important targets.

\subsubsection{Geometry of the Lunar Surface Field}

All lunar paleomagnetic studies were performed on samples collected in the regolith. Therefore, only the paleointensity of the lunar field can be retrieved, but no paleodirectional information. As with terrestrial paleomagnetism, such directional information would be invaluable. It would allow testing the hypothesis that the lunar field was dipolar. Such a geometry is expected by analogy with the dynamo observed today on Earth, Mercury and other bodies. Substantial non-dipolar geometry would imply rapid decay of the field away from the core such that the high surface paleointensities inferred from Apollo samples would indicate even more unrealistic core fields in view of the small size of the lunar core relative to the size of the Moon. Ideally, testing the dipolar hypothesis would require oriented sampling of inplace bedrock samples at different locations on the Moon, preferably at different latitudes. A few outcrops offer the opportunity to sample rocks that have never been transported by impact processes (i.e. they are at the same place than where they formed) at the surface of the Moon. For example, lava pits may offer the possibility to sample such samples through sequences of basaltic lava flows that still have their original orientations (Fig. 6).

A single oriented sample from one location can only test the dipole hypothesis if one assumes the location of the paleo spin pole. However, a sequence of oriented samples collected at a single location would enable testing whether the field reversed. This occurrence, with evidence for two antipodal sets of paleopoles would strengthen the dipole hypothesis and help indentify the location of the paleopole. If a paleopole is found away from the location of the present-day rotation axis of the Moon, this may indicate that the Moon experienced true polar wander, i.e. large differential rotation of the mantle with respect to the core (e.g., Takahashi et al. 2014)

\subsubsection{Mechanisms Behind Dynamo Generation}

Generating a lunar dynamo requires advection in its liquid core. A number of mechanisms have been proposed that can sustain convection in the Moon: thermal convection, thermochemical convection, and mechanical stirring by mantle precession or impacts. It is noteworthy that these mechanisms are expected to have been restricted to specific, although sometimes overlapping, periods in lunar history (Weiss and Tikoo 2014). For instance, pure thermal convection with a dry mantle is very unlikely to have operated after $4 \mathrm{Ga}$, impact-generated mechanical stirring is limited to before $3.7 \mathrm{Ga}$ (age of Orientale basin, the youngest impact basin on the Moon) (Suavet et al. 2013), whereas thermochemical and precession generated mechanical stirring could operate almost up to the present-day. Therefore, a better knowledge of the evolution of the field intensity with time will also shed light on which mechanisms lie behind the lunar core convection, with implications for the dynamo theory and modelling community.

\subsection{Limitation of Current Lunar Rocks}

No basalts younger than ca. 3.0 Ga are available in the Apollo collection, and regolith breccia samples older than 3.0-3.5 Ga are rare or absent (e.g., Fagan et al. 2014) because these rocks are being modified continuously at the surface of the Moon. 
Although the orientation of some samples in the regolith was documented in situ or can be determined a posteriori, the original orientation of these rocks on the Moon is unknown. The paleohorizontal of some rocks may be assessed using for instance the crystal preferred orientation (e.g., Cournède et al. 2012), or vesicles orientation. Even so, the up and down remain unresolvable, and the constraints on the field geometry remain poor.

Meteorites are another prime source of lunar rocks and, with 378 lunar meteorites for $408.6 \mathrm{~kg}$ of material as of August 2019, based on samples classified in the Meteoritical Bulletin Database, they now outweigh the total mass of samples collected by Apollo and Luna missions. Moreover, meteorites sample the lunar surface in a more global way than sample-return missions, and, therefore, are likely to provide more representative sampling of the lunar surface, both spatially and temporally. However, meteorites pose challenges for paleomagnetism. All lunar meteorites are "finds", meteorites found at the Earth surface long after their fall, typically several kyr and up to several hundred kyr for Antarctic meteorites. The magnetic carriers of lunar rocks are Ni-poor iron-nickel alloys that are prone to weathering on Earth. Weathering of magnetic carriers leads to the loss of the primary magnetization, and, worse, possible acquisition of magnetization (chemical remanent magnetisation) in the Earth field. The long stay of these meteorites on Earth also means that they have been in the geomagnetic field for long periods, leading to the acquisition of viscous remanent magnetisation. Although these overprints can be identified and partly erased in some cases, the existence of viscous and chemical remanent magnetisations add to the complexity of lunar paleomagnetism studies. Moreover, $90 \%$ of lunar meteorites come from hot deserts, in particular from the Sahara, where they are systematically tested with magnets by private collectors and dealers. Exposure to strong magnets usually totally obliterates the primary magnetisation of the meteorites, which renders them useless for paleomagnetic studies. Among these three magnetic contaminations (viscous by long term exposure to the geomagnetic field, isothermal by exposure to strong fields, and chemical by crystallisation of weathering phases), it is noteworthy that the first two can also affect return samples. Apollo samples are curated in the ambient geomagnetic field and have all been contaminated by viscous remanent magnetisations. Storage in a weak magnetic field would be a simple and efficient solution to implement for future returned samples. Exposure to strong magnetic field can also occur during sampling on the Moon, during return from the Moon, and during sample curation and preparation. The use of non-magnetic tools during curation and the absence of strongly magnetic parts in the sampling and return material are therefore highly recommended for future sample-return missions.

\section{Summary}

Despite a large body of research over the past five decades, many new discoveries are being made through continued laboratory investigations of lunar meteorites and samples returned by Apollo and Luna missions. Insights from recent orbital and landed lunar missions have allowed integration of laboratory data acquired on returned samples to address some of the outstanding questions related to the Moon's origin and evolution. At the same time, new fundamental questions have arisen, which can only be addressed by future sample-return missions from areas of the Moon identified as being more representative than was the case for Apollo and Luna missions. As we enter into a new era of sample-return missions from various Solar System bodies, and with an increasing interest in lunar exploration among the worldwide community, new samples returned from the Moon will have immense potential to address key science questions not just related to the Moon but also to the inner Solar System. 
Acknowledgements We thank the organisers of the "Role of Sample Return in Addressing Major Outstanding Questions in Planetary Sciences" workshop that took place at the International Space Science Institute in Bern in February 2018. Jim Head and two anonymous reviewers are thanked for their thorough and insightful evaluation of this manuscript. For financial support, we are grateful to the UK Science and Technology Facilities Council (STFC) (grants ST/P005225/1 to RT, ST/M001253/1 to KHJ, and ST/P000657/1 to MA), the Royal Society (grant RS/UF140190 to KHJ), the European Commission Horizon 2020 Research and Innovation programme (Marie Skłodowska-Curie Actions Fellowship grant 794287 to JFS), the Agence Nationale de la Recherche (project Maglune ANR-14-CE33-0012 to JG), the NASA Solar System Workings program (grant NNX15AL62G to BPW) and the NASA Solar System Exploration Virtual Institute (grant NNA14AB01A to BPW).

Publisher's Note Springer Nature remains neutral with regard to jurisdictional claims in published maps and institutional affiliations.

Open Access This article is distributed under the terms of the Creative Commons Attribution 4.0 International License (http://creativecommons.org/licenses/by/4.0/), which permits unrestricted use, distribution, and reproduction in any medium, provided you give appropriate credit to the original author(s) and the source, provide a link to the Creative Commons license, and indicate if changes were made.

\section{References}

V.S. Airapetian, A. Glocer, G. Gronoff, E. Hébrard, W. Danchi, Prebiotic chemistry and atmospheric warming of early Earth by an active young Sun. Nat. Geosci. 9, 452-455 (2016)

J. Aléon, F. Robert, J. Duprat, S. Derenne, Extreme oxygen isotope ratios in the early Solar System. Nature 437, 385-388 (2005)

M. Anand, R. Tartèse, J.J. Barnes, Understanding the origin and evolution of water in the Moon through lunar sample studies. Philos. Trans. R. Soc. A 372, 20130254 (2014). https://doi.org/10.1098/rsta.2013.0254

E. Anders, N. Grevesse, Abundances of the elements: meteoritic and solar. Geochim. Cosmochim. Acta 53, 197-214 (1989)

J.C. Andrews-Hanna, J. Besserer, J.W. Head, C.J.A. Howett, W.S. Kiefer, P.J. Lucey, P.J. McGovern, H.J. Melosh, G.A. Neumann, R.J. Phillips, P.M. Schenk, D.E. Smith, S.C. Solomon, M.T. Zuber, Structure and evolution of the lunar Procellarum region as revealed by GRAIL gravity data. Nature 514, 68-71 (2014)

T. Arai, H. Takeda, A. Yamaguchi, M. Ohtake, A new model of lunar crust: asymmetry in crustal composition and evolution. Earth Planets Space 60, 433-444 (2008)

T. Arai, B.R. Hawke, T.A. Giguere, K. Misawa, M. Miyamoto, H. Kojima, Antarctic lunar meteorites Yamato793169, Asuka-881757, MIL 05035, and MET 01210 (YAMM): launch pairing and possible cryptomare origin. Geochim. Cosmochim. Acta 74, 2231-2248 (2010)

J.C. Armstrong, Distribution of impact locations and velocities of Earth meteorites on the Moon. Earth Moon Planets 107, 43-54 (2010)

J.C. Armstrong, L.E. Wells, G. Gonzalez, Rummaging through Earth's Attic for remains of ancient life. Icarus 160, 183-196 (2002)

J.R. Arnold, Ice in the lunar polar regions. J. Geophys. Res. 84, 5659-5668 (1979)

G. Avice, B. Marty, The iodine-plutonium-xenon age of the Moon-Earth system revisited. Philos. Trans. R. Soc. A 372, 20130260 (2014). https://doi.org/10.1098/rsta.2013.0260

S.J. Barber, P.H. Smith, I.P. Wright, F. Abernethy, M. Anand, K.R. Dewar, M. Hodges, P. Landsberg, M.R. Leese, G.H. Morgan, A.D. Morse, J. Mortimer, H.M. Sargeant, I. Sheard, S. Sheridan, A. Verchovsky, F. Goesmann, C. Howe, T. Morse, N. Lillywhite, A. Quinn, N. Missaglia, M. Pedrali, P. Reiss, F. Rizzi, A. Rusconi, M. Savoia, A. Zamboni, J.A. Merrifield, E.K. Gibson Jr., J. Carpenter, R. Fisackerly, B. Houdou, ProSPA: the science laboratory for the processing and analysis of lunar polar volatiles within PROSPECT, in Lunar Planet. Sci. Conf. (2017), abstract 2171

M. Barboni, P. Boehnke, B. Keller, I.E. Kohl, B. Schoene, E.D. Young, K.D. McKeegan, Early formation of the Moon 4.51 billion years ago. Sci. Adv. 3, e1602365 (2017). https://doi.org/10.1126/sciadv.1602365

J.J. Barnes, D.A. Kring, R. Tartèse, I.A. Franchi, M. Anand, S.S. Russell, An asteroidal origin for water in the Moon. Nat. Commun. 7, 11684 (2016). https://doi.org/10.1038/ncomms 11684

J.A. Barrat, B. Zanda, F. Moynier, C. Bollinger, C. Liorzou, G. Bayon, Geochemistry of CI chondrites: major and trace elements, and $\mathrm{Cu}$ and $\mathrm{Zn}$ isotopes. Geochim. Cosmochim. Acta 83, 79-92 (2012)

D.W. Beaty, A.L. Albee, Comparative petrology and possible genetic relations among the Apollo 11 basalts, in Lunar Planet. Sci. Conf. Proc. (1978), pp. 359-463 
R.H. Becker, Evidence for a secular variation in the ${ }^{13} \mathrm{C} /{ }^{12} \mathrm{C}$ ratio of carbon implanted in lunar soils. Earth Planet. Sci. Lett. 50, 189-196 (1980)

R.H. Becker, R.N. Clayton, Nitrogen abundances and isotopic compositions in lunar samples, in Lunar Sci. Conf. Proc. (1975), pp. 2131-2149

R.H. Becker, R.O. Pepin, Long-term changes in solar wind elemental and isotopic ratios: a comparison of two lunar ilmenites of different antiquities. Geochim. Cosmochim. Acta 53, 1135-1146 (1989)

J.J. Bellucci, A.A. Nemchin, M. Grange, K.L. Robinson, G. Collins, M.J. Whitehouse, J.F. Snape, M.D. Norman, D.A. Kring, Terrestrial-like zircon in a clast from an Apollo 14 breccia. Earth Planet. Sci. Lett. 510, 173-185 (2019)

J.-P. Benkert, H. Baur, P. Signer, R. Wieler, He, Ne, and Ar from the solar wind and solar energetic particles in lunar ilmenites and pyroxenes. J. Geophys. Res., Planets 98, 13147-13162 (1993)

L.E. Borg, C.K. Shearer, Y. Asmerom, J.J. Papike, Prolonged KREEP magmatism on the Moon indicated by the youngest dated lunar igneous rock. Nature 432, 209-211 (2004)

L.E. Borg, A.M. Gaffney, C.K. Shearer, D.J. DePaolo, I.D. Hutcheon, T.L. Owens, E. Ramon, G. Brennecka, Mechanisms for incompatible-element enrichment on the Moon deduced from the lunar basaltic meteorite Northwest Africa 032. Geochim. Cosmochim. Acta 73, 3963-3980 (2009)

L.E. Borg, J.N. Connelly, M. Boyet, R.W. Carlson, Chronological evidence that the Moon is either young or did not have a global magma ocean. Nature 477, 70-72 (2011)

W.F. Bottke, M.D. Norman, The late heavy bombardment. Annu. Rev. Earth Planet. Sci. 45, 619-647 (2017)

S.E. Braden, J.D. Stopar, M.S. Robinson, S.J. Lawrence, C.H. van der Bogert, H. Hiesinger, Evidence for basaltic volcanism on the Moon within the past 100 million years. Nat. Geosci. 7, 787-791 (2014)

A.D. Brandon, T.J. Lapen, V. Debaille, B.L. Beard, K. Rankenburg, C.R. Neal, Re-evaluating ${ }^{142} \mathrm{Nd} /{ }^{144} \mathrm{Nd}$ in lunar mare basalts with implications for the early evolution and bulk Sm/ $\mathrm{Nd}$ of the Moon. Geochim. Cosmochim. Acta 73, 6421-6445 (2009)

S.M. Brown, T.L. Grove, Origin of the Apollo 14, 15, and 17 yellow ultramafic glasses by mixing of deep cumulate remelts. Geochim. Cosmochim. Acta 171, 201-215 (2015)

D.S. Burnett, A.J.G. Jurewicz, D.S. Woolum, The future of Genesis science. Meteorit. Planet. Sci. 54, 10921114 (2019)

P.H. Cadogan, Oldest and largest lunar basin? Nature 250, 315-316 (1974)

J.T. Cahill, C. Floss, M. Anand, L.A. Taylor, M.A. Nazarov, B.A. Cohen, Petrogenesis of lunar highlands meteorites: Dhofar 025, Dhofar 081, Dar al Gani 262, and Dar al Gani 400. Meteorit. Planet. Sci. 39, 503-529 (2004)

D.B. Campbell, B.A. Campbell, L.M. Carter, J.L. Margot, N.J.S. Stacy, No evidence for thick deposits of ice at the lunar South pole. Nature 443, 835-837 (2006)

R.W. Carlson, G.W. Lugmair, Sm-Nd constraints on early lunar differentiation and the evolution of KREEP. Earth Planet. Sci. Lett. 45, 123-132 (1979)

R.W. Carlson, G.W. Lugmair, The age of ferroan anorthosite 60025: oldest crust on a young Moon? Earth Planet. Sci. Lett. 90, 119-130 (1988)

R.W. Carlson, L.E. Borg, A.M. Gaffney, M. Boyet, Rb-Sr, Sm-Nd and Lu-Hf isotope systematics of the lunar Mg-suite: the age of the lunar crust and its relation to the time of Moon formation. Philos. Trans. R. Soc. A 372, 20130246 (2014). https://doi.org/10.1098/rsta.2013.0246

J. Carpenter, R. Fisackerly, B. Houdou, Establishing lunar resource viability. Space Policy 37, 52-57 (2016)

B. Charlier, T.L. Grove, O. Namur, F. Holtz, Crystallization of the lunar magma ocean and the primordial mantle-crust differentiation of the Moon. Geochim. Cosmochim. Acta 234, 50-69 (2018)

R.N. Clark, Detection of adsorbed water and hydroxyl on the Moon. Science 326, 562-564 (2009)

R.N. Clayton, M.H. Thiemens, Lunar nitrogen: evidence for secular change in the solar wind, in Proceedings of the Conference on the Ancient Sun, ed. by R.O. Pepin, J.A. Eddy, R.B. Merrill (Pergamon, New York, 1980), pp. 463-473

B.A. Cohen, T.D. Swindle, D.A. Kring, Support for the lunar cataclysm hypothesis from lunar meteorite impact melt ages. Science 290, 1754-1756 (2000)

B.A. Cohen, G.A. Snyder, C.M. Hall, L.A. Taylor, M.A. Nazarov, Argon-40-argon-39 chronology and petrogenesis along the eastern limb of the Moon from Luna 16, 20 and 24 samples. Meteorit. Planet. Sci. 36, 1345-1366 (2001)

B.A. Cohen, S.J. Lawrence, N.E. Petro, G.D. Bart, R.N. Clegg-Watkins, B.W. Denevi, R.R. Ghent, R.L. Klima, G.A. Morgan, P.D. Spudis, J.D. Stopar, Identifying and characterizing impact melt outcrops in the Nectaris basin, in Lunar Planet. Sci. Conf. (2016), p. abstract 1389

A. Colaprete, P. Schultz, J. Heldmann, D. Wooden, M. Shirley, K. Ennico, B. Hermalyn, W. Marshall, A. Ricco, R.C. Elphic, D. Goldstein, D. Summy, G.D. Bart, E. Asphaug, D. Korycansky, D. Landis, L. Sollitt, Detection of water in the LCROSS ejecta plume. Science 330, 463-468 (2010)

A. Colaprete, D. Andrews, W. Bluethmann, R.C. Elphic, B. Bussey, J. Trimble, K. Zacny, J.E. Captain, An overview of the Volatiles Investigating Polar Exploration Rover (VIPER) mission, in American Geophysical Union Fall Meeting (2019), abstract P34B-03 
W. Compston, M.J. Vernon, H. Berry, R. Rudowski, The age of the Fra Mauro formation: a radiometric older limit. Earth Planet. Sci. Lett. 12, 55-58 (1971)

W. Compston, M.J. Vernon, H. Berry, R. Rudowski, C.M. Gray, N. Ware, Apollo 14 mineral ages and the thermal history of the Fra Mauro formation, in Lunar Planet. Sci. Conf. Proc., ed. by A.E. Metzger, J.I. Trombka, L.E. Peterson, R.C. Reedy, J.R. Arnold (1972), pp. 1487-1501

J.N. Connelly, M. Bizzarro, Lead isotope evidence for a young formation age of the Earth-Moon system. Earth Planet. Sci. Lett. 452, 36-43 (2016)

J.W. Conrad, F. Nimmo, C.I. Fassett, S. Kamata, Lunar impact history constrained by GRAIL-derived basin relaxation measurements. Icarus 314, 50-63 (2018)

D.L. Cook, E. Berger, T. Faestermann, G.F. Herzog, K. Knie, G. Korschinek, M. Poutivtsev, G. Ruge, F. Serefiddin, ${ }^{60} \mathrm{Fe},{ }^{10} \mathrm{Be}$, and ${ }^{26} \mathrm{Al}$ in lunar cores $12025 / 8$ and $60006 / 7$ : search for a nearby supernova, in Lunar Planet. Sci. Conf. Proc. (2009), p. abstract 1129

L.M. Corley, P.J. McGovern, G.Y. Kramer, M. Lemelin, D. Trang, J.J. Gillis-Davis, G.J. Taylor, K.E. Powell, W.S. Kiefer, M. Wieczorek, M.T. Zuber, Olivine-bearing lithologies on the Moon: constraints on origins and transport mechanisms from $\mathrm{M}^{3}$ spectroscopy, radiative transfer modeling, and GRAIL crustal thickness. Icarus 300, 287-304 (2018)

C. Cournède, J. Gattacceca, P. Rochette, Magnetic study of large Apollo samples: possible evidence for an ancient centered dipolar field on the Moon. Earth Planet. Sci. Lett. 33, 31-42 (2012)

I.A. Crawford, The Moon as a recorder of nearby supernovae, in Handbook of Supernovae, ed. by A.W. Alsabti, P. Murdin (Springer, Berlin, 2017), pp. 2507-2522

I.A. Crawford, K.H. Joy, Lunar exploration: opening a window into the history and evolution of the inner Solar System. Philos. Trans. R. Soc. A 372, 20130315 (2014). https://doi.org/10.1098/rsta.2013.0315

I.A. Crawford, S.A. Fagents, K.H. Joy, Full Moon exploration. Astron. Geophys. 48, 3.18-3.21 (2007)

I.A. Crawford, E.C. Baldwin, E.A. Taylor, J.A. Bailey, K. Tsembelis, On the survivability and detectability of terrestrial meteorites on the Moon. Astrobiology 8, 242-252 (2008)

I.A. Crawford, K.H. Joy, S.A. Fagents, M.E. Rumpf, Lunar palaeoregolith deposits as recorders of the galactic environment of the Solar System and implications for astrobiology. Earth Moon Planets 107, 75-85 (2010)

S.A. Crowther, J.D. Gilmour, The Genesis solar wind composition and its relationship to planetary xenon signatures. Geochim. Cosmochim. Acta 123, 17-34 (2013)

N.M. Curran, K.H. Joy, J.F. Snape, J.F. Pernet-Fisher, J.D. Gilmour, A.A. Nemchin, M.J. Whitehouse, R. Burgess, The early geological history of the Moon inferred from ancient lunar meteorite Miller Range 13317. Meteorit. Planet. Sci. 54, 1401-1430 (2019)

E.J. Dasch, C.Y. Shih, B.M. Bansal, H. Wiesmann, L.E. Nyquist, Isotopic analysis of basaltic fragments from lunar breccia 14321: Chronology and petrogenesis of pre-Imbrium mare volcanism. Geochim. Cosmochim. Acta 51, 3241-3254 (1987)

J.M.D. Day, R.J. Walker, Highly siderophile element depletion in the Moon. Earth Planet. Sci. Lett. 423, 114-124 (2015)

J.M.D. Day, D.G. Pearson, L.A. Taylor, Highly siderophile element constraints on accretion and differentiation of the Earth-Moon system. Science 315, 217-219 (2007)

J.W. Delano, Pristine lunar glasses: criteria, data, and implications. J. Geophys. Res. 91, 201-213 (1986)

J.W. Delano, K. Livi, Lunar volcanic glasses and their constraints on mare petrogenesis. Geochim. Cosmochim. Acta 45, 2137-2149 (1981)

E. Doell, C. Grommé, Survey of magnetic properties of Apollo 11 samples at the Lunar Receiving Laboratory, in Apollo 11 Lunar Sci. Conf. Proc. (1970), pp. 2093-2096

S.S. Dolginov, E.U. Eroshenko, L.I. Zhuzgov, N.V. Pushkov, A study of the magnetic field of the Moon. The Moon, in IAU Symposium, vol. 14 (1962), pp. 45-52

K.L. Donaldson Hanna, L.C. Cheek, C.M. Pieters, J.F. Mustard, B.T. Greenhagen, I.R. Thomas, N.E. Bowles, Global assessment of pure crystalline plagioclase across the Moon and implications for the evolution of the primary crust. J. Geophys. Res., Planets 119, 1516-1545 (2014)

D.S. Draper, R.L. Klima, S.J. Lawrence, B.W. Denevi, The Inner SOlar system CHRONology (ISOCHRON) Discovery mission: Returning samples of the youngest lunar mare basalts, in Lunar Planet. Sci. Conf. (2019), p. abstract 1110

P. Dyal, W.D. Daily, Crustal magnetic scale sizes measured at Apollo landing sites, in Lunar Planet. Sci. Conf. Proc. (1978), pp. 273-275

P. Dyal, C. Parkin, C. Sonett, Apollo 12 Magnetometer: measurement of a steady magnetic field on the surface of the Moon. Science 169, 762-764 (1970)

W.F. Eichelman, W.W. Lauderdale, Apollo scientific experiments data handbook. NASA Technical Memorendum X-58131 (1974)

L.T. Elkins-Tanton, E.M. Parmentier, P.C. Hess, Magma ocean fractional crystallization and cumulate overturn in terrestrial planets: implications for Mars. Meteorit. Planet. Sci. 38, 1753-1771 (2003) 
L.T. Elkins-Tanton, B.H. Hager, T.L. Grove, Magmatic effects of the lunar late heavy bombardment. Earth Planet. Sci. Lett. 222, 17-27 (2004)

L.T. Elkins-Tanton, S. Burgess, Q.Z. Yin, The lunar magma ocean: reconciling the solidification process with lunar petrology and geochronology. Earth Planet. Sci. Lett. 304, 326-336 (2011)

S. Epstein, H.P. Taylor, ${ }^{18} \mathrm{O} /{ }^{16} \mathrm{O},{ }^{30} \mathrm{Si} /{ }^{28} \mathrm{Si}, \mathrm{D} / \mathrm{H}$, and ${ }^{13} \mathrm{C} /{ }^{12} \mathrm{C}$ studies of lunar rock and minerals. Science 167, 533-535 (1970)

O. Eugster, D. Terribilini, E. Polnau, J. Kramers, The antiquity indicator argon-40/argon-36 for lunar surface samples calibrated by uranium-235-xenon-136 dating. Meteorit. Planet. Sci. 36, 1097-1115 (2001)

A.J. Evans, M.T. Zuber, B.P. Weiss, S.M. Tikoo, A wet,heterogeneous lunar interior: lower mantle and core dynamo evolution. J. Geophys. Res., Planets 119, 1061-1077 (2014)

A.J. Evans, S.M. Tikoo, J.C. Andrews-Hanna, The case against an early lunar dynamo powered by core convection. Geophys. Res. Lett. 45, 98-107 (2018)

A.L. Fagan, K.H. Joy, D.D. Bogard, D.A. Kring, Ages of globally distributed lunar paleoregoliths and soils from 3.9 Ga to the present. Earth Moon Planets 112, 59-71 (2014)

S.A. Fagents, M.E. Rumpf, I.A. Crawford, K.H. Joy, Preservation potential of implanted solar wind volatiles in lunar paleoregolith deposits buried by lava flows. Icarus 207, 595-604 (2010)

W.M. Farrell, D.M. Hurley, M.I. Zimmerman, Solar wind implantation into lunar regolith: hydrogen retention in a surface with defects. Icarus 255, 116-126 (2015)

C.I. Fassett, Analysis of impact crater populations and the geochronology of planetary surfaces in the inner Solar System. J. Geophys. Res., Planets 121, 1900-1926 (2016)

C.I. Fassett, J.W. Head, S.J. Kadish, E. Mazarico, G.A. Neumann, D.E. Smith, M.T. Zuber, Lunar impact basins: stratigraphy, sequence and ages from superposed impact crater populations measured from Lunar Orbiter Laser Altimeter (LOLA) data. J. Geophys. Res., Planets 117, E00H06 (2012). https://doi.org/ 10.1029/2011JE003951

W.C. Feldman, S. Maurice, A.B. Binder, B.L. Barraclough, R.C. Elphic, D.J. Lawrence, Fluxes of fast and epithermal neutrons from Lunar Prospector: Evidence for water ice at the lunar poles. Science 281, 1496-1500 (1998)

W.C. Feldman, D.J. Lawrence, R.C. Elphic, B.L. Barraclough, S. Maurice, I. Genetay, A.B. Binder, Polar hydrogen deposits on the Moon. J. Geophys. Res. 105, 4175-4195 (2000)

V.A. Fernandes, R. Burgess, Volcanism in Mare Fecunditatis and Mare Crisium: Ar-Ar age studies. Geochim. Cosmochim. Acta 69, 4919-4934 (2005)

V.A. Fernandes, J. Fritz, B.P. Weiss, I. Garrick-Bethell, D.L. Shuster, The bombardment history of the Moon as recorded by ${ }^{40} \mathrm{Ar}-{ }^{39} \mathrm{Ar}$ chronology. Meteorit. Planet. Sci. 48, 241-269 (2013)

L. Fimiani, D.L. Cook, T. Faestermann, J.M. Gómez-Guzmán, K. Hain, G. Herzog, K. Knie, G. Korschinek, P. Ludwig, J. Park, R.C. Reedy, G. Rugel, Interstellar ${ }^{60} \mathrm{Fe}$ on the surface of the Moon. Phys. Rev. Lett. 116, 151104 (2016). https://doi.org/10.1103/PhysRevLett.116.151104

M. Fischer-Gödde, H. Becker, What is the age of the Nectaris basin? New Re-Os constraints for a pre-4.0 Ga bombardment history of the Moon, in Lunar Planet. Sci. Conf. (2011), p. abstract 1414

M. Fischer-Gödde, H. Becker, Osmium isotope and highly siderophile element constraints on ages and nature of meteoritic components in ancient lunar impact rocks. Geochim. Cosmochim. Acta 77, 135-156 (2012)

E.A. Fisher, P.G. Lucey, M. Lemelin, B.T. Greenhagen, M.A. Siegler, E. Mazarico, O. Aharonson, J.P. Williams, P.O. Hayne, G.A. Neumann, D.A. Paige, D.E. Smith, M.T. Zuber, Evidence for surface water ice in the lunar polar regions using reflectance measurements from the Lunar Orbiter Laser Altimeter and temperature measurements from the Diviner Lunar Radiometer Experiment. Icarus 292, 74-85 (2017)

U. Frick, H. Baur, H. Ducati, H. Funk, D. Phinney, P. Signer, On the origin of helium, neon, and argon isotopes in sieved mineral separates from an Apollo 15 soil, in Lunar Sci. Conf. Proc. (1975), pp. 20972129

U. Frick, R.H. Becker, R.O. Pepin, Solar wind record in the lunar regolith: nitrogen and noble gases, in Lunar Planet. Sci. Conf. Proc. (1988), pp. 87-120

I. Friedman, J.R. O’Neill, L.H. Adami, J.D. Gleason, K. Hardcastle, Water, hydrogen, deuterium, carbon, carbon-13, and oxygen-18 content of selected lunar material. Science 167, 533-535 (1970)

M. Fuller, S.M. Cisowski, Lunar paleomagnetism. Geomagnetism 2, 307-455 (1987)

E. Füri, B. Marty, S.S. Assonov, Constraints on the flux of meteoritic and cometary water on the Moon from volatile element (N-Ar) analyses of single lunar soil grains, Luna 24 core. Icarus 218, 220-229 (2012)

E. Füri, L. Zimmermann, A.E. Saal, Apollo 15 green glass He-Ne-Ar signatures-In search for indigenous lunar noble gases. Geochem. Perspect. Lett. 8, 1-5 (2018)

A.M. Gaffney, L.E. Borg, A young solidification age for the lunar magma ocean. Geochim. Cosmochim. Acta 140, 227-240 (2014) 
I. Garrick-Bethell, K. Miljković, Age of the lunar South pole-Aitken basin, in Lunar Planet. Sci. Conf. (2018), p. abstract 2633

I. Garrick-Bethell, M.T. Zuber, Elliptical structure of the lunar South pole-Aitken basin. Icarus 204, 399-408 (2009)

I. Garrick-Bethell, J. Wisdom, M.T. Zuber, Evidence for a past high-eccentricity lunar orbit. Science 313, 652-655 (2006)

I. Garrick-Bethell, F. Nimmo, M.A. Wieczorek, Structure and formation of the lunar farside highlands. Science 330, 949-951 (2010)

I. Garrick-Bethell, B.P. Weiss, D.L. Shuster, S.M. Tikoo, M.M. Tremblay, Further evidence for early lunar magnetism from troctolite 76535. J. Geophys. Res., Planets 122, 76-93 (2017)

J. Geiss, P. Bochsler, Nitrogen isotopes in the Solar System. Geochim. Cosmochim. Acta 46, 529-548 (1982)

J. Geiss, P. Bochsler, Long time variations in solar wind properties: possible causes versus observations, in The Sun in Time, ed. by C.P. Sonett, M.S. Giampapa, M.S. Matthews (University of Arizona Press, Tucson, 1991), pp. 98-117

J. Geiss, F. Bühler, H. Cerutti, P. Eberhardt, C.H. Filleux, J. Meister, P. Signer, The Apollo SWC experiment: results, conclusions, consequences. Space Sci. Rev. 110, 307-335 (2004)

J. Geiss, P. Eberhardt, P. Signer, F. Buehler, J. Meister, The Solar-Wind Composition experiment, in Apollo 11 Preliminary Science Report (NASA SP-214, Washington, DC, 1969), pp. 183-186

E.K. Gibson, G.W. Moore, Volatile-rich lunar soil: evidence of possible cometary impact. Science 179, 69-71 (1973)

D.R. Gies, J.W. Helsel, Ice age epochs and the Sun's path through the Galaxy. Astrophys. J. 626, 844-848 (2005)

K. Gillet, L. Margerin, M. Calvet, M. Monnereau, Scattering attenuation profile of the Moon: implications for shallow moonquakes and the structure of the megaregolith. Phys. Earth Planet. Inter. 262, 28-40 (2017)

M.P. Gillman, H.E. Erenler, P.J. Sutton, Mapping the location of terrestrial impacts and extinctions onto the spiral arm structure of the Milky Way. Int. J. Astrobiol. 18, 323-328 (2019)

G.R. Gladstone, D.M. Hurley, K.D. Retherford, P.D. Feldman, W.R. Pryor, J.Y. Chaufray, M. Versteeg, T.K. Greathouse, A.J. Steffl, H. Throop, J.W. Parker, D.E. Kaufmann, A.F. Egan, M.W. Davis, D.C. Slater, J. Mukherjee, P.F. Miles, A.R. Hendrix, A. Colaprete, A. Stern, LRO-LAMP observations of the LCROSS impact plume. Science 330, 472-476 (2010)

P. Gleißner, H. Becker, Formation of Apollo 16 impactites and the composition of late accreted material: constraints from Os isotopes, highly siderophile elements and sulfur abundances. Geochim. Cosmochim. Acta 200, 1-24 (2017)

R.O. Green, C. Pieters, P. Mouroulis, M. Eastwood, J. Boardman, T. Glavich, P. Isaacson, M. Annadurai, S. Besse, D. Barr, B. Buratti, D. Cate, A. Chatterjee, R. Clark, L. Cheek, J. Combe, D. Dhingra, V. Essandoh, S. Geier, J.N. Goswami, R. Green, V. Haemmerle, J. Head, L. Hovland, S. Hyman, R. Klima, T. Koch, G. Kramer, A.S.K. Kumar, K. Lee, S. Lundeen, E. Malaret, T. McCord, S. McLaughlin, J. Mustard, J. Nettles, N. Petro, K. Plourde, C. Racho, J. Rodriquez, C. Runyon, G. Sellar, C. Smith, H. Sobel, M. Staid, J. Sunshine, L. Taylor, K. Thaisen, S. Tompkins, H. Tseng, G. Vane, P. Varanasi, M. White, D. Wilson, The Moon Mineralogy Mapper $\left(\mathrm{M}^{3}\right)$ imaging spectrometer for lunar science: instrument description, calibration, on-orbit measurements, science data calibration and on-orbit validation. J. Geophys. Res., Planets 116, E00G19 (2011). https://doi.org/10.1029/2011JE003797

J. Gross, K.H. Joy, Evolution, lunar: from magma ocean to crust formation, in Encyclopedia of Lunar Science, ed. by B. Cudnik (Springer, Berlin, 2016). https://doi.org/10.1007/978-3-319-05546-6_39-1

J. Gross, A.H. Treiman, C.N. Mercer, Lunar feldspathic meteorites: constraints on the geology of the lunar highlands, and the origin of the lunar crust. Earth Planet. Sci. Lett. 388, 318-328 (2014)

T.L. Grove, M.J. Krawczynski, Lunar mare volcanism: where did the magmas come from? Elements 5, 29-34 (2009)

M. Güdel, The Sun in time: activity and environment. Living Rev. Sol. Phys. 4, 3 (2007). https://doi.org/ 10.12942/lrsp-2007-3

S. Guggisberg, P. Eberhardt, J. Geiss, N. Groegler, A. Stettler, G.M. Brown, A. Peckett, Classification of the Apollo-11 mare basalts according to $\mathrm{Ar}^{39}-\mathrm{Ar}^{40}$ ages and petrological properties, in Lunar Planet. Sci. Conf. Proc., ed. by N.W. Hinners (1979), pp. 1-39

A.N. Halliday, D.-C. Lee, Tungsten isotopes and the early development of the Earth and Moon. Geochim. Cosmochim. Acta 63, 4157-4179 (1999)

L.J. Hallis, M. Anand, S. Strekopytov, Trace-element modelling of mare basalt parental melts: implications for a heterogeneous lunar mantle. Geochim. Cosmochim. Acta 134, 289-316 (2014)

J.K. Harmon, M.A. Slade, Radar mapping of Mercury: full-disk images and polar anomalies. Science 258, 640-643 (1992)

W.K. Hartmann, Lunar cratering chronology. Icarus 13, 299-301 (1970) 
W.K. Hartmann, D.R. Davis, Satellite-sized planetesimals and lunar origin. Icarus 24, 504-515 (1975)

W.K. Hartmann, C.A. Wood, Moon: origin and evolution of multi-ring basins. Moon 3, 3-78 (1971)

K. Hashizume, M. Chaussidon, A non-terrestrial ${ }^{16} \mathrm{O}$-rich isotopic composition for the protosolar nebula. Nature 434, 619-622 (2005)

K. Hashizume, M. Chaussidon, Two oxygen isotopic components with extra-selenial origins observed among lunar metallic grains-In search for the solar wind component. Geochim. Cosmochim. Acta 73, 30383054 (2009)

K. Hashizume, M. Chaussidon, B. Marty, F. Robert, Solar wind record on the Moon: deciphering presolar from planetary nitrogen. Science 290, 1142-1145 (2000)

K. Hashizume, M. Chaussidon, B. Marty, K. Terada, Protosolar carbon isotopic composition: implications for the origin of meteoritic organics. Astrophys. J. 600, 480-484 (2004)

L.A. Haskin, The Imbrium impact event and the thorium distribution at the lunar highlands surface. J. Geophys. Res., Planets 103, 1679-1689 (1998)

E.H. Hauri, A.E. Saal, M. Nakajima, M. Anand, M.J. Rutherford, J.A. Van Orman, M. Le Voyer, Origin and evolution of water in the Moon's interior. Annu. Rev. Earth Planet. Sci. 45, 89-111 (2017)

P.O. Hayne, B.T. Greenhagen, M.C. Foote, M.A. Siegler, A.R. Vasavada, D.A. Paige, Diviner lunar radiometer observations of the LCROSS impact. Science 330, 477-479 (2010)

P.O. Hayne, A. Hendrix, E. Sefton-Nash, M.A. Siegler, P.G. Lucey, K.D. Retherford, J.P. Williams, B.T. Greenhagen, D.A. Paige, Evidence for exposed water ice in the Moon's south polar regions from Lunar Reconnaissance Orbiter ultraviolet albedo and temperature measurements. Icarus 255, 58-69 (2015)

J.W. Head III, L. Wilson, Generation, ascent and eruption of magma on the Moon: new insights into source depths, magma supply, intrusions and effusive/explosive eruptions (part 2: observations). Icarus $\mathbf{2 8 3}$, 176-223 (2017)

J.W. Head, L. Wilson, Lunar mare volcanism: stratigraphy, eruption conditions, and the evolution of secondary crusts. Geochim. Cosmochim. Acta 56, 2155-2175 (1992)

V.S. Heber, H. Baur, R. Wieler, Helium in lunar samples analyzed by high-resolution stepwise etching: implications for the temporal constancy of solar wind isotopic composition. Astrophys. J. 597, 602-614 (2003)

V.S. Heber, R. Wieler, H. Baur, C. Olinger, T.A. Friedmann, D.S. Burnett, Noble gas composition of the solar wind as collected by the Genesis mission. Geochim. Cosmochim. Acta 73, 7414-7432 (2009)

G.H. Heiken, D.T. Vaniman, B.M. French, Lunar Sourcebook (Cambridge University Press, Cambridge, 1991)

P.C. Hess, E.M. Parmentier, A model for the thermal and chemical evolution of the Moon's interior: implications for the onset of mare volcanism. Earth Planet. Sci. Lett. 134, 501-514 (1995)

H. Hiesinger, R. Jaumann, G. Neukum, J.W. Head, Ages of mare basalts on the lunar nearside. J. Geophys. Res. 105, 29239-29275 (2000)

H. Hiesinger, J.W. Head, U. Wolf, R. Jaumann, G. Neukum, Ages and stratigraphy of mare basalts in Oceanus Procellarum, Mare Nubium, Mare Cognitum, and Mare Insularum. J. Geophys. Res., Planets 108, 5065 (2003). https://doi.org/10.1029/2002JE001985

H. Hiesinger, J.W. Head, U. Wolf, R. Jaumann, G. Neukum, Ages and stratigraphy of lunar mare basalts in Mare Frigoris and other nearside maria based on crater size-frequency distribution measurements. J. Geophys. Res., Planets 115, E03003 (2010). https://doi.org/10.1029/2009JE003380

H. Hiesinger, J.W. Head, U. Wolf, R. Jaumann, G. Neukum, Ages and stratigraphy of lunar mare basalts: a synthesis, in Recent Advances and Current Research Issues in Lunar Stratigraphy, ed. by W.A. Ambrose, D.A. Williams. Geol. Soc. of America Special Paper, vol. 477 (2011), pp. 1-51. https://doi.org/ 10.1130/2011.2477(01)

H. Hiesinger, C.H. van der Bogert, J.H. Pasckert, N. Schmedemann, M.S. Robinson, B. Jolliff, N. Petro, New crater size-frequency distribution measurements of the South pole-Aitken basin, in Lunar Planet. Sci. Conf. (2012), p. abstract 2863

F. Hörz, R. Grieve, G. Heiken, P. Spudis, A. Binder, Lunar surface processes, in Lunar Sourcebook, ed. by G. Heiken, D. Vaniman, B.M. French (Cambridge University Press, Cambridge, 1991), pp. 61-120

N. Hosono, S. Karato, J. Makino, T.R. Saitoh, Terrestrial magma ocean origin of the Moon. Nat. Geosci. 12, 418-423 (2019)

J. Huang, Z. Xiao, J. Flahaut, M. Martinot, J. Head, X. Xiao, M. Xie, L. Xiao, Geological characteristics of Von Kármán crater, northwestern South pole-Aitken basin: Chang'E-4 landing site region. J. Geophys. Res., Planets 123, 1684-1700 (2018)

D. Hurwitz, D.A. Kring, Identifying the geologic context of Apollo 17 impact melt breccias. Earth Planet. Sci. Lett. 436, 64-70 (2016)

L. Husain, ${ }^{40} \mathrm{Ar}-{ }^{39} \mathrm{Ar}$ chronology and cosmic ray exposure ages of the Apollo 15 samples. J. Geophys. Res. 79, 2588-2606 (1974) 
G.R. Huss, K. Nagashima, D.S. Burnett, A.J.G. Jurewicz, C.T. Olinger, A new upper limit on the D/H ratio in the solar wind, in Lunar Planet. Sci. Conf. Proc. (2012a), abstract 1709

G.R. Huss, K. Nagashima, A.J.G. Jurewicz, D.S. Burnett, C.T. Olinger, The isotopic composition and fluence of solar-wind nitrogen in a Genesis B/C array collector. Meteorit. Planet. Sci. 47, 1436-1448 (2012b)

R. Jaumann, H. Hiesinger, M. Anand, I.A. Crawford, R. Wagner, F. Sohl, B.L. Jolliff, F. Scholten, M. Knapmeyer, H. Hoffmann, H. Hussmann, M. Grott, S. Hempel, U. Köhler, K. Krohn, N. Schmitz, J. Carpenter, M. Wieczorek, T. Spohn, M.S. Robinson, J. Oberst, Geology, geochemistry, and geophysics of the Moon: status of current understanding. Planet. Space Sci. 74, 15-41 (2012)

E.A. Jerde, G.A. Snyder, L.A. Taylor, Y.G. Liu, R.A. Schmitt, The origin and evolution of lunar high-Ti basalts: periodic melting of a single source at Mare Tranquillitatis. Geochim. Cosmochim. Acta 58, 515-527 (1994)

B.L. Jolliff, J.J. Gillis, L.A. Haskin, R.L. Korotev, M.A. Wieczorek, Major lunar crustal terranes: surface expressions and crust-mantle origins. J. Geophys. Res. 105, 4197-4216 (2000)

B.L. Jolliff, R.C. Watkins, N.E. Petro, D.P. Moriarty, S.J. Lawrence, J.W. Head, C.M. Pieters, J.J. Hagerty, R.L. Fergason, T.M. Hare, L.R. Gaddis, P.O. Hayne, Selecting and certifying a landing site for moonrise in South pole-Aitken basin, in Lunar Planet. Sci. Conf. (2017), p. abstract 1326

K.H. Joy, Trace elements in lunar plagioclase as indicators of source lithology, in Lunar Planet. Sci. Conf. (2013), p. abstract 1033

K.H. Joy, T. Arai, Lunar meteorites: new insights into the geological history of the Moon. Astron. Geophys. 54, 4.28-4.32 (2013). https://doi.org/10.1093/astrogeo/att121

K.H. Joy, I.A. Crawford, M. Anand, R.C. Greenwood, I.A. Franchi, S.S. Russell, The petrology and geochemistry of Miller range 05035: a new lunar gabbroic meteorite. Geochim. Cosmochim. Acta 72, 3822-3844 (2008)

K.H. Joy, R. Burgess, R. Hinton, V.A. Fernandes, I.A. Crawford, A.T. Kearsley, A.J. Irving, EIMF, Petrogenesis and chronology of lunar meteorite Northwest Africa 4472: a KREEPy regolith breccia from the Moon. Geochim. Cosmochim. Acta 75, 2420-2452 (2011a)

K.H. Joy, D.A. Kring, D.D. Bogard, D.S. McKay, M.E. Zolensky, Re-examination of the formation ages of the Apollo 16 regolith breccias. Geochim. Cosmochim. Acta 75, 7208-7225 (2011b)

K.H. Joy, I.A. Crawford, N.M. Curran, M. Zolensky, A.F. Fagan, D.A. Kring, The Moon: an archive of small body migration in the Solar System. Earth Moon Planets 118, 133-158 (2016)

M. Jutzi, E. Asphaug, Forming the lunar farside highlands by accretion of a companion Moon. Nature 476, 69-72 (2011)

R.R. Keays, R. Ganapathy, J.C. Laul, E. Anders, G.F. Herzog, P.M. Jeffery, Trace elements and radioactivity in lunar rocks: implications for meteorite infall, solar-wind flux, and formation conditions of Moon. Science 167, 490-493 (1970)

J.F. Kerridge, Solar nitrogen: evidence for a secular increase in the ratio of nitrogen-15 to nitrogen-14. Science 188, 162-164 (1975)

J.F. Kerridge, Secular variations in composition of the solar wind: evidence and causes, in Proc. Conf. Ancient Sun (1980), pp. 475-489

J.F. Kerridge, Long-term compositional variation in solar corpuscular radiation: Evidence from nitrogen isotopes in the lunar regolith. Rev. Geophys. 31, 423-437 (1993)

J.F. Kerridge, P. Signer, R. Wieler, R.H. Becker, R.O. Pepin, Long-term changes in composition of solar particles implanted in extraterrestrial materials, in The Sun in Time, ed. by C.P. Sonett, M.S. Giampapa, M.S. Matthews (University of Arizona Press, Tucson, 1991), pp. 389-412

A. Khan, K. Mosegaard, K.L. Rasmussen, A new seismic velocity model for the Moon from a Monte Carlo inversion of the Apollo lunar seismic data. Geophys. Res. Lett. 27, 1591-1594 (2000)

A. Khan, J.A.D. Connolly, A. Pommier, J. Noir, Geophysical evidence for melt in the deep lunar interior and implications for lunar evolution. J. Geophys. Res., Planets 119, 2197-2221 (2014)

R.M. Killen, D.M. Hurley, W.M. Farrell, The effect on the lunar exosphere of a coronal mass ejection passage. J. Geophys. Res. 117, E00K02 (2012). https://doi.org/10.1029/2011JE00401

T. Kleine, H. Palme, K. Mezger, A.N. Halliday, Hf-W chronometry of lunar metals and the age and early differentiation of the Moon. Science 310, 1671-1674 (2005)

L. Kööp, P.R. Heck, H. Busemann, A.M. Davis, J. Greer, C. Maden, M.M.M. Meier, R. Wieler, High early solar activity inferred from helium and neon excesses in the oldest meteorite inclusions. Nat. Astron. 2, 709-713 (2018)

R.L. Korotev, Lunar geochemistry as told by lunar meteorites. Chem. Erde Geochem. 65, 297-346 (2005)

R.L. Korotev, B.L. Jolliff, R.A. Zeigler, J.J. Gillis, L.A. Haskin, Feldspathic lunar meteorites and their implications for compositional remote sensing of the lunar surface and the composition of the lunar crust. Geochim. Cosmochim. Acta 67, 4895-4923 (2003)

T.S. Kruijer, T. Kleine, Tungsten isotopes and the origin of the Moon. Earth Planet. Sci. Lett. 475, 15-24 (2017) 
T.S. Kruijer, T. Kleine, M. Fischer-Godde, P. Sprung, Lunar tungsten isotopic evidence for the late veneer. Nature 520, 534-537 (2015)

D.R. Lammlein, Lunar seismicity, structure, and tectonic. Philos. Trans. R. Soc. Lond. A 285, 451-461 (1977)

M. Laneuville, M.A. Wieczorek, D. Breuer, J. Albert, G. Morard, T. Rückriemen, A long-lived lunar dynamo powered by core crystallization. Earth Planet. Sci. Lett. 40, 251-260 (2014)

G. Latham, M. Ewing, J. Dorman, D. Lammlein, F. Press, N. Toksoz, G. Sutton, F. Duennebier, Y. Nakamura, Moonquakes. Science 174, 687-692 (1971)

M. Le Feuvre, M.A. Wieczorek, Nonuniform cratering of the Moon and a revised crater chronology of the inner Solar System. Icarus 214, 1-20 (2011)

D.C. Lee, A.N. Halliday, G.A. Snyder, L.A. Taylor, Age and origin of the Moon. Science 278, 1098-1103 (1997)

M. Lemelin, P.G. Lucey, E. Song, G.J. Taylor, Lunar central peak mineralogy and iron content using the Kaguya Multiband Imager: reassessment of the compositional structure of the lunar crust. J. Geophys. Res., Planets 120, 869-887 (2015)

C. Lepaulard, J. Gattacceca, M. Uehara, P. Rochette, Y. Quesnel, R.J. Macke, S.J.W. Kiefer, A survey of the natural remanent magnetization and magnetic susceptibility of Apollo whole rocks. Phys. Earth Planet. Inter. 290, 36-43 (2019)

J. Levine, P.R. Renne, R.A. Muller, Solar and cosmogenic argon in dated lunar impact spherules. Geochim. Cosmochim. Acta 71, 1624-1635 (2007)

S. Li, R.E. Milliken, Water on the surface of the Moon as seen by the Moon Mineralogy Mapper: distribution, abundance, and origins. Sci. Adv. 3, e1701471 (2017). https://doi.org/10.1126/sciadv.1701471

S. Li, P.G. Lucey, R.E. Milliken, P.O. Hayne, E. Fisher, J.P. Williams, D.M. Hurley, R.C. Elphic, Direct evidence of surface exposed water ice in the lunar polar regions. Proc. Natl. Acad. Sci. USA 115, 89078912 (2018)

C. Li, D. Liu, B. Liu, X. Ren, J. Liu, Z. He, W. Zuo, X. Zeng, R. Xu, X. Tan, X. Zhang, W. Chen, R. Shu, W. Wen, Y. Su, H. Zhang, Z. Ouyang, Chang'E-4 initial spectroscopic identification of lunar far-side mantle-derived materials. Nature 569, 378-382 (2019)

Y. Liu, C. Floss, J.M.D. Day, E. Hill, L.A. Taylor, Petrogenesis of lunar mare basalt meteorite Miller Range 05035. Meteorit. Planet. Sci. 44, 261-284 (2009)

Y. Liu, Y. Guan, Y. Zhang, G.R. Rossman, J.M. Eiler, L.A. Taylor, Direct measurement of hydroxyl in the lunar regolith and the origin of lunar surface water. Nat. Geosci. 5, 779-782 (2012)

J. Liu, M. Sharp, R.D. Ash, D.A. Kring, R.J. Walker, Diverse impactors in Apollo 15 and 16 impact rocks: evidence from osmium isotopes and highly siderophile elements. Geochim. Cosmochim. Acta 155, 122-153 (2015)

J. Longhi, Experimental petrology and petrogenesis of mare volcanics. Geochim. Cosmochim. Acta 56, 2235-2251 (1992)

D.E. Loper, C.L. Werner, On lunar asymmetries 1. Tilted convection and crustal asymmetry. J. Geophys. Res. 107, 5046 (2002)

G.W. Lugmair, R.W. Carlson, The Sm-Nd history of KREEP, in Lunar Planet. Sci. Conf. Proc. (1978), pp. 689-704

J.R. Lyons, E. Gharib-Nezhad, T.R. Ayres, A light carbon isotope composition for the Sun. Nat. Commun. 9, 908 (2018). https://doi.org/10.1038/s41467-018-03093-3

S. Marchi, S. Mottola, G. Cremonese, M. Massironi, E. Martellato, A new chronology for the Moon and Mercury. Astron. J. 137, 4936-4948 (2009)

S. Marchi, W.F. Bottke, D.A. Kring, A. Morbidelli, The onset of the lunar cataclysm as recorded in its ancient crater populations. Earth Planet. Sci. Lett. 325, 27-38 (2012)

S. Marchi, W.F. Bottke, B.A. Cohen, K. Wünnemann, D.A. Kring, H.Y. McSween, M.C. De Sanctis, D.P. O'Brien, P. Schenk, C.A. Raymond, C.T. Russell, High-velocity collisions from the lunar cataclysm recorded in asteroidal meteorites. Nat. Geosci. 6, 303-307 (2013)

B. Marty, L. Zimmermann, P.G. Burnard, R. Wieler, V.S. Heber, D.L. Burnett, R.C. Wiens, P. Bochsler, Nitrogen isotopes in the recent solar wind from the analysis of Genesis targets: evidence for large scale isotope heterogeneity in the early Solar System. Geochim. Cosmochim. Acta 74, 340-355 (2010)

B. Marty, M. Chaussidon, R.C. Wiens, A.J.G. Jurewicz, D.S. Burnett, A ${ }^{15} \mathrm{~N}$-poor isotopic composition for the Solar System as shown by Genesis solar wind samples. Science 332, 1533-1536 (2011)

T.B. McCord, J.B. Adams, T.V. Johnson, Asteroid Vesta: spectral reflectivity and compositional implications. Science 168, 1445-1447 (1970)

T.J. McCoy, D.W. Middlefehldt, L. Wilson, Asteroid differentiation, in Meteorites and the Early Solar System II, ed. by D.S. Lauretta, H.Y. McSween Jr. (University of Arizona Press, Tucson, 2006), pp. 733-745

F.M. McCubbin, K.E. Vander Kaaden, R. Tartèse, R.L. Klima, Y. Liu, J. Mortimer, J.J. Barnes, C.K. Shearer, A.H. Treiman, D.J. Lawrence, S.M. Elardo, D.M. Hurley, J.W. Boyce, M. Anand, Magmatic volatiles 
$(\mathrm{H}, \mathrm{C}, \mathrm{N}, \mathrm{F}, \mathrm{S}, \mathrm{Cl})$ in the lunar mantle, crust, and regolith: abundances, distributions, processes, and reservoirs. Am. Mineral. 100, 1668-1707 (2015)

D.S. McKay, G.A. Heiken, G.M. Taylor, U.S. Clanton, D.A. Morrison, G.H. Ladle, Apollo 14 soils: size distribution and particle types, in Lunar Sci. Conf. Proc. (1972), pp. 983-994

D.S. McKay, D.D. Bogard, R.V. Morris, R.L. Korotev, P. Johnson, S.J. Wentworth, Apollo 16 regolith breccias: characterization and evidence for early formation in the mega-regolith. J. Geophys. Res. 91, D277D303 (1986)

D.S. McKay, G. Heiken, A. Basu, G. Blanford, S. Simon, R. Reedy, B.M. French, J.J. Papike, The lunar regolith, in Lunar Sourcebook, ed. by G. Heiken, D. Vaniman, B.M. French (Cambridge University Press, Cambridge, 1991), pp. 286-356

K.D. McKeegan, M. Chaussidon, F. Robert, Incorporation of short-lived ${ }^{10} \mathrm{Be}$ in a calcium-aluminum-rich inclusion from the Allende meteorite. Science 289, 1334-1337 (2000)

K.D. McKeegan, A.P.A. Kallio, V.S. Heber, G. Jarzebinski, P.H. Mao, C.D. Coath, T. Kunihiro, R.C. Wiens, J.E. Nordholt, R.W. Moses Jr., D.B. Reisenfeld, A.J.G. Jurewicz, D.S. Burnett, The oxygen isotopic composition of the Sun inferred from captured solar wind. Science 332, 1528-1532 (2011)

C.L. McLeod, A.D. Brandon, R.M.G. Armytage, Constraints on the formation age and evolution of the Moon from ${ }^{142} \mathrm{Nd}^{143} \mathrm{Nd}$ systematics of Apollo 12 basalts. Earth Planet. Sci. Lett. 396, 179-189 (2014)

H.Y. McSween Jr., R.P. Binzel, M.C. De Sanctis, E. Ammannito, T.H. Prettyman, A.W. Beck, V. Reddy, L. Le Corre, M. Gaffey, T.B. McCord, C.A. Raymond, C.T. Russell, Dawn, the Vesta-HED connection, and the geologic context for eucrites, diogenites, and howardites. Meteorit. Planet. Sci. 48, 2090-2104 (2013)

H.J. Melosh, A.M. Freed, B.C. Johnson, D.M. Blair, J.C. Andrews-Hanna, G.A. Neumann, R.J. Phillips, D.E. Smith, S.C. Solomon, M.A. Wieczorek, M.T. Zuber, The origin of lunar Mascon basins. Science 340, 1552-1555 (2013)

H.J. Melosh, J. Kendall, B. Horgan, B.C. Johnson, T. Bowling, P.G. Lucey, G.J. Taylor, South pole-Aitken basin ejecta reveal the Moon's upper mantle. Geology 45, 1063-1066 (2017)

C.M. Mercer, K.E. Young, J.R. Weirich, K.V. Hodges, B.L. Jolliff, J.A. Wartho, M.C. van Soest, Refining lunar impact chronology through high spatial resolution ${ }^{40} \mathrm{Ar} /{ }^{39} \mathrm{Ar}$ dating of impact melts. Sci. Adv. 1, e1400050 (2015). https://doi.org/10.1126/sciadv.1400050

A. Meshik, J. Mabry, C. Hohenberg, Y. Marrocchi, O. Pravdivtseva, D. Burnett, C. Olinger, R. Wiens, D. Reisenfeld, J. Allton, K. McNamara, E. Stansbery, A.J.G. Jurewicz, Constraints on neon and argon isotopic fractionation in solar wind. Science 318, 433-435 (2007)

A. Meshik, C. Hohenberg, O. Pravdivtseva, D. Burnett, Heavy noble gases in solar wind delivered by Genesis mission. Geochim. Cosmochim. Acta 127, 326-347 (2014)

A.E. Metzger, E.L. Haines, R.E. Parker, R.G. Radocinski, Thorium concentrations in the lunar surface. IRegional values and crustal content, in Lunar Planet. Sci. Conf. Proc. (1977), pp. 949-999

K. Misawa, M. Tatsumoto, G.B. Dalrymple, K. Yanai, An extremely low U/Pb source in the Moon: U-Th-Pb, $\mathrm{Sm}-\mathrm{Nd}, \mathrm{Rb}-\mathrm{Sr}$, and ${ }^{40} \mathrm{Ar} /{ }^{39} \mathrm{Ar}$ isotopic systematics and age of lunar meteorite Asuka 881757. Geochim. Cosmochim. Acta 57, 4687-4702 (1993)

I.G. Mitrofanov, A.B. Sanin, W.V. Boynton, G. Chin, J.B. Garvin, D. Golovin, L.G. Evans, K. Harshman, A.S. Kozyrev, M.L. Litvak, A. Malakhov, E. Mazarico, T. McClanahan, G. Milikh, M. Mokrousov, G. Nandikotkur, G.A. Neumann, I. Nuzhdin, R. Sagdeev, V. Shevchenko, V. Shvetsov, D.E. Smith, R. Starr, V.I. Tretyakov, J. Trombka, D. Usikov, A. Varenikov, A. Vostrukhin, M.T. Zuber, Hydrogen mapping of the Lunar South Pole using the LRO neutron detector experiment LEND. Science 330, 483-486 (2010)

A. Morbidelli, S. Marchi, W.F. Bottke, D.A. Kring, A sawtooth-like timeline for the first billion years of lunar bombardment. Earth Planet. Sci. Lett. 355-356, 144-151 (2012)

A. Morbidelli, D. Nesvorny, V. Laurenz, S. Marchi, D.C. Rubie, L. Elkins-Tanton, M. Wieczorek, S. Jacobson, The timeline of the lunar bombardment: revisited. Icarus 305, 262-276 (2018)

J.W. Morgan, U. Krähenbühl, R. Ganapathy, E. Anders, Trace elements in Apollo 15 samples: implications for meteorite influx and volatile depletion on the Moon, in Lunar Sci. Conf. Proc. (1972), pp. 13611376

R.V. Morris, Surface exposure indices of lunar soils-A comparative FMR study, in Lunar Planet. Sci. Conf. Proc. (1976), pp. 315-335

R.V. Morris, The surface exposure (maturity) of lunar soils-Some concepts and $\mathrm{I}_{\mathrm{s}} / \mathrm{FeO}$ compilation, in Lunar Planet. Sci. Conf. Proc. (1978), pp. 2287-2297

R.V. Morris, Origins and size distribution of metallic iron particles in the lunar regolith, in Lunar Planet. Sci. Conf. Proc. (1980), pp. 1697-1712

J. Mortimer, A.B. Verchovsky, M. Anand, Predominantly non-solar origin of nitrogen in lunar soils. Geochim. Cosmochim. Acta 193, 36-53 (2016)

V.R. Murthy, M.R. Coscio Jr., Rb-Sr ages and isotopic systematics of some Serenitatis mare basalts, in Lunar Planet. Sci. Conf. Proc., ed. by R.B. Merrill (1976), pp. 1529-1544 
Y. Nakamura, Shallow moonquakes: how they compare with earthquakes, in Lunar Planet. Sci. Conf. Proc. (1980), pp. 1847-1853

Y. Nakamura, G.V. Latham, H.J. Dorman, Apollo lunar seismic experiment final summary, in Lunar Planet. Sci. Conf. Proc. (1982), pp. A117-A123

Y. Nakamura, G.V. Latham, H.J. Dorman, J.E. Harris, Passive Seismic Experiment, Long Period Event Catalog, Final Version (1969 Day 202-1977 Day 273, ALSEP Stations 11, 12, 13, 14, 15, and 16). Univ. Texas Institute Geophys. Tech. Report No. 18 (originally published 19 June 1981, revised 2 October 2008) (2008)

National Research Council, The Scientific Context for the Exploration of the Moon (The National Academies Press, Washington, DC, 2007). https://www.nap.edu/catalog/11954/the-scientific-context-forexploration-of-the-Moon. Accessed 12 June 2019

C.R. Neal, Establishing a lunar geophysical network for exploration and Solar System science, in Annual Meeting Lunar Exploration Analysis Group (2011), abstract 2052

C.R. Neal, G.Y. Kramer, The petrogenesis of the Apollo 14 high-Al mare basalts. Am. Mineral. 91, 15211535 (2006)

C.R. Neal, L.A. Taylor, Petrogenesis of mare basalts: a record of lunar volcanism. Geochim. Cosmochim. Acta 56, 2177-2212 (1992)

C.R. Neal, M.D. Hacker, G.A. Snyder, L.A. Taylor, Y.G. Liu, R.A. Schmitt, Basalt generation at the Apollo 12 site, part 1: new data, classification, and re-evaluation. Meteoritics 29, 334-348 (1994)

C.R. Neal, W.B. Banerdt, C. Beghein, P. Chi, D. Currie, S. Del'Agnello, I. Garrick-Bethell, R. Grimm, M. Grott, H. Haviland, S. Kedar, S. Nagihara, M. Panning, N. Petro, N. Schmerr, M. Siegler, R. Weber, M. Wieczorek, K. Zacny, The lunar geophysical network mission, in Lunar Planet. Sci. Conf. (2019), abstract 2455

A. Nemchin, N. Timms, R. Pidgeon, T. Geisler, S. Reddy, C. Meyer, Timing of crystallization of the lunar magma ocean constrained by the oldest zircon. Nat. Geosci. 2, 133-136 (2009)

G. Neukum, B. Ivanov, W.K. Hartmann, Cratering records in the inner Solar System in relation to the lunar reference system. Space Sci. Rev. 96, 55-86 (2001)

G.A. Neumann, M.T. Zuber, M.A. Wieczorek, J.W. Head, D.M.H. Baker, S.C. Solomon, D.E. Smith, F.G. Lemoine, E. Mazarico, T.J. Sabaka, S.J. Goossens, H.J. Melosh, R.J. Phillips, S.W. Asmar, A.S. Konopliv, J.G. Williams, M.M. Sori, J.M. Soderblom, K. Miljković, J.C. Andrews-Hanna, F.W.S. Nimmo, W. Kiefer, Lunar impact basins revealed by gravity recovery and interior laboratory measurements. Sci. Adv. 1, e1500852 (2015). https://doi.org/10.1126/sciadv.1500852

M.D. Norman, The lunar cataclysm: reality or "mythconception"? Elements 5, 23-28 (2009)

M.D. Norman, R.A. Duncan, J.J. Huard, Identifying impact events within the lunar cataclysm from ${ }^{40} \mathrm{Ar}-{ }^{39} \mathrm{Ar}$ ages and compositions of Apollo 16 impact melt rocks. Geochim. Cosmochim. Acta 70, 6032-6049 (2006)

S. Nozette, C.L. Lichtenberg, P.D. Spudis, R. Bonner, W. Ort, E. Malaret, M. Robinson, E.M. Shoemaker, The Clementine bistatic radar experiment. Science 274, 1495-1498 (1996)

S. Nozette, E.M. Shoemaker, P.D. Spudis, C.L. Lichtenberg, The possibility of ice on the Moon. Science 278, 144-145 (1997)

L.E. Nyquist, C.-Y. Shih, The isotopic record of lunar volcanism. Geochim. Cosmochim. Acta 56, 2213-2234 (1992)

L.E. Nyquist, B.M. Bansal, H. Wiesmann, Rb-Sr ages and initial ${ }^{87} \mathrm{Sr} /{ }^{86} \mathrm{Sr}$ for Apollo 17 basalts and KREEP basalt 15386, in Lunar Planet. Sci. Conf. Proc. (1975), pp. 1445-1465

L.E. Nyquist, B.M. Bansal, H. Wiesmann, Sr-isotopic constraints on the petrogenesis of Apollo 17 mare basalts, in Lunar Planet. Sci. Conf. Proc., ed. by R.B. Merrill (1976), pp. 1507-1528

L.E. Nyquist, H. Wiesmann, B. Bansal, C.Y. Shih, J.E. Keith, C.L. Harper, ${ }^{146} \mathrm{Sm}^{142} \mathrm{Nd}$ formation interval for the lunar mantle. Geochim. Cosmochim. Acta 59, 2817-2837 (1995)

L.E. Nyquist, C.Y. Shih, D. Reese, J. Park, D.D. Bogard, D.H. Garrison, A. Yamaguchi, Lunar crystal history recorded in lunar anorthosites, in Lunar Planet. Sci. Conf. (2010), p. abstract 1383

K.W. Ogilvie, M.A. Coplan, Solar wind composition. Rev. Geophys. 33, 615-622 (1995)

M. Ohtake, T. Matsunaga, J. Haruyama, Y. Yokota, T. Morota, C. Honda, Y. Ogawa, M. Torii, H. Miyamoto, T. Arai, N. Hirata, A. Iwasaki, R. Nakamura, T. Hiroi, T. Sugihara, H. Takeda, H. Otake, C.M. Pieters, K. Saiki, K. Kitazato, M. Abe, N. Asada, H. Demura, Y. Yamaguchi, S. Sasaki, S. Kodama, J. Terazono, M. Shirao, A. Yamaji, S. Minami, H. Akiyama, J.L. Josset, The global distribution of pure anorthosite on the Moon. Nature 461, 236-240 (2009)

M. Ohtake, H. Takeda, T. Matsunaga, Y. Yokota, J. Haruyama, T. Morota, S. Yamamoto, Y. Ogawa, T. Hiroi, Y. Karouji, K. Saiki, P.G. Lucey, Asymmetric crustal growth on the Moon indicated by primitive farside high materials. Nat. Geosci. 5, 384-388 (2012)

J.B. Paces, C.R. Neal, L.A. Taylor, S. Nakai, A.N. Halliday, D.C. Lee, A strontium and neodymium isotopic study of Apollo 17 high-Ti mare basalts: resolution of ages, evolution of magmas, and origins of source heterogeneities. Geochim. Cosmochim. Acta 55, 2025-2043 (1991) 
D.A. Paige, M.C. Foote, B.T. Greenhagen, J.T. Schofield, S. Calcutt, A.R. Vasavada, D.J. Preston, F.W. Taylor, C.C. Allen, K.J. Snook, B.M. Jakosky, B.C. Murray, L.A. Soderblom, B. Jau, S. Loring, J. Bulharowski, N.E. Bowles, I.R. Thomas, M.T. Sullivan, C. Avis, E.M. De Jong, W. Hartford, D.J. McCleese, The Lunar Reconnaissance Orbiter Diviner lunar radiometer experiment. Space Sci. Rev. 150, 125-160 (2010a)

D.A. Paige, M.A. Siegler, J.A. Zhang, P.O. Hayne, E.J. Foote, K.A. Bennett, A.R. Vasavada, B.T. Greenhagen, J.T. Schofield, D.J. McCleese, M.C. Foote, E. DeJong, B.G. Bills, W. Hartford, B.C. Murray, C.C. Allen, K. Snook, L.A. Soderblom, S. Calcutt, F.W. Taylor, N.E. Bowles, J.L. Bandfield, R. Elphic, R. Ghent, T.D. Glotch, M.B. Wyatt, P.G. Lucey, Diviner Lunar radiometer observations of cold traps in the Moon's South Polar Region. Science 330, 479-482 (2010b)

D.A. Papanastassiou, G.J. Wasserburg, Rb-Sr ages of igneous rocks from the Apollo 14 mission and the age of the Fra Mauro formation. Earth Planet. Sci. Lett. 12, 36-48 (1971a)

D.A. Papanastassiou, G.J. Wasserburg, Lunar chronology and evolution from Rb-Sr studies of Apollo 11 and 12 samples. Earth Planet. Sci. Lett. 11, 37-62 (1971b)

D.A. Papanastassiou, G.J. Wasserburg, Rb-Sr ages and initial strontium in basalts from Apollo 15. Earth Planet. Sci. Lett. 17, 324-337 (1973)

J.J. Papike, F.N. Hodges, A.E. Bence, M. Cameron, J.M. Rhodes, Mare basalts: crystal chemistry, mineralogy, and petrology. Rev. Geophys. 14, 475-540 (1976)

J.J. Papike, G.W. Fowler, C.K. Shearer, G.D. Layne, Ion microprobe investigation of plagioclase and orthopyroxene from lunar Mg-suite norites: implications for calculating parental melt REE concentrations and for assessing postcrystallization REE redistribution. Geochim. Cosmochim. Acta 60, 3967-3978 (1996)

R.O. Pepin, R.H. Becker, P.E. Rider, Xenon and Krypton in extraterrestrial regolith soil and in the solar wind. Geochim. Cosmochim. Acta 59, 4997-5022 (1995)

R.O. Pepin, D.J. Schlutter, R.H. Becker, D.B. Reisenfeld, Helium, neon, and argon composition of the solar wind as recorded in gold and other Genesis collector materials. Geochim. Cosmochim. Acta 89, 62-80 (2012)

J.F. Pernet-Fisher, E. Deloule, K.H. Joy, Evidence of chemical heterogeneity within lunar anorthosite parental magmas. Geochim. Cosmochim. Acta (2019a). https://doi.org/10.1016/j.gca.2019.03.033

J.F. Pernet-Fisher, F.E. McDonald, R.A. Zeigler, K.H. Joy, 50 years on: legacies of the Apollo programme. Astron. Geophys. 60, 4.22-4.28 (2019b)

C.M. Pieters, J. Boardman, B. Buratti, A. Chatterjee, R. Clark, T. Glavich, R. Green, J. Head III, P. Isaacson, E. Malaret, T. McCord, J. Mustard, N. Petro, C. Runyon, M. Staid, J. Sunshine, L. Taylor, S. Tompkins, P. Varanasi, M. White, The Moon Mineralogy Mapper (M3) on Chandrayaan-1. Current. Science 96, 500-505 (2009a)

C.M. Pieters, J.N. Goswami, R.N. Clark, M. Annadurai, J. Boardman, B. Buratti, J.P. Combe, M.D. Dyar, R. Green, J.W. Head, C. Hibbitts, M. Hicks, P. Isaacson, R. Klima, G. Kramer, S. Kumar, E. Livo, S. Lundeen, E. Malaret, T. McCord, J. Mustard, J. Nettles, N. Petro, C. Runyon, M. Staid, J. Sunshine, L.A. Taylor, S. Tompkins, P. Varanasi, Character and spatial distribution of $\mathrm{OH} / \mathrm{H}_{2} \mathrm{O}$ on the surface of the Moon seen by $\mathrm{M}^{3}$ on Chandrayaan-1. Science 326, 568-572 (2009b)

C.M. Pieters, S. Besse, J. Boardman, B. Buratti, L. Cheek, R.N. Clark, J.P. Combe, D. Dhingra, J.N. Goswami, R.O. Green, J.W. Head, P. Isaacson, R. Klima, G. Kramer, S. Lundeen, E. Malaret, T. McCord, J. Mustard, J. Nettles, N. Petro, C. Runyon, M. Staid, J. Sunshine, L.A. Taylor, K. Thaisen, S. Tompkins, J. Whitten, Mg-spinel lithology: a new rock type on the lunar farside. J. Geophys. Res., Planets 116, E00G08 (2011). https://doi.org/10.1029/2010JE003727

T.H. Prettyman, J.J. Hagerty, R.C. Elphic, W.C. Feldman, D.J. Lawrence, G.W. McKinney, D.T. Vaniman, Elemental composition of the lunar surface: analysis of gamma ray spectroscopy data from lunar prospector. J. Geophys. Res., Planets 111, E12007 (2006)

I.S. Puchtel, R.J. Walker, O.B. James, D.A. Kring, Osmium isotope and highly siderophile element systematic of lunar impact melt breccias: implications for the late accretion history of the Moon and Earth. Geochim. Cosmochim. Acta 72, 3022-3042 (2008)

Y.Q. Qian, L. Xiao, S.Y. Zhao, J.N. Zhao, J. Huang, J. Flahaut, M. Martinot, J.W. Head, H. Hiesinger, G.X. Wang, Geology and scientific significance of the Rümker region in Northern Oceanus Procellarum: China's Chang'E-5 landing region. J. Geophys. Res., Planets 123, 1407-1430 (2018)

K. Rankenburg, A.D. Brandon, C.R. Neal, Neodymium isotope evidence for a chondritic composition of the Moon. Science 312, 1369-1372 (2006)

J.F. Rapp, D.S. Draper, Fractional crystallization of the lunar magma ocean: updating the dominant paradigm. Meteorit. Planet. Sci. 53, 1432-1455 (2018)

J.M. Rhodes, N.J. Hubbard, H. Wiesmann, K.V. Rodgers, J.C. Brannon, B.M. Bansal, Chemistry, classification and petrogenesis of Apollo 17 mare basalts, in Lunar Planet. Sci. Conf., ed. by D.C. Kinsler (1976), pp. 1467-1489 
J.M. Rhodes, D.P. Blanchard, M.A. Dungan, J.C. Brannon, K.V. Rodgers, Chemistry of Apollo 12 mare basalts: magma types and fractionation processes, in Lunar Planet. Sci. Conf., ed. by R.B. Merril (1977), pp. $1305-1338$

K. Righter, M.J. Drake, A magma ocean on Vesta: core formation and petrogenesis of eucrites and diogenites. Meteorit. Planet. Sci. 32, 929-944 (1997)

K. Righter, C.K. Shearer, Magmatic fractionation of Hf and W: constraints on the timing of core formation and differentiation in the Moon and Mars. Geochim. Cosmochim. Acta 67, 2497-2507 (2003)

K. Righter, M.J. Drake, G. Yaxley, Prediction of siderophile element metal-silicate partition coefficients to $20 \mathrm{GPa}$ and $2800^{\circ} \mathrm{C}$ : the effects of pressure, temperature, oxygen fugacity, and silicate and metallic melt compositions. Phys. Earth Planet. Inter. 100, 115-134 (1997)

S.J. Robbins, New crater calibrations for the lunar crater-age chronology. Earth Planet. Sci. Lett. 403, 188198 (2014)

M.S. Robinson, J.W. Ashley, A.K. Boyd, R.V. Wagner, E.J. Speyerer, B. Ray Hawke, H. Hiesinger, C.H. van der Bogert, Confirmation of sublunarean voids and thin layering in mare deposits. Planet. Space Sci. 69, 18-27 (2012a)

K.L. Robinson, A.H. Treiman, K.H. Joy, Basaltic fragments in lunar feldspathic meteorites: connecting sample analyses to orbital remote sensing. Meteorit. Planet. Sci. 47, 387-399 (2012b)

S.S. Russell, K.H. Joy, T.E. Jeffries, G.J. Consolmagno, A.T. Kearsley, Heterogeneity in lunar anorthosite meteorites: implications for the lunar magma ocean model. Philos. Trans. R. Soc. A 372, 20130241 (2014). https://doi.org/10.1098/rsta.2013.0241

M.J. Rutherford, J.W. Head III, A.E. Saal, E.H. Hauri, L. Wilson, Model for the origin, ascent and eruption of lunar picritic magmas. Am. Mineral. 102, 2045-2053 (2017)

G. Ryder, Lunar samples, lunar accretion, and the early bombardment history of the Moon. Eos 71, 322-323 (1990)

A.E. Saal, E.H. Hauri, M.L. Cascio, J.A. Van Orman, M.C. Rutherford, R.F. Cooper, Volatile content of lunar volcanic glasses and the presence of water in the Moon's interior. Nature 454, 192-195 (2008)

P. Saxena, R.M. Killen, V. Airapetian, N.E. Petro, N.M. Curran, A.M. Mandell, Was the Sun a Slow Rotator? Sodium and Potassium Constraints from the Lunar Regolith. Astrophys. J. Lett. 876, 1 (2019). https://doi.org/10.3847/2041-8213/ab18fb

N. Schorghofer, G.J. Taylor, Subsurface migration of $\mathrm{H}_{2} \mathrm{O}$ at lunar cold traps. J. Geophys. Res., Planets 112, E02010 (2007). https://doi.org/10.1029/2006JE002779

P.H. Schultz, P.D. Spudis, Evidence for ancient mare volcanism, in Lunar Planet. Sci. Conf., ed. by N.W. Hinners (1979), pp. 2899-2918

P.H. Schultz, P.D. Spudis, Beginning and end of lunar mare volcanism. Nature 302, 233-236 (1983)

P.H. Schultz, B. Hermalyn, A. Colaprete, K. Ennico, M. Shirley, W.S. Marshall, The LCROSS cratering experiment. Science 330, 468-472 (2010)

M. Sharp, I. Gerasimenko, L.C. Loudin, J. Liu, O.B. James, I.S. Puchtel, R.J. Walker, Characterization of the dominant impactor signature for Apollo 17 impact melt rocks. Geochim. Cosmochim. Acta 131, 62-80 (2014)

E.K. Shea, B.P. Weiss, W.S. Cassata, D.L. Shuster, S.M. Tikoo, J. Gattacceca, T.L. Grove, M.D. Fuller, A long-lived lunar core dynamo. Science 335, 453-456 (2012)

C.K. Shearer, P.C. Hess, M.A. Wieczorek, M.E. Pritchard, E.M. Parmentier, L.E. Borg, J. Longhi, L.T. ElkinsTanton, C.R. Neal, I. Antonenko, R.M. Canup, A.N. Halliday, T.L. Grove, B.H. Hager, D.C. Lee, U. Wiechert, Thermal and magmatic evolution of the Moon. Rev. Mineral. Geochem. 60, 365-518 (2006)

J.W. Shervais, J.J. McGee, Ion and electron microprobe study of troctolites, norite, and anorthosites from Apollo 14: evidence for urKREEP assimilation during petrogenesis of Apollo $14 \mathrm{Mg}$-suite rocks. Geochim. Cosmochim. Acta 62, 3009-3023 (1998)

J.W. Shervais, J.J. McGee, KREEP cumulates in the western lunar highlands: ion and electron microprobe study of alkali-suite anorthosites and norites from Apollo 12 and 14. Am. Mineral. 84, 806-820 (1999)

E.M. Shoemaker, R.J. Hackman, Stratigraphic basis for a lunar time scale, in The Moon, ed. by Z. Kopal, Z.K. Mikhailov (Academic, San Diego, 1962), pp. 289-300

A. Smith, I.A. Crawford, R.A. Gowen, R. Ambrosi, M. Anand, B. Banerdt, N. Bannister, N. Bowles, C. Braithwaite, P. Brown, J. Chela-Flores, T. Cholinser, P. Church, A.J. Coates, T. Colaprete, G. Collins, G. Collinson, T. Cook, R. Elphic, G. Fraser, Y. Gao, E. Gibson, T. Glotch, M. Grande, A. Griffiths, J. Grygorczuk, M. Gudipati, A. Hagermann, J. Heldmann, L.L. Hood, A.P. Jones, K.H. Joy, O.B. Khavroshkin, G. Klingelhoefer, M. Knapmeyer, G. Kramer, D. Lawrence, W. Marczewski, S. McKenna-Lawlor, K. Miljkovic, S. Narendranath, E. Palomba, A. Phipps, W.T. Pike, D. Pullan, J. Rask, D.T. Richard, K. Seweryn, S. Sheridan, M. Sims, M. Sweeting, T. Swindle, D. Talboys, L. Taylor, N. Teanby, V. Tong, S. Ulamec, R. Wawrzaszek, M. Wieczorek, L. Wilson, I. Wright, Lunar Net-a proposal in response to an ESA M3 call in 2010 for a medium sized mission. Exp. Astron. 33, 587-644 (2012) 
J.F. Snape, A.A. Nemchin, J.J. Bellucci, M.J. Whitehouse, R. Tartèse, J.J. Barnes, M. Anand, I.A. Crawford, K.H. Joy, Lunar basalt chronology, mantle differentiation and implications for determining the age of the Moon. Earth Planet. Sci. Lett. 451, 149-158 (2016a)

J.F. Snape, A.A. Nemchin, M.L. Grange, J.J. Bellucci, F. Thiessen, M.J. Whitehouse, Phosphate ages in Apollo 14 breccias: resolving multiple impact events with high precision U-Pb SIMS analyses. Geochim. Cosmochim. Acta 174, 13-29 (2016b)

J.F. Snape, N.M. Curran, M.J. Whitehouse, A.A. Nemchin, K.H. Joy, T. Hopkinson, M. Anand, J.J. Bellucci, G.G. Kenny, Ancient volcanism on the Moon: insights from Pb isotopes in the MIL 13317 and Kalahari 009 lunar meteorites. Earth Planet. Sci. Lett. 502, 84-95 (2018a)

J.F. Snape, B. Davids, A.A. Nemchin, M.J. Whitehouse, J.J. Bellucci, Constraining the timing and sources of volcanism at the Apollo 12 landing site using new $\mathrm{Pb}$ isotopic compositions and crystallisation ages. Chem. Geol. 482, 101-112 (2018b)

J.F. Snape, A.A. Nemchin, M.J. Whitehouse, R.E. Merle, T. Hopkinson, M. Anand, The timing of basaltic volcanism at the Apollo landing sites. Geochim. Cosmochim. Acta (2019). https://doi.org/10.1016/ j.gca.2019.07.042

G.A. Snyder, L.A. Taylor, C.R. Neal, A chemical model for generating the sources of mare basalts-combined equilibrium and fractional crystallization of the lunar magmasphere. Geochim. Cosmochim. Acta 56, 3809-3823 (1992)

G.A. Snyder, D.C. Lee, L.A. Taylor, A.N. Halliday, E.A. Jerde, Evolution of the upper mantle of the Earth's Moon: neodymium and strontium isotopic constraints from high-Ti mare basalts. Geochim. Cosmochim. Acta 58, 4795-4808 (1994)

G.A. Snyder, C.R. Neal, L.A. Taylor, A.N. Halliday, Anatexis of lunar cumulate mantle in time and space: clues from trace-element, strontium, and neodymium isotopic chemistry of parental Apollo 12 basalts. Geochim. Cosmochim. Acta 61, 2731-2747 (1997)

A.K. Sokol, V.A. Fernandes, T. Schulz, A. Bischoff, R. Burgess, R.N. Clayton, C. Münker, K. Nishiizumi, H. Palme, L. Schultz, G. Weckwerth, K. Mezger, M. Horstmann, Geochemistry, petrology and ages of the lunar meteorites Kalahari 008 and 009: new constraints on early lunar evolution. Geochim. Cosmochim. Acta 72, 4845-4873 (2008)

S.C. Solomon, J.W. Head, Lunar Mascon Basins: lava filling, tectonics, and evolution of the lithosphere. Rev. Geophys. 18, 107-141 (1980)

C.P. Sonett, D.S. Colburn, R.G. Currie, J.D. Mihalov, The geomagnetic tail topology, reconnection and interaction with the Moon, in Physics of the Magnetosphere, ed. by R.L. Carovillano, J.F. McClay, H.F. Radoski (Reidel, Dordrecht, 1967), pp. 461-484

P.A. Sossi, F. Moynier, M. Chaussidon, J. Villeneuve, C. Kato, M. Gounelle, Early Solar System irradiation quantified by linked vanadium and beryllium isotope variations in meteorites. Nat. Astron. 1, 0055 (2017). https://doi.org/10.1038/s41550-017-0055

T. Spohn, W. Konrad, D. Breuer, R. Ziethe, The longevity of lunar volcanism: implications of thermal evolution calculations with 2D and 3D mantle convection models. Icarus 149, 54-65 (2001)

P.D. Spudis, The Once and Future Moon (Smithsonian Inst. Press, Washington, 1996)

P.D. Spudis, D.E. Wilhelms, M.S. Robinson, The sculptured hills of the taurus highlands: implications for the relative age of serenitatis, basin chronologies and the cratering history of the Moon. J. Geophys. Res., Planets 116, E00H03 (2011). https://doi.org/10.1029/2011JE003903

P.D. Spudis, D.B.J. Bussey, S.M. Baloga, J.T.S. Cahill, L.S. Glaze, G.W. Patterson, R.K. Raney, T.W. Thompson, B.J. Thomson, E.A. Ustinov, Evidence for water ice on the Moon: results for anomalous polar craters from the LRO mini-RF imaging radar. J. Geophys. Res., Planets 118, 2016-2029 (2013)

A.C. Stadermann, M.R. Zanetti, B.L. Jolliff, H. Hiesinger, C.H. van der Bogert, C.W. Hamilton, The age of lunar mare basalts south of the Aristarchus Plateau and effects of secondary craters formed by the Aristarchus event. Icarus 309, 45-60 (2018)

A. Stettler, P. Eberhardt, J. Geiss, N. Grögler, P. Maurer, $\mathrm{Ar}^{39}-\mathrm{Ar}^{40}$ ages and $\mathrm{Ar}^{37}-\mathrm{Ar}^{38}$ exposure ages of lunar rocks, in Lunar Planet. Sci. Conf. (1973), pp. 1865-1888

D. Stöffler, G. Ryder, Stratigraphy and isotope ages of lunar geologic units: chronological standard for the inner Solar System. Space Sci. Rev. 96, 9-54 (2001)

D. Stöffler, G. Ryder, B.A. Ivanov, N.A. Artemieva, M.J. Cintala, R.A.F. Grieve, Cratering history and lunar chronology. Rev. Mineral. Geochem. 60, 519-596 (2006)

D.E. Stuart-Alexander, D.E. Wilhelms, The Nectarian system, a new lunar time-stratigraphic unit. J. Res. U.S. Geol. Surv. 3, 53-58 (1975)

C. Suavet, B.P. Weiss, W.S. Cassata, D.L. Shuster, J. Gattacceca, L. Chan, I. Garrick-Bethell, J.W. Head, T.L. Grove, M.D. Fuller, Persistence and origin of the lunar core dynamo. Proc. Natl. Acad. Sci. USA 110, 8453-8456 (2013)

J.M. Sunshine, T.L. Farnham, L.M. Feaga, O. Groussin, F. Merlin, R.E. Milliken, M.F. A'Hearn, Temporal and spatial variability of Lunar hydration as observed by the Deep Impact spacecraft. Science 326, 565-568 (2009) 
F. Takahashi, H. Tsunakawa, H. Shimizu, H. Shibuya, M. Matsushima, Reorientation of the early lunar pole. Nat. Geosci. 7, 409-412 (2014)

M. Tatsumoto, Age of the Moon: an isotopic study of U-Th-Pb systematics of Apollo 11 lunar samples-II, in Apollo 11 Lunar Sci. Conf. Proc. (1970), pp. 1595-1612

L.A. Taylor, J.W. Shervais, R.H. Hunter, C.-Y. Shih, B.M. Bansal, J. Wooden, L.E. Nyquist, L.C. Laul, Pre4.2 AE mare-basalt volcanism in the lunar highlands. Earth Planet. Sci. Lett. 66, 33-47 (1983)

S.R. Taylor, C.M. Pieters, G.J. MacPherson, Earth-Moon system, planetary science, and lessons learned. Rev. Mineral. Geochem. 60, 657-704 (2006)

D.J. Taylor, K.D. McKeegan, T.M. Harrison, Lu-Hf zircon evidence for rapid lunar differentiation. Earth Planet. Sci. Lett. 279, 157-164 (2009)

F. Tera, G.J. Wasserburg, U-Th-Pb systematics on lunar rocks and inferences about lunar evolution and the age of the Moon, in Lunar Sci. Conf. Proc. (1974), pp. 1571-1599

F. Tera, D.A. Papanastassiou, G.J. Wasserburg, Isotopic evidence for a terminal lunar cataclysm. Earth Planet. Sci. Lett. 22, 1-21 (1974)

K. Terada, M. Anand, A.K. Sokol, A. Bischoff, Y. Sano, Cryptomare magmatism 4.35 Gyr ago recorded in lunar meteorite Kalahari 009. Nature 450, 849-853 (2007a)

K. Terada, Y. Sasaki, M. Anand, K.H. Joy, Y. Sano, Uranium-lead systematics of phosphates in lunar basaltic regolith breccia, Meteorite Hills 01210. Earth Planet. Sci. Lett. 259, 77-84 (2007b)

M.H. Thiemens, R.N. Clayton, Ancient solar wind in lunar microbreccias. Earth Planet. Sci. Lett. 47, 34-42 (1980)

M.M. Thiemens, P. Sprung, R.O.C. Fonseca, F.P. Leitzke, C. Münker, Early Moon formation inferred from hafnium-tungsten systematics. Nat. Geosci. (2019). https://doi.org/10.1038/s41561-019-0398-3

F. Thiessen, A.A. Nemchin, J.F. Snape, M.J. Whitehouse, J.J. Bellucci, Impact history of the Apollo 17 landing site revealed by U-Pb SIMS ages. Meteorit. Planet. Sci. 52, 584-611 (2017)

S.M. Tikoo, B.P. Weiss, J. Buz, E.A. Lima, E.K. Shea, G. Melo, T.L. Grove, Magnetic fidelity of lunar samples and implications for an ancient core dynamo. Earth Planet. Sci. Lett. 337-338, 93-103 (2012)

S.M. Tikoo, B.P. Weiss, W.S. Cassata, D.L. Shuster, J. Gattacceca, C. Suavet, F. Nimmo, M.D. Fuller, Decline of the lunar core dynamo. Earth Planet. Sci. Lett. 404, 89-97 (2014)

S.M. Tikoo, B.P. Weiss, D.L. Shuster, C. Suavet, H. Wang, T.L. Grove, A two-billion-year history for the lunar dynamo. Sci. Adv. 3, e1700207 (2017). https://doi.org/10.1126/sciadv.1700207

G.R. Tilton, J.H. Chen, Lead isotope systematics of three Apollo 17 mare basalts, in Lunar Planet. Sci. Conf. Proc. (1979), pp. 259-274

M. Touboul, I.S. Puchtel, R.J. Walker, Tungsten isotopic evidence for disproportional late accretion to the Earth and Moon. Nature 520, 530-533 (2015)

A.H. Treiman, A.K. Maloy, C.K. Shearer Jr., J. Gross, Magnesian anorthositic granulites in lunar meteorites Allan Hills A81005 and Dhofar 309: geochemistry and global significance. Meteorit. Planet. Sci. 45, 163-180 (2010)

G. Turner, Argon-40/Argon-39 dating of lunar rock samples. Science 167, 466-468 (1970a)

G. Turner, Argon-40/argon-39 dating of lunar rock samples, in Lunar Sci. Conf. Proc. (1970b), pp. 16651684

G. Turner, A Monte Carlo fragmentation model for the production of meteorites: implications for gas retention ages, in Lunar Planet. Sci. Conf. Proc. (1979), pp. 1917-1941

G. Turner, P.H. Cadogan, C.J. Yonge, Argon selenochronology, in Lunar Sci. Conf. Proc. (1973), pp. 18891914

N. Vogel, V.S. Heber, H. Baur, D.S. Burnett, R. Wieler, Argon, krypton, and xenon in the bulk solar wind as collected by the Genesis mission. Geochim. Cosmochim. Acta 75, 3057-3071 (2011)

R.V. Wagner, D.M. Nelson, J.B. Plescia, M.S. Robinson, E.J. Speyerer, E. Mazarico, Coordinates of anthropogenic features on the Moon. Icarus 283, 92-103 (2017)

R.J. Walker, Highly siderophile elements in the Earth, Moon and Mars: update and implications for planetary accretion and differentiation. Chem. Erde Geochem. 69, 101-125 (2009)

A. Wallner, J. Feige, N. Kinoshita, M. Paul, L.K. Fifield, R. Golser, M. Honda, U. Linnemann, H. Matsuzaki, S. Merchel, G. Rugel, S.G. Tims, P. Steier, T. Yamagata, S.R. Winkler, Recent near-Earth supernovae probed by global deposition of interstellar radioactive ${ }^{60} \mathrm{Fe}$. Nature 532, 69-72 (2016)

R.D. Warner, G.J. Taylor, G.H. Conrad, H.R. Northrop, S. Barker, K. Keil, M.-S. Ma, R. Schmitt, Apollo 17 high-Ti mare basalts: new bulk compositional data, magma types, and petrogenesis, in Lunar Planet. Sci. Conf. Proc., ed. by N.W. Hinners (1979), pp. 225-247

P.H. Warren, J.T. Wasson, The origin of KREEP. Rev. Geophys. 17, 73-88 (1979)

K. Watson, B.C. Murray, H. Brown, The behavior of volatiles on the lunar surface. J. Geophys. Res. 66, 3033-3045 (1961)

T.R. Watters, R.C. Weber, G.C. Collins, I.J. Howley, N.C. Schmerr, C.L. Johnson, Shallow seismic activity and young thrust faults on the Moon. Nat. Geosci. 12, 411-417 (2019) 
R.C. Weber, Interior of the Moon, in Encyclopedia of the Solar System (2014), pp. 539-554. https://doi.org/ 10.1016/B978-0-12-415845-0.00024-4. Chap. 24

R.C. Weber, P.Y. Lin, E.J. Garnero, Q. Williams, P. Lognonné, Seismic detection of the lunar core. Science 331, 309-312 (2011)

B.P. Weiss, S.M. Tikoo, The lunar dynamo. Science 346, 1246753-1-1246753-10 (2014). https://doi.org/ $10.1126 /$ science. 1246753

S.C. Werner, Moon, Mars, Mercury: basin formation ages and implications for the maximum surface age and the migration of gaseous planets. Earth Planet. Sci. Lett. 400, 54-65 (2014)

J.L. Whitten, J.W. Head III, Lunar cryptomaria: physical characteristics, distribution, and implications for ancient volcanism. Icarus 247, 150-171 (2015a)

J.L. Whitten, J.W. Head III, Lunar cryptomaria: mineralogy and composition of ancient volcanic deposits. Planet. Space Sci. 106, 67-81 (2015b)

J. Whitten, J.W. Head III, M.I. Staid, C.M. Pieters, J.F. Mustard, R. Clark, J.W. Nettles, R.L. Klima, L.A. Taylor, Lunar mare deposits associated with the Orientale impact basin: New insights into mineralogy, history, mode of emplacement, and relation to Orientale Basin evolution from Moon Mineralogy Mapper (M3) data from Chandrayaan-1. J. Geophys. Res. 116, E00G09 (2011). https://doi.org/10.1029/ 2010JE003736

M.A. Wieczorek, B.L. Jolliff, A. Khan, M.E. Pritchard, B.P. Weiss, J.G. Williams, L.L. Hood, K. Righter, C.R. Neal, C.K. Shearer, I.S. McCallum, S. Tompkins, B.R. Hawke, C. Peterson, J.J. Gillis, B. Bussey, The constitution and structure of the lunar interior. Rev. Mineral. Geochem. 60, 221-364 (2006)

M.A. Wieczorek, G.A. Neumann, F. Nimmo, W.S. Kiefer, G.J. Taylor, H.J. Melosh, R.J. Phillips, S.C. Solomon, J.C. Andrews-Hanna, S.W. Asmar, A.S. Konopliv, F.G. Lemoine, D.E. Smith, M.M. Watkins, J.G. Williams, M.T. Zuber, The crust of the Moon as seen by GRAIL. Science 339, 671-675 (2013)

R. Wieler, Do lunar and meteoritic archives record temporal variations in the composition of solar wind noble gases and nitrogen? A reassessment in the light of Genesis data. Chem. Erde 76, 463-480 (2016)

R. Wieler, V.S. Heber, Noble gas isotopes on the Moon. Space Sci. Rev. 106, 197-210 (2003)

R. Wieler, K. Kehm, A.P. Meshik, C.M. Hohenberg, Secular changes in the xenon and krypton abundances in the solar wind recorded in single lunar grains. Nature 384, 46-49 (1996)

D.E. Wilhelms, The geologic history of the Moon. USGS Prof. Pap. 1348 (1987)

L. Wilson, J.W. Head III, Generation, ascent and eruption of magma on the Moon: new insights into source depths, magma supply, intrusions and effusive/explosive eruptions (part 1: theory). Icarus 283, 146-175 (2017)

L. Wilson, J.W. Head III, Controls on lunar basaltic volcanic erupton structure and morphology: gas release patterns in sequential eruption phases. Geophys. Res. Lett. 45, 5852-5859 (2018)

S.F. Wolf, M.S. Wang, M.E. Lipschutz, Labile trace elements in basaltic achondrites: can they distinguish between meteorites from the Moon, Mars, and V-type asteroids? Meteorit. Planet. Sci. 44, 891-903 (2009)

J.A. Wood, Bombardment as a cause of the lunar asymmetry. Moon 8, 73-103 (1973)

J.A. Wood, J.S. Dickey, U.B. Marvin, B.N. Powell, Lunar anorthosites and a geophysical model of the Moon, in Lunar Sci. Conf. Proc. (1970), pp. 965-988

S. Yamamoto, R. Nakamura, T. Matsunaga, Y. Ogawa, Y. Ishihara, T. Morota, N. Hirata, M. Ohtake, T. Hiroi, Y. Yokota, J. Haruyama, Possible mantle origin of olivine around lunar impact basins detected by SELENE. Nat. Geosci. 3, 533-536 (2010)

S. Yamamoto, R. Nakamura, T. Matsunaga, Y. Ogawa, Y. Ishihara, T. Morota, N. Hirata, M. Ohtake, T. Hiroi, Y. Yokota, J. Haruyama, Featureless spectra on the Moon as evidence of residual lunar primordial crust. J. Geophys. Res., Planets 120, 2190-2205 (2015)

N.E.B. Zellner, Cataclysm no more: new views on the timing and delivery of lunar impactors. Orig. Life Evol. Biosph. 47, 261-280 (2017)

J. Zhao, L. Xiao, L. Qiao, T.D. Glotch, Q. Huang, The Mons Rümker volcanic complex of the Moon: a candidate landing site forthe Chang'e-5 mission. J. Geophys. Res., Planets 122, 1419-1442 (2017)

M.H. Zhu, K. Wünnemann, R.W.K. Potter, T. Kleine, A. Morbidelli, Are the Moon's nearside-farside asymmetries the result of a giant impact? J. Geophys. Res., Planets (2019). https://doi.org/10.1029/ 2018JE005826

M.T. Zuber, D.E. Smith, F.G. Lemoine, G.A. Neumann, The shape and internal structure of the Moon from the Clementine mission. Science 266, 1839-1843 (1994)

M.T. Zuber, D.E. Smith, M.M. Watkins, S.W. Asmar, A.S. Konopliv, F.G. Lemoine, H.J. Melosh, G.A. Neumann, R.J. Phillips, S.C. Solomon, M.A. Wieczorek, J.G. Williams, S.J. Goossens, G. Kruizinga, E. Mazarico, R.S. Park, D.N. Yuan, Gravity Field of the Moon from the Gravity Recovery and Interior Laboratory (GRAIL) Mission. Science 339, 668-671 (2013) 